\title{
Das bajuWARISCHE GrÄBERFELD VON RUdeLSDORF, OBERÖSTERREICH
}

\author{
Peter CSAR, Wien
}

\section{Fundort und Grabungsgeschichte Fundort}

Rudelsdorf, Ortsgemeinde Hörsching, Katastralgemeinde Neubau, liegt an der Südgrenze der Bezirkshauptmannschaft Linz-Land. Am Rand der einst malerischen Traunauen, nur etwa $10 \mathrm{~km}$ von der oberösterreichischen Landeshauptstadt entfernt, im Süden der Hauptverbindungsstraße zwischen Linz und Wels (Abb. 1). Seit Juni 1955 befindet sich das Schotterwerk Rieder und Lehner neben dem Wohnbezirk (Abb. 2). Das Gelände wurde durch die Schottergewinnung grundlegend verändert, da man die Terrasse weitgehend abgetragen und teilweise durch Aushubmaterial ersetzt hat (Abb. 3, 4). Der 1955 ausgegrabene Teil der Nekropole befand sich auf den Parzellen 3351 und 3232, wobei zwischen diesen beiden Parzellen der Feldweg mit der Parzellennummer 3234 verläuft, in dessen unmittelbarer Nähe die bedeutendsten Funde zu Tage traten. Dieses Areal bezeichnete man als „Rudelsdorf I“, da in den Jahren 1959 und 1960 etwa 200 m östlich ein weiterer Gräberbezirk (,Rudelsdorf II“) gefunden wurde, der von „Rudelsdorf I“ durch ein kleines Eichen- und Fichtenwäldchen getrennt war. Es gibt jedoch berechtigte Gründe dafür, dass beide Komplexe ursprünglich zu ein und demselben Friedhof gehörten. 1963 wurde im Zuge einer neuerlichen Notgrabung ein großer Teil dieses bewaldeten Gebiets untersucht, wo weitere 40 Bestattungen geborgen werden konnten.

Der Fundort spiegelt die Vorliebe der Bajuwaren für Randzonen von Flussterrassen wider. Es handelte es sich um

1 M. Pertlwieser, Bestattungsformen in oberösterreichischen Reihengräberfeldern des 7. und 8. Jahrhunderts, Baiernzeit in Oberösterreich, Linz 1977, 90. - L. KrEINER, Der frühmittelalterliche Friedhof von Peigen, Gde. Pilsting, Lkr. Dingelfing-Landau, Vortr. d. 5. Niederbayer. Archäologentages 1987, 174. den langgezogenen, südlichen Ausläufer des Hanges einer Landschaftsterrasse an der Traun, wo sich bis zur gewerblichen Nutzung des Gebiets das oben erwähnte kleine Föhren- und Eichenwäldchen befand. Diese Wahl der Landschaftsform teilt das Rudelsdorfer Gräberfeld mit den meisten übrigen bajuwarischen Bestattungsplätzen zwischen Traun und Inn-Salzach-Linie. Keiner dieser Friedhöfe lag unterhalb des Niederterrassenniveaus. ${ }^{1}$

Die zum Gräberfeld gehörige Siedlung dürfte sich etwas tiefer an den damals weitverzweigten Nebenarmen der Traun befunden haben, wurde bislang jedoch nicht entdeckt. Dass sie aber in der Nähe des Friedhofs gewesen sein müsste, kann man aus der Tatsache ableiten, dass bisher kein bajuwarisches Gräberfeld bekannt ist, dessen zeitgleiche Siedlung mehr als 300 Meter entfernt war. ${ }^{2}$ Wie viele Gräber hier im 7. und frühen 8. Jh. angelegt wurden, lässt sich nur schätzen, da dem Abbau der Terrasse eine unbekannte Anzahl von Bestattungen zum Opfer fiel.

Es gibt Anzeichen dafür, dass das bajuwarische Gräberfeld zum Teil innerhalb eines Siedlungsbezirks aus der Spätlatènezeit angelegt wurde. Die Ausgräber konnten überdies auch noch ältere, urnenfelderzeitliche Spuren entdecken. Überdies wurden einige wenige Bodenverfärbungen und eine ungeklärte Trockenmauer aus Rollsteinen im Verband mit Latène D-Keramik festgestellt, die aber keiner genaueren Untersuchung zugeführt wurden, da man sich keine nennenswerten Ergebnisse davon versprach. Diese am Terrassenrand gelegene Trockenmauer aus Rollsteinen wurde durch zwei bajuwarische Bestattungen teilweise gestört.

2 J. Reitinger, Die baierische Landnahme aus Sicht der Archäologie, Baiernzeit in Oberösterreich, Linz 1977, 61. 


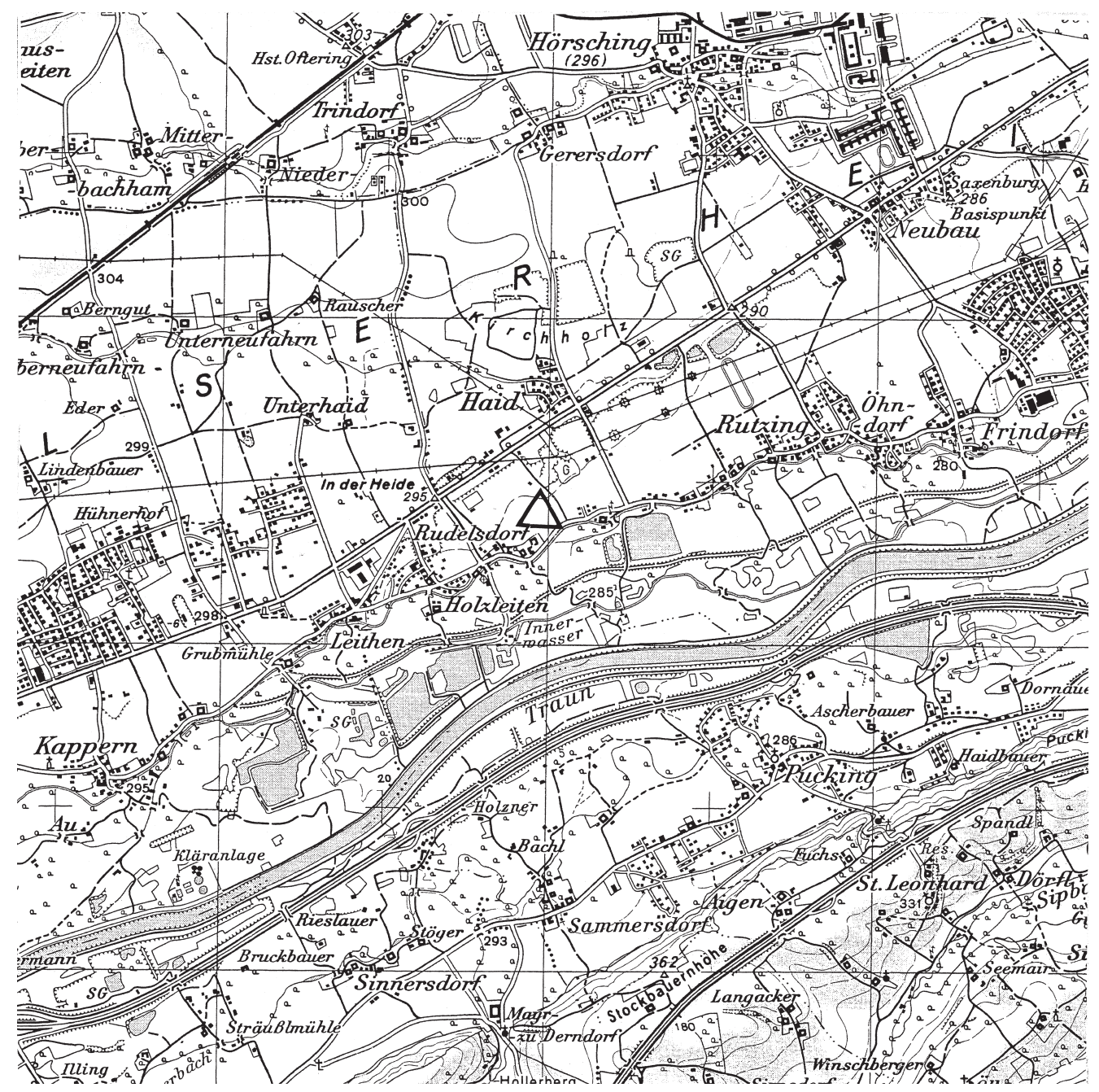

Abb. 1. Ausschnitt aus der Österreichischen Karte 1: 50.000, Blatt 50. $\triangle$ Lage des Gräberfeldes von Rudelsdorf.

Außerdem entdeckte man noch zwei von den Ausgräbern nicht näher definierte Siedlungsgruben, aus denen einige Brandlehmknollen, Eisenfragmente, Knochen und Rotund Graphittonscherben mit Kammstrichverzierung geborgen wurden.

Geologisch wurde das Tal vor allem durch den eis- und nacheiszeitlichen Rhythmus der Aufschotterung und Eintiefung geprägt. ${ }^{3}$ Menschliche Eingriffe der Regulierung um 1920 veränderten die ursprüngliche Aulandschaft. Der Auwald verschwindet mehr und mehr, und es gibt kaum Zuwächse, was nicht zuletzt auf ein Absinken des Grundwasserspiegels zurückzuführen ist. Zur Zeit der Belegung unseres Gräberfeldes war das Gleichgewicht wahrscheinlich noch relativ intakt. Der durch natürliche Gegebenheiten behinderte Fluss baute Schotter auf, den eine dünne Schicht aus Sand und Geschiebelehm bedeckte, auf der eine sehr sensible Auvegetation gedieh. Dass diese Schicht nur sehr dünn war, ist vor allem den Salzkammergutseen zuzuschreiben, in denen die meisten der nährstoffreichen Bodenpartikel verblieben und der geringe Rest, der sich angesammelt hatte, konnte durch Hochwasser und Eintiefung sehr leicht weggeschwemmt werden.

Die Vegetation der Traunau war und ist trotz der labilen Bodenverhältnisse recht üppig. Der Fluss war in zahlreiche Arme geteilt. Auf den kleinen Inseln gedieh reichlich Buschwerk. Diese Inseln sind heute größtenteils verschwun- 
den, d.h. in einer großflächigen Au aufgegangen. Auf den Schotterbänken und entlang der heute noch relativ intakten Nebenarme wuchsen am Ufer einst Purpur- und Grauweiden, Pappeln und andere Laubbäume wie z.B. Eichen. Zur Zeit des Grabungsbeginns 1955 sah die Bodensituation im Bereich des ehemaligen Gräberfeldes folgendermaßen aus: „Unter einer etwa $5 \mathrm{~cm}$ dicken Humusschicht erstreckte sich ein ca. $35 \mathrm{~cm}$ dickes Gemisch aus Granitbruchsteinen und Lehm, auf das ca. $30 \mathrm{~cm}$ reinen, hellgelben Lehms folgten, an den sich ca. $10 \mathrm{~cm}$ erdigen Lehms anschlossen. Zwischen dieser Schicht und dem sterilen Schotter am Grund der Au fand sich schließlich noch eine Lage schottrigen Lehms mit taubeneiergroßen Kieselsteinen in einer Stärke von ca. $7 \mathrm{~cm} .{ }^{*}{ }^{4}$

\section{Grabungsgeschichte ${ }^{5}$}

Ende September 1955 erreichte den mittlerweile verstorbenen Vorstand des Biologisch-Anthropologischen Instituts der Universität Linz, Ä. Kloiber, die Nachricht, dass im Schotterwerk Rieder und Lehner in Rudelsdorf durch Aushubarbeiten ein Teil eines noch nicht näher bezeichneten Gräberfeldes angeschnitten worden war. Um die geplante Schottergewinnung in diesem Bereich nicht allzu lange zu hemmen, ersuchte Ä. Kloiber am 5. Oktober den pensionierten Direktor des Naturhistorischen Museums Wien, E. Beninger, die rasche Bergung der Funde im Rahmen einer Notgrabung zu veranlassen (Abb. 5).

Als das erste Grabungsteam noch am selben Tag in der Schottergrube eintraf, war bereits großer Schaden am Gräberfeld angerichtet worden. Die Planierraupe hatte die Humusdecke bis in eine Tiefe von $30 \mathrm{~cm}$ entfernt, und die darunter liegende ca. 10 bis $30 \mathrm{~cm}$ dicke Schotterschicht war schon teilweise abgetragen, weswegen einige Gräber schon erheblich gestört waren. Dennoch waren viele Bestattungen oberflächlich noch klar an ihren dunklen Verfärbungen erkennbar.

Insgesamt wurden bei dieser ersten Grabungskampagne, die von 5. bis 9. 1995 Oktober dauerte, 32 Körpergräber am linken Rand des Friedhofs geborgen, der, wie sich später herausstellte, den Westteil des „Rudelsdorf I“ genannten Abschnitts des Gräberfeldes umfasste. Hier fand man auch einige Doppelbestattungen (Gräber 2, 3, 4, 24, 25 und 28).

Diese Angaben stammen aus einer Originalskizze vom 21. Oktober 1955.

5 Auskunft M. Pertlwieser, Abt. f. Ur- u. Frühgesch., Oberösterr. Landesmus., Linz.

6 Ä.KLOIBER, Wissenschaftliche Tätigkeit und Heimatpflege in Oberösterreich, Abteilung Biologie, Jahrb.OÖ.Mus.ver. 101, 1956, 34.
Die Gräber waren teils in Reihen, teils in Gruppen angelegt, wobei letztere vor allem Frauen- und Kindergräber umfassten. Sämtliche Skelette waren West-Ost orientiert. Mit einer Ausnahme - einer offenen Hockerstellung im Grab 3A befanden sich alle Bestatteten in Rückenstrecklage, wobei die Extremitäten meistens parallel und nur selten gekreuzt wurden. Da man die Toten im reinen Schotter bestattet hatte, war der Erhaltungszustand der Skelette zumeist bemerkenswert gut.

In unmittelbarer Nähe der meisten Bestattungen stellte man überdies Verfärbungen oder Holzreste fest, die als mehr oder weniger vergangene Särge interpretiert wurden. Die meisten Gräber enthielten Beigaben, wenn auch oft nur spärlich. Auffällig war das Fehlen von Gefäßbeigaben, was sich - mit Ausnahme von Grab 90 (ein Wellenbandtopf) und Grab 143 (ein Glasbecher) - auch bei den späteren erfolgten Untersuchungen bestätigte.

Am 24. Oktober 1955 wurden die Grabungsarbeiten unter der Leitung von $\ddot{A}$. Kloiber bzw. M. Pertlwieser wieder aufgenommen. Bis 9. Dezember sollen angeblich unter Einschluss der bereits genannten 32 Bestattungen insgesamt 120 Körpergräber, also die Gesamtheit der Bestattungen von „Rudelsdorf I“" geborgen worden sein. ${ }^{6}$

Die Notbergung zwischen dem 28. November und dem 3. Dezember 1959 deckte nach Ä. Kloiber weitere 16 Körpergräber auf,7 dieses Mal im „Rudelsdorf II“ genannten Ostteil des Fundorts (Abb. 6). Diese Untersuchungen wurden 1960, und zwar zwischen dem 11. und 13. Mai, am 18. August, am 29. September und am 4. sowie am 11. Oktober fortgesetzt. Dass Ä. Kloibers Angaben jedoch nicht ganz den Tatsachen entsprachen, hat M. Pertlwieser in einer Studie zum Gräberfeld klargestellt. ${ }^{8}$ Demnach handelte es sich bei den Notbergungen von 1959 und 1960 um ,kleinere Bergungen und Fundaufsammlungen“, d.h. es erfolgten z.T. keine ordnungsgemäßen Grabungen. Pertlwieser spricht von 24 Körpergräbern, die 1959 und 1960 „mehr oder weniger vollständig geborgen werden konnten“. Er stellt fest, dass es sich „um den letzten Rest eines durch den maschinellen Schotterabbau weitgehend zerstörten großen Gräberfeldes mit einer noch feststellbaren Längsausdehnung von wenigstens 120 Metern“ handelte. Darüber hinaus wurden am 3. Oktober 1960 bei einem großen Kalkofen mit mittelalterlichen und neuzeitlichen Ziegeln am Rand

7 Kloiber, s. Anm. 6.

8 M. Pertlwieser, Die frühmittelalterlichen Gräberfeld-Grabungen des OÖ. Landesmuseums, Schriftenr. OÖ. Mus.ver.10, 1980, $43 \mathrm{ff}$. 


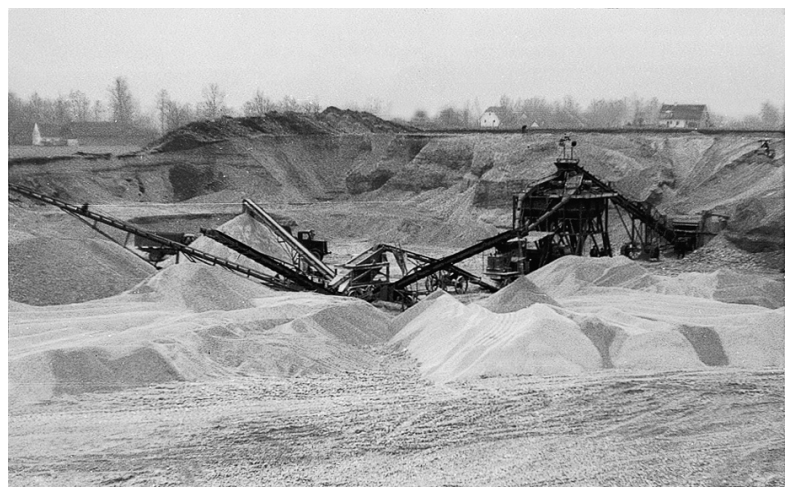

Abb. 2. Rudelsdorf. Schotterwerk Rieder und Lehner 1955.

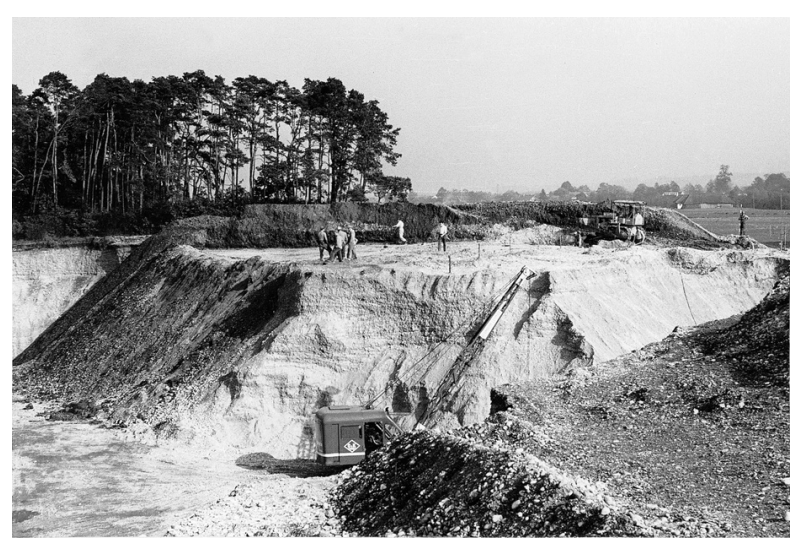

Abb. 3. Abtragung der Traunterasse 1955.

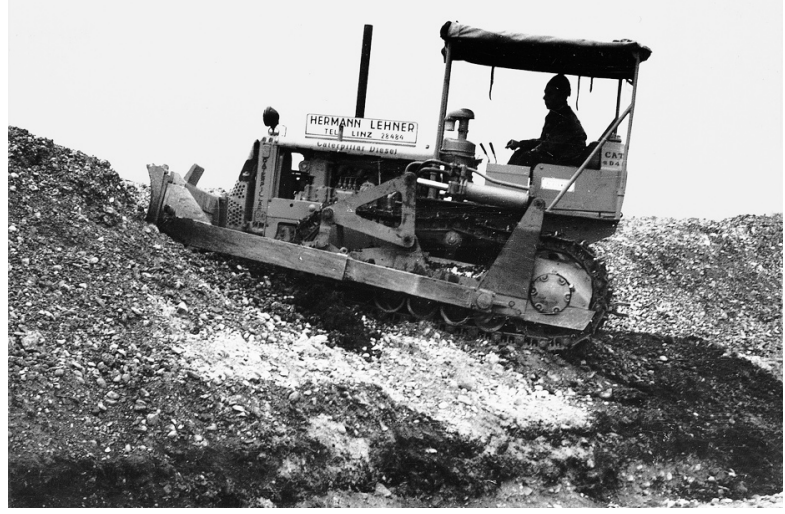

Abb. 4. Rudelsdorf. Planierraupe des Schotterwerks 1955.

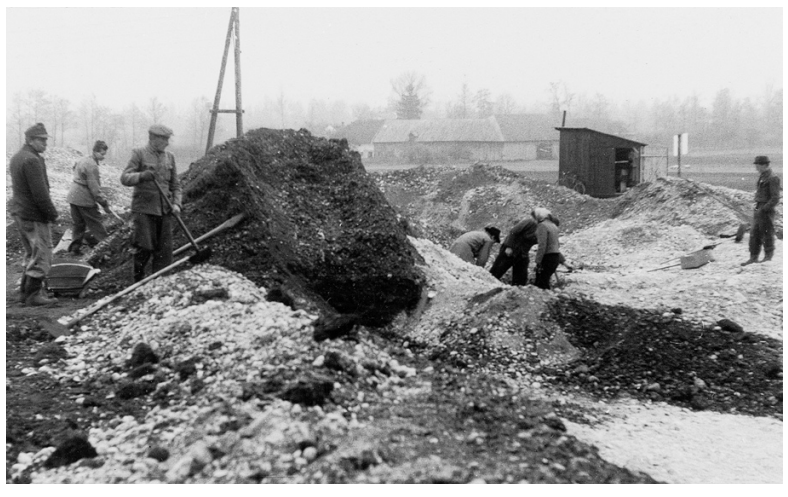

Abb. 5. Rudelsdorf. Grabung 1955.

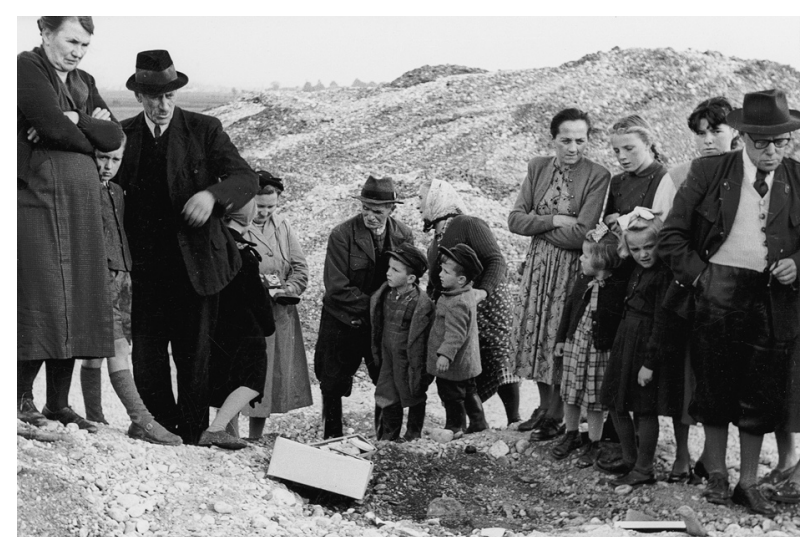

Abb. 6. Rudelsdorf. Grabung 1959.

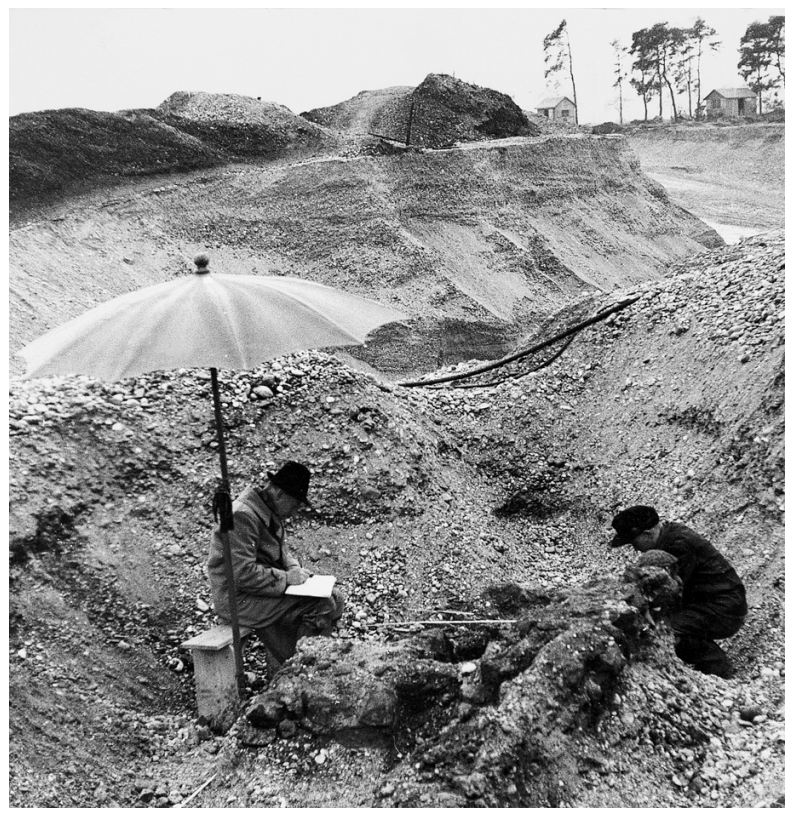

Abb. 7. Rudelsdorf. Grabung 1963. 
der Niederterrasse von Erdarbeitern Reste von ,durch den Baggerbetrieb zerstörten 16 Gräber (Nr. 145-160) gefunden, wobei es sich um ein Rechteck mit einer Länge von $25 \mathrm{~m}$ und einer Breite von $15 \mathrm{~m}$ handelte" und, nach Angaben des Platzwartes, „4 Gräberreihen à 4 Gräber anzunehmen seien".

Es wurde weiters festgestellt, dass Tiefe und Richtung der Gräber den Gräbern entsprachen, die 1960 in „Rudelsdorf II“ ergraben wurden. Die Beigaben aus diesen zerstörten Gräbern wurden um eine Fundprämie von S 100,- erworben

Die Grabung des Jahres 1963 lieferte die bei weitem die beste Dokumentation (Abb. 7). Sie fand zwischen dem 5. Juni und dem 8. Juli auf der linksufrigen Niederterrasse der Traun in Fortsetzung des Gräberfeldes „Rudelsdorf I“ statt. Nachdem durch den Bagger einige Gräber bereits stark in Mitleidenschaft gezogen worden waren, konnten 40 Gräber (181-220) freigelegt und geborgen werden. Diese Bestattungen mit Ausnahme des Grabes 207 schlossen unmittelbar im Osten der Grabung von 1955 an, d.h. sie verlängern „Rudelsdorf I“ Richtung Osten.

1964, nach den bislang letzten Ausgrabungen, bemerkte $\ddot{A}$. Kloiber, dass ,,der Fundplatz erschöpft sei und nicht mehr bestehe, weil die Niederterrasse völlig abgeschottert und ein neuer, künstlicher Terrassenrand weiter westlich parallel zur Bundesstraße Linz-Wels angelegt worden war". 9 M. Pertlwieser gibt die Gesamtanzahl der de facto geborgenen Gräber mit 151 an. ${ }^{10}$

\section{Grabungskritik}

Hier sollen die Gründe angeführt werden, die eine detaillierte Bearbeitung vor allem der Gräber 1 bis 180 sehr erschwert bzw. fast unmöglich gemacht haben. Welche konkreten Auswirkungen sich dadurch im einzelnen für die Bearbeitung des Fundmaterials ergaben, ist dem Katalogteil zu entnehmen.

Eine prägnante, in den Fundberichten aus Österreich $1964^{11}$ veröffentlichte Kurzkritik soll am Anfang stehen: „In den Jahren 1955 bis 1962 wurden 141 Gräber ausgegraben, eine geschätzte Anzahl zerstörter Gräber wurde jedoch fallweise ebenfalls in Grabnummern ausgedrückt, sodass in Bezug auf den gesamten Friedhof, d.h. „Rudelsdorf I“ und „Rudelsdorf II“, inklusive der Grabbergungen von 1963 (40 tatsächliche Gräber) 220 Grabnummern den 181 ausgegrabenen Gräbern gegenüberstehen“. Die im Originalproto- koll nur als Grabnummern aufscheinenden „Bestattungen“ 221-228 wurden im Zuge einer Bearbeitung aus dem Jahre 1973 als „nicht existent“ bezeichnet und offensichtlich schon damals nicht berücksichtigt. Vom 5. bis 9. Oktober 1955 wurden 32 Grabnummern an tatsächlich vorhandene Gräber ausgegeben. Wie bereits erwähnt, ist allerdings zu beachten, dass die Gräber 2, 3, 4, 24, 25 und 28 Doppelbestattungen waren. Die Originaldokumentation zu diesen Gräbern ist nicht sehr präzise. So wurde z.B. verabsäumt, die Tiefe der Bestattung anzugeben.

Bei der Fortsetzung dieser Kampagne, die laut Originalprotokoll am 24. Oktober 1955 mit Grab 33 begann und am 5. Dezember mit Grab 120 endete, kam es, aus welchen Gründen auch immer, gleich zu Beginn zu mehreren Dreifachnummerierungen. M. Pertlwieser, von Ä. Kloiber zum stellvertretenden Grabungsleiter ernannt, durfte jene Gräber, die in dessen Abwesenheit gegraben wurden, nur mit Buchstaben bezeichnen, die dieser sodann durch Zahlen ersetzte. Diese zunächst noch durchschaubare Manipulation bot schließlich folgendes Bild: Grab A wurde zu Grab 33, B zu 34, C zu 35, D zu 36, E zu 37 und $F$ zu 38. Die Gräber G bis $N$ verwandelten sich in die Gräber 81 bis 88 . Gegen Ende der Grabungskampagne dürfte Ä. Kloiber jedoch aufgefallen sein, dass sich in den 60iger bis 80iger Grabnummern eine große Lücke mit Leernummern eingeschlichen hatte, und tatsächlich lässt sich heute nicht mehr eruieren, ob die Gräber 69 bis 74 überhaupt jemals existierten. Um diese Lücke zu füllen, ging er laut M. Pertlwieser schließlich daran, sie mit schon nummerierten Gräbern zu füllen, was aufgrund des Originalprotokolls und der Fundkartei wie folgt ausgesehen haben könnte: Grab 33 (A) war nun gleichzeitig Grab 75, Grab 34 (B) war 76, Grab 35 (C) war 77, Grab 36 (D) war wahrscheinlich 78A, Grab 37 (E) war 79, Grab 38 (F) war 80 und Grab 39 (G) war wahrscheinlich 82B, d.h. alle diese Gräber dürften also einer Art doppelter Buchführung unterworfen worden sein. Um das hinter diesem Nummernwirrwarr verborgene „System“ bis zur Unkenntlichkeit zu verschleiern, schweigen sich Originalprotokoll und Fundkartei über die Gräber 40 und 41 aus. Wir dürfen nun rätseln, welchen 40iger Gräbern die Gräber 78B, 81 und 82A zugehören. Dass die Gräber 38 und 80 zwar nicht nach dem Originalprotokoll, wohl aber laut Fundkartei verschiedene Beigaben mit verschiedenen Inventarnummern aufweisen, ist einer ordnungsgemäßen Bearbeitung mehr als abträglich, doch dürfte diese offensichtlich Diskrepanz wohl damit zusammenhängen, dass $\ddot{A}$.

10 Pertlwieser, s. Anm. 8.

11 Fundber. Österr. 8, 1974, $165 \mathrm{ff}$ 
Kloiber, wie M. Pertlwieser mir mitteilte, manchmal Beigaben aus reicheren Gräbern entnahm und sie beigabenlosen Bestattungen zuordnete. Es wurde später wiederholt versucht, solche Verfälschungen zu korrigieren, wodurch aber in einigen Fällen offensichtlich genau das Gegenteil erreicht wurde. ${ }^{12}$

Die Grabung 1959 umfasste den oben erwähnten Bereich von „Rudelsdorf II“ und damit die im Originalplan nicht eingezeichneten und nach M. Pertlwiesers Angaben auch nur sehr oberflächlich eingemessenen Grabnummern 121 bis 138. Zum ersten ließ Ä. Kloiber seine Grabnummern verwirrender Weise wieder mit Grab 1 beginnen vielleicht, weil er diese Gräber von „Rudelsdorf I“ abgrenzen wollte. Zum zweiten wurden aus in Bauhütten längere Zeit aufbewahrten Skeletteilen und durch Schottergrubenarbeiter aufgesammelten Beigaben zumindest 3 Gräber konstruiert. Dazu meinte M. Pertlwieser, ,es handelte sich zumindest bei den ersten Grabnummern um die sog. ,Michiganphase“, wobei „Michigan“ der Bagger war, der diese Gräber fast vollständig zerstört hatte, sodass nur vereinzelt Skelettfragmente und einige verstreute Beigaben gerettet werden konnten.

Die Grabung 1960 brachte die Gräber 139 bis $180 \mathrm{zu}$ Tage, die, mit Ausnahme der Gräber 163 bis 165, ebenfalls dem Bereich von „Rudelsdorf II“ zuzuordnen sind und deshalb im Originalplan nicht aufscheinen. Die Gräber 139 bis 143 sind durchaus brauchbar dokumentiert. Grab 144 ist laut Originalprotokoll ,,anscheinend eine bereits zugeschüttete und wiederentdeckte Grabgrube“. Zu den Gräbern 145 bis 160 wurde festgehalten, dass sie durch den Baggerbetrieb zerstört worden wären. Sie hätten sich in einem Rechteck von $25 \times 15 \mathrm{~m}$ befunden. Die Funde wären schließlich vom Platzmeister des Schotterwerks herausgegeben worden, wonach wiederum aus aufgesammeltem Material Gräber konstruiert wurden. Die Gräber 167 bis 180 wird man - egal, welche Quellen man auch zu Rate zieht - nicht finden. M. Pertlwieser erklärt sich dies so, dass der Grabungsleiter zu Beginn der Grabung im Jahre 1963 eine Lücke freiließ, die den mittlerweile durch den Schotterabbau zerstörten Bestattungen entsprechen sollte. Sie wurde - glücklicherweise - nie aufgefüllt.

Diese Grabung im Jahr 1963, die unter der Leitung M. Pertlwiesers stand, umfasste die im Plan eingezeichneten und zufriedenstellend dokumentierten Gräber 181 bis 220 . Nur sehr selten zeigen sich Diskrepanzen zwischen Originalprotokoll und Fundkartei.

\section{KATALOG}

Das Hauptproblem bei der Bearbeitung des Gräberfeldes von Rudelsdorf waren, wie oben angeführt, die uneinheitliche, oft mangelhafte Dokumentation und die oft widersprüchlichen Quellen.

Folgende Unterlagen standen zur Verfügung:

a) Das Originalprotokoll

b) Die Fundkartei

c) Der Gräberfeldplan

d) Ein anthropologisches Gutachten

e) Eine Aufstellung von in Plänen eingezeichneten Bestattungen, die vom Ausgräber M. Pertlwieser am 14. März 1979, also 16 Jahre nach Beendigung der letzten Grabungskampagne, offensichtlich im Zuge von Rekonstruktionsversuchen gemacht worden war. ${ }^{13}$

Der Katalog folgt grundsätzlich dem Originalprotokoll. Was die Beigaben betrifft, wurden die Angaben des Originalprotokolls jeweils mit denen in der Fundkartei und den tatsächlich vorgefundenen Beigaben des jeweiligen Grabes verglichen, wobei im Falle von Diskrepanzen dem vorhandenen Material der Vorzug gegeben wurde.

Die kritische Bewertung der Dokumentation führte schließlich zur Einteilung der Gräber in drei Gruppen:

Gruppe A. A1 Gräber mit guter bzw. A2 Gräber mit mangelhafter Originaldokumentation bei gleichzeitig glaubwürdigem Fundzusammenhang. Bei letzteren fehlen wichtige Angaben, wie Grabtiefe, Orientierung etc., liegen anthropologische Unklarheiten vor oder sind ein oder mehrere Beigaben nicht vorhanden.

Gruppe B. B1 Gräber mit unklarem Fundzusammenhang, auch zerstörte Gräber mit ungeklärter Bergung und mangelhafter Originaldokumentation. Gräber mit fragwürdigen Beigaben. Wenn die übrigen Beigaben solcher Gräber sowohl im Originalprotokoll als auch in der Fundkartei aufscheinen, können diese als Beigaben der Kategorie A gewertet werden. Fragwürdige Beigaben der B1-Gräber werden als Einzelfunde behandelt. Unter B2 sind jene Bestattungen zusammengefasst, deren Lage im Gräberfeld ungeklärt ist.

Gruppe C. Gräber ohne Originaldokumentation bzw. Leer- und Doppelnummern.

Alle Funde sind frühbajuwarisch und sind ins 7. Jh. n. Chr. zu datieren. Die Funde befinden sich im Oberöster-

13 Auch in diesem Dokument finden sich Widersprüche zu den anderen Quellen. 
reichischen Landesmuseum, Außenstelle Linz Wegscheid, Abteilung Frühgeschichte. Die Angaben zu Alter und Geschlecht wurden dem Originalprotokoll und einer anthropologischen Untersuchung des Instituts für Anthropologie der Johannes-Gutenberg-Universität Mainz aus dem Jahr 1980 unter der Leitung von Prof. Dr. W. Bernhard entnommen.

Grab und Beigaben wurden nach der oben angeführten Klassifikation (A, B, C) bewertet.

\section{Grabung 1955}

\section{Grab 1}

Frau (43-52 Jahre); W-O-Orientierung; Rückenstrecklage; Schädel und Rumpf hochgelagert; Skelettlänge $170 \mathrm{~cm}$; keine Beigaben.

Bewertung: A2

\section{Grab 2A}

Schräg über der darunter liegenden Bestattung 2B.

Mann (36 Jahre); W-O-Orientierung; Rückenstrecklage; untere Extremitäten gekreuzt; Skelettlänge $160 \mathrm{~cm}$.

Beigaben:

Eisenschnalle in Beckenmitte (nicht vorhanden)

Bewertung: A2

\section{Grab 2B}

Schräg unterhalb der darüber liegenden Bestattung 2A.

Kind; weiblich (8 Jahre);W-O-Orientierung; Rückenstrecklage; rechte Hand unter dem Schädel; Skelettlänge 110 $\mathrm{cm}$.

Beigaben:

a) Schlaufenohrringe (Paar) aus Bronzedraht in Trachtlage (A, Taf. 1/1 und 2, Inv. Nr. A-10661).

b) Halskette aus 14 Perlen; 11 orangebraun, opak, davon 3 doppelkonisch, 2 zylindrisch und 6 kugelig; 1 Drehperle aus grünblauem Glas, opak; 2 zweiteilige Hohlkugeln aus Silberblech (B, Taf. 1/3, Inv. Nr. A-10662).

\section{Bewertung: B1}

Das Originalprotokoll erwähnt ein nicht vorhandenes ,,8bzw. S-förmiges Ohrgehänge aus Bronze mit je 4 gelben Tonperlen“.

\section{Grab 3A}

Erwachsener; offene Hockerstellung.

Beigaben:

a) Flügelpfeilspitze, Tülle gespalten und tordiert, in der Tülle Holzschaftreste; L 9,5 cm (B, Taf. 1/4, Inv. Nr. A10663a).

b) Flügelpfeilspitze; erh. L 5,5 cm (B, Taf. 1/5, Inv. Nr. A10663b)

c) S-Haken, Eisen, bandförmig; L 4,5 cm (B, Taf. 1/6, Inv. Nr. A-10664).

Die Beigaben sind in der Fundkartei, nicht aber im Originalprotokoll erwähnt. Das Grab ist im anthropologischen Gutachten nicht erwähnt.

\section{Grab 3B}

Frau (34 Jahre); W-O-Orientierung; Rückenstrecklage, deutliche Sargverfärbung.

Beigaben:

Beinkammfragment, dreilagig und zweireihig, feine Zähnung, 1 Eisenniet; erh. L 4,5 cm (A, Taf. 1/7, Inv. Nr. A10665)

Bewertung: A2

\section{Grab 4A}

Kind (7-8 Jahre).

Bewertung: C

Siehe Grab 4B

\section{Grab $4 B$}

Frau (34 Jahre); W-O-Orientierung; Rückenstrecklage; Grabschacht (L 180 cm, B 80 cm, T 100 cm); keine Beigaben.

\section{Bewertung: C}

Laut Plan Erwachsenengrab, nach anthropologischem Gutachten Doppelbestattung 4A und 4B, wobei 4A als Kinderund $4 \mathrm{~B}$ als Frauengrab angesprochen wird. Möglicherweise ist das Grab 4 des Originalprotokolls das im anthropologischen Gutachten erwähnte Grab 4B.

\section{Grab 5}

Frau (41-58 Jahre); W-O-Orientierung; Rückenstrecklage; Skelett stark zersetzt, Schädel hochgelagert.

Beigaben:

a) Beinkammfragment, dreilagig und zweireihig, senkrechte und schräge Linienverzierung (B Taf. 1/9, Inv. Nr. A10666).

b) Halskette aus 19 Glasperlen; 10 kugelig, orange, opak, davon 2 fragmentiert; 4 kugelig, braunocker, opak; 1 gedrückt kugelig, blauschwarz, opak; 1 konisch, blauschwarz, opak; 1 doppelkonisch, dunkelgraublau, transluzid; 1 zylindrisch, grünblau, transluzid; 11 quaderförmig, braunoliv, transluzid (A, Taf. 1/8, Inv. Nr. A10667).

c) Goldfaden, bandförmig und gedreht (A, Taf. 1/10, Inv. Nr. A-10668).

\section{Bewertung: B1}

Originalprotokoll und Fundkartei führen die Perlen und den Golddraht an, während der Beinkamm nur in der Fundkartei aufscheint.

\section{Grab 6}

Frau (16-19 Jahre); W-O-Orientierung; Rückenstrecklage; Skelettlänge $168 \mathrm{~cm}$; Sargschatten; keine Beigaben.

Bewertung: A2

Grab 7 (Abb. 8)

Mann (37-46 Jahre);W-O-Orientierung; Rückenstrecklage; Skelettlänge $170 \mathrm{~cm}$.

Beigaben:

a) Langsax, fragmentiert, beidseitig Blutrinne; GL $75 \mathrm{~cm}, \mathrm{~KB}$ 4,5 cm, GrL 11,5 cm (A, Taf. 2/1, Inv. Nr. A-10669).

b) Schnallenbügelfragment auf dem Becken, Geweberest (B, Taf. 2/2, Inv. Nr. A-10670).

Bewertung: B1 


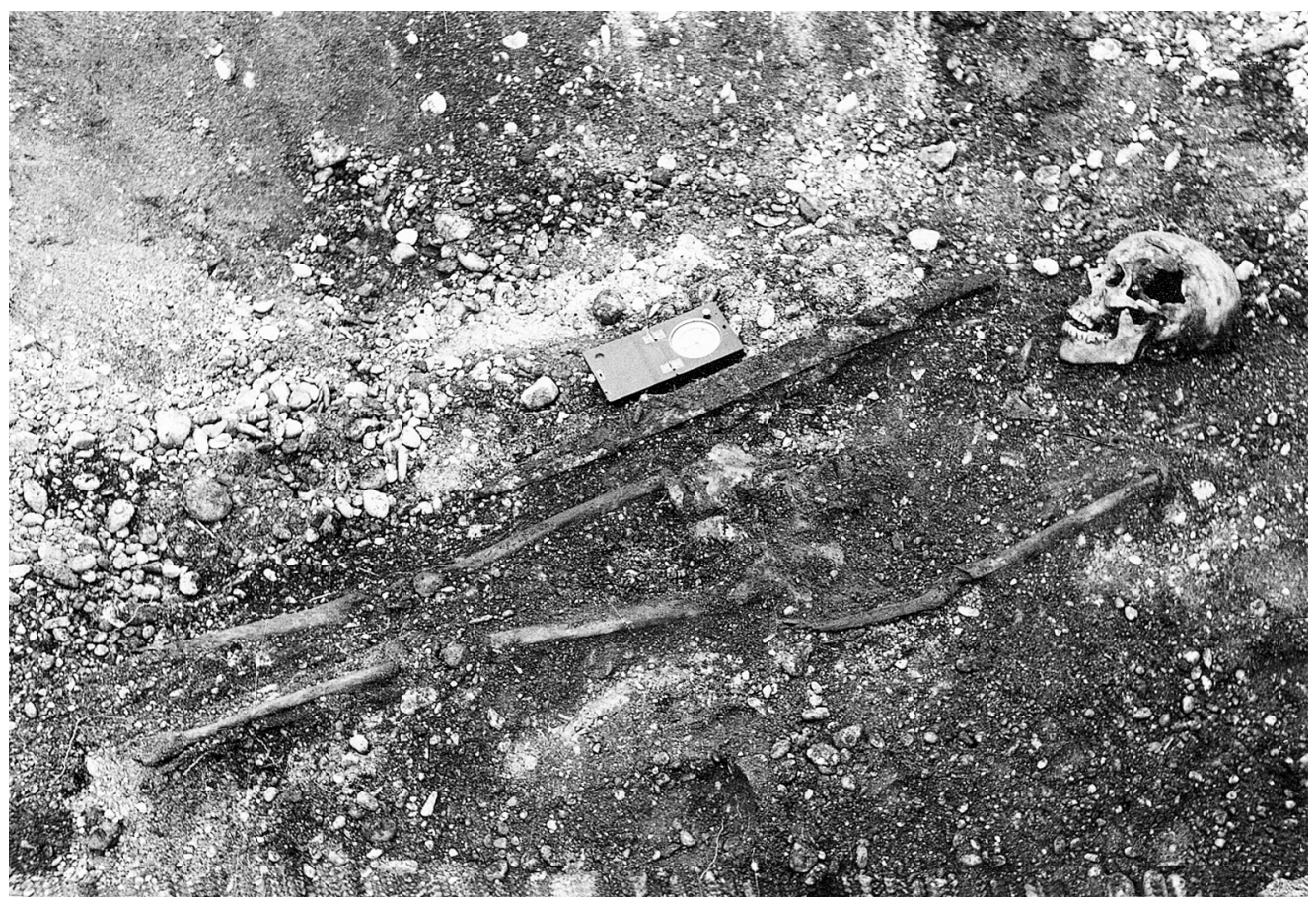

Abb. 8. Rudelsdorf. Grab 7.

Sowohl Originalprotokoll als auch Fundkartei führen den Langsax, den Schnallenbügel auf dem Becken nur die Fundkartei.

\section{Grab 8}

Mann (35-52 Jahre);W-O-Orientierung; Rückenstrecklage; kräftiger Knochenbau; Skelettlänge $170 \mathrm{~cm}$.

Beigaben:

a) Langsax, Spitze abgebrochen aber vorhanden, beidseitig Blutrinne; GL $81,5 \mathrm{~cm}, \mathrm{~KB} 4 \mathrm{~cm}$, GrL $14 \mathrm{~cm}(\mathbf{B}$, Taf. 2/3, Inv. Nr. A-10671).

b) Beinkammfragment, dreilagig und zweireihig, feine und grobe Zähnung, Fischgrätverzierung, 2 Eisenniete; erh. L 3,7 cm (B, Taf. 2/4, Inv. Nr. A-10672).

Bewertung: B1

Die Beigaben sind in der Fundkartei, nicht aber im Originalprotokoll erwähnt.

\section{Grab 9}

Kind (10 Jahre); W-O-Orientierung; Rückenstrecklage; Skelett stark zersetzt; rechte Hand über rechtem Oberschenkel; Skelettlänge $130 \mathrm{~cm}$; unterhalb der Bestattung schwarze Sargverfärbung (L $50 \mathrm{~cm}$, B $16 \mathrm{~cm}$, D $2 \mathrm{~cm}$ ).

Beigaben:

a) Griffangelmesser zwischen Brust und rechtem Oberarm, Rücken gewölbt; L $14 \mathrm{~cm}$ (A, Taf. 3/1, Inv. Nr. A10673).

b) Beinkammfragment, dreilagig und zweireihig, schraffierte Dreiecke und waag- und senkrechte Linienverzierung, 4 Eisennieten; erh. L 7,9 cm (A, Taf. 3/2, Inv. Nr. A10674).

Bewertung: A2
Grab 10

Mann (23 Jahre); W-O-Orientierung; Rückenstrecklage; rechte Hand unter der Hüfte, linker Arm gestreckt; Skelettlänge $170 \mathrm{~cm}$.

Beigaben:

a) Rasiermesser von der linken Hand umklammert, stark korrodiert; L $10 \mathrm{~cm}$ (B, Taf. 3/3, Inv. Nr. A-10675a).

b) Rasiermesser, Griffstück mit Rollöse erhalten; $\mathrm{L} 10 \mathrm{~cm}$ (B, Taf. 3/4, Inv. Nr. A-10675b).

\section{Bewertung: B1}

Im Originalprotokoll sind ein Eisenmesser und eine Schnalle, in der Fundkartei zwei Rasiermesser erwähnt.

Grab 11 (Abb. 9)

Frau (40-49 Jahre); W-O-Orientierung; Rückenstrecklage; Schädel rechtwinkelig nach links geneigt; Skelettlänge 150 cm; Baumsarg (L 194 cm, B 60 cm, D 40 cm), Sargdeckel $23 \mathrm{~cm}$ nach unten versunken, rechte Seitenwand schräg. Beigaben:

a) Beinkammfragment links unter dem Schädel, dreilagig und zweireihig, grobe und feine Zahnung, unverziert, 4 Nietlöcher, 1 Eisenniet erhalten; erh. L 9 cm, erh. B 3,2 cm (A, Taf. 4/1, Inv. Nr. A-10676).

b) Eisenschnalle an der linken Hüfte (nicht vorhanden). Bewertung: A2

\section{Grab 12}

Frau (35-45 Jahre); geringe Skelettreste und einzelne Zähne erhalten; keine Beigaben.

Bewertung: B1

Unklar bleibt, weshalb dieses Frauengrab im Gräberfeldplan als Doppelgrab eingezeichnet ist. Vielleicht handelt es sich um eine Verwechslung mit den Gräbern 212A und B. 


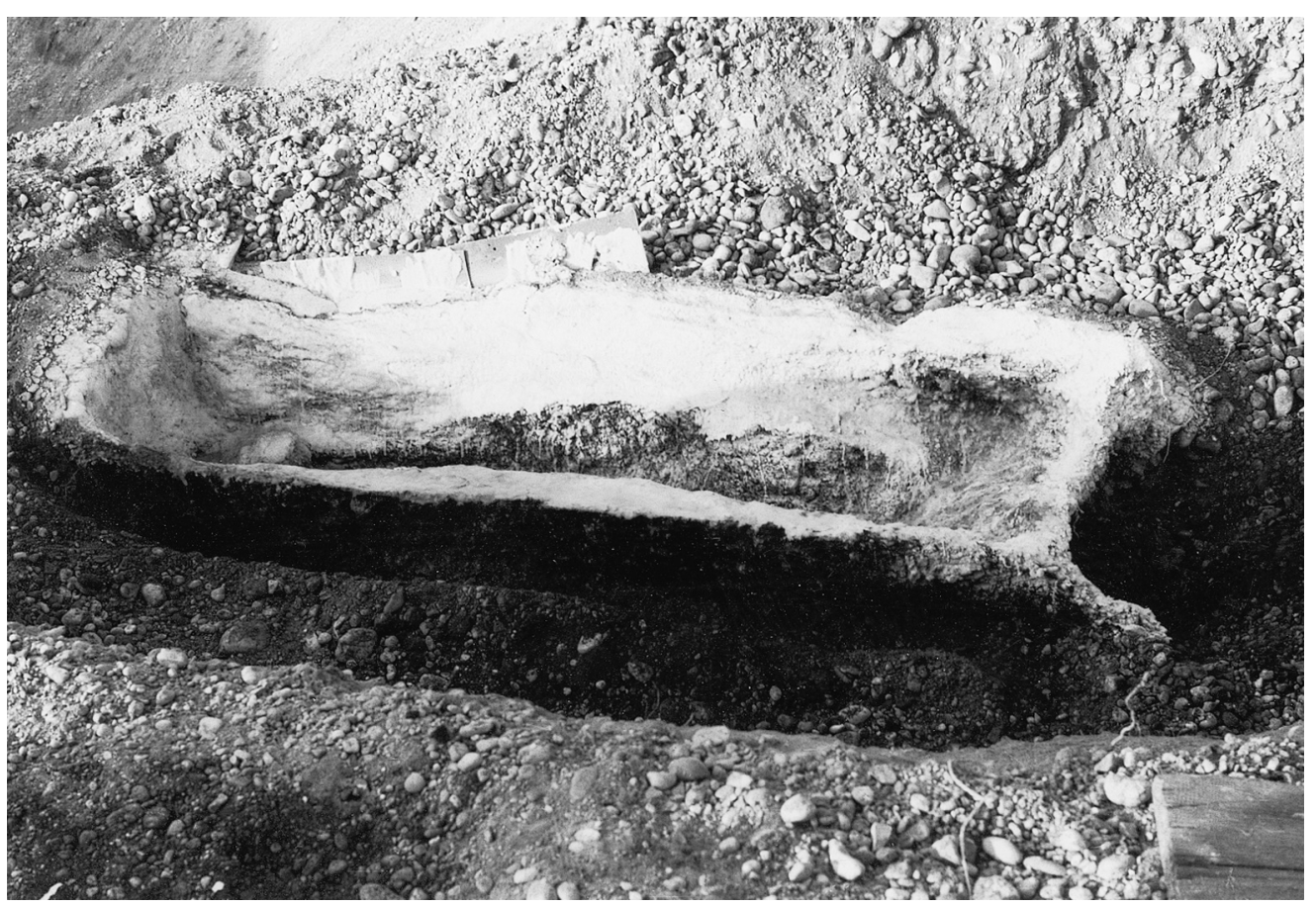

Abb. 9. Rudelsdorf. Grab 11, Baumsarg.

\section{Grab 13}

Mann (45 Jahre); W-O-Orientierung; Rückenstrecklage; Skelett schlecht erhalten, nur Schädel intakt; Skelettlänge ca. $160 \mathrm{~cm}$; bei den Füßen Aschenreste.

Beigaben:

a) Langsax auf dem rechten Arm mit dem Griff auf der Schulter, Rücken gerade, beidseitig Blutrinne, Holzgriffreste; GesamtL 69,5 cm, KlingenB 4,1 cm, GriffL 11,5 cm (A, Taf. 4/2, Inv. Nr. A-10677).

b) Griffangelmesser unterhalb des Schwertes, Rücken gerade, Holzgriffreste; L $13 \mathrm{~cm}$ (A, Taf. 4/3, Inv. Nr. A10678).

c) Flügelpfeilspitze an der rechten Schulter unterhalb des Schwertes, in der Tülle Holzreste, erh. L $7 \mathrm{~cm}$; Spitze einer weiteren, erh. L 2,1 cm (A, Taf. 4/4, Inv. Nr. A10679).

d) Eisenstift mit Öse; L 3,5 cm (B, Taf. 4/5, Inv. Nr. A10680).

e) Eisenstift unterhalb des Beckens, T-förmig, Lederreste; L 4,5 cm (B, Taf. 4/6, Inv. Nr. A-10681).

f) Riemenzwingenfragment mit 2 Bronzenieten; 3 weitere Eisenfragmente mit Geweberesten (B, Taf. 4/7, Inv. Nr. A-10682).

Bewertung: B1

Nur im Originalprotokoll sind der Eisenring und ein längliches Eisenstück, nur in der Fundkartei zwei Eisenstifte und eine Riemenzunge erwähnt.

\section{Grab 14}

Mann (25-35 Jahre);W-O-Orientierung; Rückenstrecklage; Skelettlänge $165 \mathrm{~cm}$; Sargverfärbungen (zwei ca. $1 \mathrm{~cm}$ dicke, schwarze Schichten unterhalb des Skeletts); bei den Füßen Aschenreste.

Beigaben:

a) Bronzepinzette unterhalb des Beckens, breitarmig mit gewundener Drahtaufhängung (Ring $\operatorname{Dm} 1,7 \mathrm{~cm}$ ), Randpunzierung, Gewebereste; L 6,3 cm (A, Taf. 5/1, Inv. Nr. A-10683).

b) Stachelsporn aus Eisen am linken Unterarm, rundstabig, ein Arm abgebrochen, Stachel spitzkonisch; L 7,2 cm (B, Taf. 5/2, Inv. Nr. A-10684).

c) Griffangelmesser bei der linken Hand, Rücken gekrümmt; L 14 cm (A, Taf. 5/3, Inv. Nr. A-10685).

d) Beinkammfragment am rechten Darmbein, dreilagig und zweireihig, unverziert (A, Taf. 5/4, Inv. Nr. A-10686).

e) Eisenstift; L 6,8 cm (A, Taf. 5/5, Inv. Nr. A-10687).

Bewertung: B1

Unklar ist, ob der im Originalprotokoll erwähnte „Eisenbügel in C-Form“ der in der Fundkartei genannte Sporn oder ein nicht mehr vorhandener Fund ist.

\section{Grab 15}

Frau; W-O-Orientierung; Rückenstrecklage; Finger der rechten Hand unter dem Becken; Skelettlänge $130 \mathrm{~cm}$; Sargverfärbung unterhalb des Nackens (L $35 \mathrm{~cm}$, B $10 \mathrm{~cm}$, D $4 \mathrm{~cm}$ ); unter der rechten Ferse eine graue, flaumige Masse.

Beigaben:

a) Halskette aus 8 Glasperlen; 3 kugelig, orange, opak; 5 kugelig, dunkelviolettblau, opak; 1 zweischalige Hohlperle aus Silberblech (A, Taf. 5/6, Inv. Nr. A-10688).

b) Eisenschnalle (nicht vorhanden).

Bewertung: B1 
Anmerkung im anthropologischen Gutachten: ,vertauscht mit Grab 14?"“. Tatsächlich ist Grab 15 im Plan als Kindergrab eingezeichnet. Die Halskette, lässt überdies auf ein weibliches Individuum schließen, während zumindest der Stachelsporn aus Grab 14, sofern er wirklich aus diesem Grab stammt, übereinstimmend mit dem anthropologischen Gutachten ein männliches Individuum wahrscheinlich macht. Ein Eisenmesser fehlt.

\section{Grab 16}

Mann; keine Beigaben.

Bewertung: B1

\section{Grab 17}

Frau (19-28 Jahre); keine Beigaben.

Bewertung: B1

\section{Grab 18}

Mann (37 Jahre)

Beigaben:

a) Rechteckschnallenfragment in der Beckengegend, Eisen, Dornrest (B, Taf. 5/7)

b) Dünne Beschlagplatte mit Gewebe- und Lederresten (B, Taf. 5/8, beide Inv. Nr. A-10689).

Bewertung: B1

\section{Grab 19}

Frau (?); W-O-Orientierung; Rückenstrecklage; rechte Hand über dem Becken, linker Arm anliegend, linke Hand auf linkem Oberschenkel; Skelettlänge 160 cm; Sargverfärbung hinter dem Schädel (L $20 \mathrm{~cm}$, B $15 \mathrm{~cm}$, D $1 \mathrm{~cm}$ ).

Beigaben:

a) Halskette aus 28 Glas- und 3 Silberperlen; 6 kugelig, orange, opak; 6 kugelig, braunocker, opak; 2 kugelig, dunkelgraublau, opak; 1 gedrückt kugelig, orange, opak; 1 gedrückt kugelig, dunkelgraublau, opak; 1 doppelkonisch, schwefelgelb, opak; 1 doppelkonisch, karminbraun, opak; 1 doppelkonisch, braunocker, opak; 2 doppelkonisch, dunkelgraublau, opak; 1 zylindrisch, orange, opak; 1 zylindrisch, braunocker, opak; 1 gedrückt kugelig, hellbläulichgrün, transluzid; 1 ringförmig, dunkelviolettblau, transluzid; 1 doppelkonisch, braunschwarz mit mattgrauer Spiralfadenauflage, opak; 1 hohle, silberne Perle aus 2 Halbschalen- und 2 Silberblechperlen (A, Taf. 6/1, Inv. Nr. A-10690).

b) Beinkammfragment, dreilagig und zweireihig; erh. L ca. $4 \mathrm{~cm}$ (B, Taf. 6/2, Inv. Nr. A-10691).

Bewertung: B1

Im Originalprotokoll ist eine Perlenkette genannt. Die Fundkartei führt eine Halskette aus 28 Glas-und Silberperlen und einen dreilagigen Beinkamm an. Das anthropologische Gutachten vermerkt: ,,archäologisch weiblich“, wahrscheinlich aufgrund der Halskette. Allerdings kommen andernorts zwar selten aber doch Männergräber mit Perlenketten vor.

\section{Grab 20}

Kind; weiblich (3 Jahre); W-O-Orientierung; Rückenstrecklage; Skelett fast völlig zersetzt; Sargverfärbung (L $120 \mathrm{~cm}$, B $45 \mathrm{~cm}$, D $30 \mathrm{~cm}$ ).
Beigaben:

a) Beinkamm links neben dem Schädel, dreilagig und einreihig, senkrechte Linienverzierung und Fischgrätmuster, 5 Eisennieten; L 12 cm (A, Taf. 6/3, Inv. Nr. A-10692).

b) Halskette aus 45 Perlen; 1 kugelig, weiß, opak; 3 kugelig, schwefelgelb, opak; 10 kugelig, orange, opak; 3 kugelig, braunocker, opak; 1 kugelig, dunkelbraun, opak; 6 kugelig, braunschwarz, opak; 1 gedrückt kugelig, weiß, opak; 1 gedrückt kugelig, orange, opak; 1 doppelkonisch, schwefelgelb, opak; 1 doppelkonisch, karminbraun, opak; 2 doppelkonisch, braunschwarz, opak; 1 zylindrisch, dunkelgraublau, opak; 2 Drehperlen, braunschwarz, opak; 1 kugelig, kornblumenblau, transluzid; 1 gedrückt kugelig, grünlichblau, transluzid; 1 gedrückt kugelig, dunkelviolettblau, transluzid; 1 doppelkonisch, weiß, transluzid; 1 doppelkonisch, silbrig, transluzid; 1 quaderförmig, dunkelgraublau, transluzid; 1 Drehperle, hellbläulichgrün, transluzid; 1 doppelkonisch, mattgrau mit dunkelgrünblauer Wellenbandverzierung und Mittel- sowie Randstreifen, opak; 2 kleine Bronzeperlen; 2 hohle Blechperlen aus Silber; 1 Fragment einer hohlen Silberblechperle (A, Taf. 6/4, Inv. Nr. A-10693).

Bewertung: A2

Grab 21

Mann (37 Jahre); W-O-Orientierung; gestört; Rückenstrecklage; Grab gestört; Skelettlänge $170 \mathrm{~cm}$; ungewöhnlich seichte Bestattung.

Beigaben:

Eisenschnalle mit Dorn (nicht vorhanden).

Bewertung: A2

Grab 22

Frau? (23 Jahre); W-O-Orientierung; Skelett stark beschädigt; stellenweise Sargverfärbungen; keine Beigaben.

Bewertung: A2

\section{Grab 23}

Mann (19-28 Jahre)

Bewertung: C

Keine Angaben im Originalprotokoll; in der Fundkartei nicht erwähnt.

\section{Grab 24A}

Schräg über der Bestattung aus Grab 24B.

Frau? (19-28 Jahre); Grab stark gestört; Skelettlänge 170 $\mathrm{cm}$.

Beigaben:

Eisenschnalle mit Dorn (nicht vorhanden).

Bewertung: A2

\section{Grab 24B}

Schräg unterhalb der Bestattung aus Grab 24A.

Sargreste entlang des rechten Unterschenkels sowie links und rechts oberhalb des Schädels; keine Beigaben.

Bewertung: C

Keine Angaben im Originalprotokoll. Im anthropologischen Gutachten nicht erwähnt. 
Grab 25A

Kind (7-8 Jahre); W-O-Orientierung; Rückenstrecklage; Grab stark gestört; keine Beigaben.

Bewertung: B1

Im Originalprotokoll keine Unterteilung des Grabes 25 in A und B, wohl aber im anthropologischen Gutachten und im Gräberfeldplan.

\section{Grab 25B}

Kind (3 Jahre); W-O-Orientierung; Rückenstrecklage; Grab stark gestört; keine Beigaben.

Bewertung: B1

Siehe Grab 25A.

\section{Grab 26}

Kind (?); W-O-Orientierung; Rückenstrecklage; rechte Hand auf der Hüfte; Skelettlänge $105 \mathrm{~cm}$; keine Beigaben. Bewertung: B1

Die im Originalprotokoll angegebene Skelettlänge von 105 $\mathrm{cm}$ lässt auf ein Kind schließen. Der Gräberfeldplan weist Grab 26 allerdings als Erwachsenengrab aus. Im anthropologischen Gutachten nicht erwähnt.

\section{Grab 27}

Kind (?); Skelett völlig zersetzt; vermutlich Sarggrab; keine Beigaben.

Bewertung: A2

Im anthropologischen Gutachten nicht erwähnt.

\section{Grab 28A}

Frau (?)

Bewertung: C

Nur im Originalprotokoll erwähnt, dass es sich um eine Frau handeln könnte. In der Fundkartei, im anthropologischen Gutachten sowie im Gräberfeldplan nur Grab 28B vorhanden.

\section{Grab 28B}

Mann (31 Jahre); Skelett grobknochig; Zähne stark abgekaut; Skelettlänge $180 \mathrm{~cm}$; Grabtiefe $85 \mathrm{~cm}$.

Beigaben:

a) Griffangelmesser unter dem rechten Unterarm, Rücken gekrümmt, Holzgriffreste; L 13,8 cm (A, Taf. 7/2, Inv. Nr. A-10694).

b) Rasiermesser; L 8,5 cm, B 2,5 cm (A, Taf. 7/1, Inv. Nr. A-10695).

c) Eisenmesser mit Dorn unter der linken Hüfte (nicht vorhanden).

Bewertung: A2

\section{Grab 29}

Kind (1,5 Jahre); Skelettlänge 72 cm; Grabtiefe ca. 100 cm; keine Beigaben.

Bewertung: A2

\section{Grab 30}

Kind (7 Jahre); Skelett stark beschädigt; Reste eines Baumsarges.
Beigaben:

Eisenschnalle beim Becken (nicht vorhanden)

Bewertung: A2

Während die Skelettlänge laut Originalprotokoll $170 \mathrm{~cm}$ beträgt und das Grab im Plan als Erwachsenengrab eingezeichnet ist, weist das anthropologische Gutachten ein 7 jähriges Kind aus.

\section{Grab 31}

Kind (1,5 Jahre); Grab zerstört; Sargschatten (L 100 cm, B $60 \mathrm{~cm}$, D $40 \mathrm{~cm}$ ); keine Beigaben.

Bewertung: A1

Grab 32

Kind (8 Jahre); W-O-Orientierung; rechte Hand über der rechten Hüfte; Skelettlänge ca. 105 cm; Sargverfärbungen; keine Beigaben.

Bewertung: A2

\section{Grab 33}

Doppelnummerierung; siehe Grab 75.

Bewertung: C

Obwohl im Gräberfeldplan als Erwachsenengrab eingezeichnet, handelt es sich offensichtlich um eine Doppelnummerierung (siehe Kindergrab 75 ${ }^{14}$ ). Das Grab wird weder in der Fundkartei noch im anthropologischen Gutachten erwähnt.

\section{Grab 34}

Doppelnummerierung; siehe Grab 76.

Bewertung: C

\section{Grab 35}

Doppelnummerierung; siehe Grab 77.

Bewertung: $\mathbf{C}$

\section{Grab 36}

Doppelnummerierung; siehe Grab 78A.

Bewertung: C

\section{Grab 37}

Doppelnummerierung; siehe Grab 79.

Bewertung: C

\section{Grab 38}

Mann; W-O-Orientierung; Rückenstrecklage; Skelettlänge $173 \mathrm{~cm}$; Grabtiefe $130 \mathrm{~cm}$; Sargverfärbung unterhalb der Beine.

Beigaben:

a) Langsax, deutlich abgesetzte Klinge, beidseitig Blutrinne, Holzgriffreste; GesamtL $62 \mathrm{~cm}$, KlingenB $4 \mathrm{~cm}$, GriffL $14,5 \mathrm{~cm} \mathrm{(B,} \mathrm{Taf.} \mathrm{7/3,} \mathrm{Inv.} \mathrm{Nr.} \mathrm{A-10696a).}$

b) Kantenschutzbeschläge für die Scheide, bandförmig, Eisenniet (B, Taf. 7/4-9, Inv. Nr. A-10696b).

c) Eisenbeschlag, zungenförmig; L 4,5 cm (B, Taf. 7/10, Inv. Nr. A-10697).

d) Schnallenbügelfragment mit Dornrest, Eisen, oval (B, Taf. 7/11, Inv. Nr. A-10698). 
e) Schnallenbügelfragment oberhalb des Kreuzbeins, Eisen, quadratisch; möglicherweise zu A-10698 gehörig (B, Taf. 7/12, Inv. Nr. A-10699)

f) Eisenstift unterhalb der rechten Handwurzel (B, Taf. 7/ 13, Inv. Nr. A-10700).

g) Beinkammfragment, dreilagig und zweireihig, 2 Eisennieten (B, Taf. 7/14, Inv. Nr. A-10701).

h) Pfeilspitze bei der rechten Hand (erh. L 4,5 cm); geschlitzte Tülle mit Holzresten (erh. L cm); (B, Taf. 7/15, Inv. Nr. A-10702).

i) Eisenfragmente mit Geweberesten (B,Taf. 7/16-19, ohne Inv. Nr.).

Bewertung: B1-C

Die Übereinstimmung mit dem Skelett aus Grab 80 ist nicht zu übersehen. Möglicherweise wurden die Beigaben eines reichen Grabes auf zwei Gräber aufgeteilt, von denen es eines nie gab. Allerdings sind beide „Gräber“ im Plan eingezeichnet. Der Langsax aus der Fundkartei ist im Originalprotokoll nicht erwähnt. Das Grab ist im anthropologischen Gutachten nicht erwähnt.

\section{Grab 39}

Keine Angaben über das Individuum.

Beigaben:

Beinkamm, dreilagig und zweireihig, grobe und feine Zähnung, schraffierte Dreiecke und senkrechte Linienverzierung, 6 Eisennieten; L $11 \mathrm{~cm}$, erh. B $3 \mathrm{~cm}$ (B, Taf. 8/1, Inv. Nr. A-10704), siehe auch Grab 82B.

Bewertung: C

Es kann sich entweder um eine Doppelnummerierung (Grab 82B nach M. Pertelwieser oder Grab 81 laut Originalprotokoll) oder um eine Leernummer handeln, da das Grab im Plan nicht eingezeichnet ist und auch im anthropologischen Gutachten nicht erwähnt wird. In der Fundkartei ist aber ein Beinkamm genannt.

\section{Gräber 40 und 41}

Keine Angaben; keine Beigaben.

\section{Bewertung: C}

Es handelt sich entweder um eine Doppelnummerierung (Originalprotokoll: ,,vgl. Grab 82A“ im Falle von Grab 40 bzw. ,vgl. Grab 82B“" im Falle von Grab 41) oder um Leernummern, da diese Gräber weder im Plan noch im anthropologischen Gutachten oder in der Fundkartei aufscheinen.

\section{Grab 42}

Mann (35-45 Jahre); SW-NO-Orientierung; Rückenstrecklage; Skelett schlecht erhalten; Schädel etwas nach links geneigt; Skelettlänge $178 \mathrm{~cm}$; Grabtiefe $85 \mathrm{~cm}$; Sargverfärbungen.

Beigaben:

a) Ösennadel aus Bronze auf dem rechten Oberarm mit der Öse nach oben, Schaft gebogen und umlaufend rautenförmig verziert; L $12 \mathrm{~cm}$ (A, Taf. 8/2, Inv. Nr. A10705).

b) 2 Flügelpfeilspitzen beim rechten Unterarm, Tüllen geschlitzt, Holzschaftreste; L 8 und $7 \mathrm{~cm}$ (A, Taf. 8/3,4, Inv. Nr. A-10706). c) 2 Griffangelmesser, eines mit gekrümmtem Rücken beim linken Ellbogen, das andere schlankere auf der linken Hüfte; L 14,5 und $12 \mathrm{~cm}$ (A, Taf. 8/5,6, Inv. Nr. A-10707).

d) Rechteckschnalle in der Mitte des Kreuzbeins, Eisen, Dornrolle erhalten; $3,2 \times 2,5 \mathrm{~cm}$ (A, Taf. 8/7, Inv. Nr. A-10708).

e) Beinkammfragment gemeinsam mit dem Griffangelmesser beim linken Ellbogen, dreilagig und zweireihig, senkrechte Linienverzierung; erh. L ca. 8,2 cm (A, Taf. 8/8, Inv. Nr. A-10709).

Bewertung: A1

\section{Grab 43}

Frau (33 Jahre); SW-NO-Orientierung; Rückenstrecklage; Skelettlänge $173 \mathrm{~cm}$; Grabtiefe $80 \mathrm{~cm}$; Sargreste.

Beigaben:

a) Griffangelmesser in der Brustgegend, Rücken gerade; L 18 cm, KB $2 \mathrm{~cm}$ (A, Taf. 9/1, Inv. Nr. A-10710).

b) Rechteckschnalle aus Eisen auf der linken Hüfte; 3,5 $\times$ 2,5 cm (A, Taf. 9/2, Inv. Nr. A-10711).

c) Perlen (nicht vorhanden).

Bewertung: A2

\section{Grab 44}

Frau? (44-52 Jahre); SW-NO-Orientierung; Rückenstrecklage; Skelettlänge $170 \mathrm{~cm}$; Grabtiefe $80 \mathrm{~cm}$; deutliche Sargverfärbung; keine Beigaben.

Bewertung: A1

\section{Grab 45}

Mann (36 Jahre); SW-NO-Orientierung; Rückenstrecklage; Schädel nach links gekippt; Skelettlänge $173 \mathrm{~cm}$; Grabtiefe $80 \mathrm{~cm}$; deutliche Sargverfärbung.

Beigaben:

a) Breitsax auf der linken Seite, vom Ellbogen bis zum Knie reichend, beidseitig je 2 Blutrinnen; GesamtL $58 \mathrm{~cm}$, KlingenB 4,5 cm, Griffl $19 \mathrm{~cm}$ (A, Taf. 9/3, Inv. Nr. A10712).

b) Schwertscheide (nicht vorhanden).

c) Griffangelmesser bei der linken Schläfe, fragmentiert, Holzgriff- und Lederreste, erh. L 12 cm, (A, Taf. 9/4, Inv. Nr. A-10713a).

d) Griffangelmesser beim rechten Oberarm, fragmentiert, Rücken gerade, erh. L 8 cm, (A, Taf. 9/5, Inv. Nr. A10713b).

e) Griffangel eines weiteren Messers mit Klingenansatz; erh. L $6 \mathrm{~cm}$ (A, Taf. 9/6, Inv. Nr. A-10713c).

f) Schnallenbügelfragment mit Dorn beim Kreuzbein, Eisen, oval (A, Taf. 9/7, Inv. Nr. A-10714).

g) Rechteckschnallenfragment mit Dorn beim Kreuzbein, Eisen (A, Taf. 9/8, Inv. Nr. A-10715).

h) Öse aus Eisendraht mit Schaftansatz; L 2 cm (A, Taf. 9/9, Inv. Nr. A-10716).

i) Flügelpfeilspitze beim rechten Knie; L $7 \mathrm{~cm}$ (A, Taf. 10/1, Inv. Nr. A-10717a).

j) Schaft einer weiteren Flügelpfeilspitze beim rechten Knie, in der Tülle Holzreste; erh. L 4,7 cm (A, Taf. 10/2, Inv. Nr. A-10717b). 
k) Scheidenzierbeschläge aus Bronze: 3 Flachkopfnieten mit kreisförmiger Punzverzierung (Dm 2,1 cm); dazugehörig 28 kleine, halbkugelige Nietköpfe (Dm 0,6 cm) (A, Taf. 10/3, Inv. Nr. A-10718).

1) Beinkamm an der linken Wange (nicht vorhanden). Bewertung: A2

\section{Grab 46}

Frau? (35-45 Jahre); SW-NO-Orientierung; Grab zerstört. Beigaben:

2 längliche Beschlagbleche aus Eisen (L 2,2 und 2,7 cm) und ein weiteres Beschlagblech mit Mittelniet und Holzresten (B, Taf. 10/4-6, Inv. Nr. A-10719).

Bewertung: B1

Nur die Fundkartei nennt die zwei länglichen Beschlagbleche aus Eisen.

\section{Grab 47}

Kind (9 Jahre); SW-NO-Orientierung, Rückenstrecklage; Schädel nach rechts abgerutscht; Skelettlänge $107 \mathrm{~cm}$; Grabtiefe $80 \mathrm{~cm}$; Sargverfärbungen.

Beigaben:

a) Griffangelmesser mit breiter Griffangel zwischen der rechten Hand und dem rechten Oberschenkel; L $16 \mathrm{~cm}$, KlingenB 2,3 cm (A, Taf. 11/1, Inv. Nr. A-10720a).

b) Griffangel eines weiteren Messers mit Klingenansatz, Holzreste; erh. L 7 cm (B, Taf. 10/7, Inv. Nr. A10720b).

c) Flügelpfeilspitze außerhalb des linken Fußknöchels, Tülle geschlitzt, Holzschaftreste; L 7 cm (A Taf. 10/8, Inv. Nr. A-10721).

Bewertung: B1-B2

Die Griffangel scheint nur in der Fundkartei, nicht aber im Originalprotokoll auf.

\section{Grab 48}

Frau (43 Jahre); WSW-ONO-Orientierung; rechte Hand auf dem rechten Hüftbein, linke Hand am linken Oberschenkel; Skelettlänge $157 \mathrm{~cm}$; Grabtiefe $60 \mathrm{~cm}$; Sargverfärbungen (L $192 \mathrm{~cm}$, B $62 \mathrm{~cm}$ ).

Beigaben:

Schnallenbügel aus Eisen, fragmentiert, Gewebereste (B, Taf. 11/2, Inv. Nr. A-10722).

Bewertung: B1

Der Schnallenbügel existiert nur in der Fundkartei (Originalprotokoll: ,keine Beigaben“).

\section{Grab 49}

Mann (43 Jahre); WSW-ONO-Orientierung; Rückenstrecklage; beide Unterschenkel nach links gekippt, verheilter Bruch des rechten Schien- und Wadenbeins; Skelettlänge $170 \mathrm{~cm}$; Grabtiefe $60 \mathrm{~cm}$; Sargverfärbungen (L $200 \mathrm{~cm}$, B $65 \mathrm{~cm})$.

Beigaben:

Griffangelmesser auf dem rechten Oberarm, Schneide nach außen; L 15 cm (A, Taf. 11/3, Inv. Nr. A-10723).

Bewertung: A1

\section{Grab 50A}

Doppelbestattung mit Grab 50B.

Frau (25-34 Jahre); WSW-ONO-Orientierung; Rückenstrecklage; Skelettlänge $155 \mathrm{~cm}$; Grabtiefe $124 \mathrm{~cm}$; teilweise deutliche Reste eines Eichen-Baumsarges.

Beigaben:

a) Halskette aus 65 Glasperlen; 51 kugelig bzw. gedrückt kugelig, orange bis braunocker, opak; 1 kugelig, braunschwarz, opak; 1 quaderförmig, dunkelgrünblau, opak; 1 mandelförmig, blauschwarz, opak; 1 kugelig, dunkelviolettblau, transluzid; 7 mandelförmig, hellbläulichgrün, transluzid, mit Bronzeröllchen, 1 davon fragmentiert; 3 oval, hellbläulichgrün, transluzid, mit Bronzeröllchen (A, Taf. 11/4, Inv. Nr. A-10724).

b) Rechteckschnalle mit Dorn auf dem rechten Hüftgelenk, Eisen, Gewebereste; $4 \times 3 \mathrm{~cm}$ (A, Taf. 11/5, Inv. Nr. A10725).

c) Eisenschnallenfragment, oval, 2 Eisenniete, Gewebereste (A, Taf. 11/6, Inv. Nr. A-10726).

\section{Bewertung: A1}

\section{Grab 50B}

$\mathrm{Zu} \mathrm{Grab} \mathrm{50A} \mathrm{gehöriger} \mathrm{Foetus.}$

Bewertung: C

Im Originalprotokoll nicht erwähnt.

\section{Grab 51}

Kind (4 Jahre).

Bewertung: C

Nur im Gräberfeldplan und im anthropologischen Gutachten enthalten.

\section{Grab 52}

Mann (25-35 Jahre)

Bewertung: C

Nur im Gräberfeldplan und im anthropologischen Gutachten enthalten. Nicht im Gräberfeldplan eingezeichnet. Es gibt allerdings ein mit einem Fragezeichen versehenes Erwachsenengrab nahe Grab 8. Ob es sich dabei um Grab 52 handelt, ist unklar.

\section{Grab 53}

Frau (50-65 Jahre); keine weiteren Angaben.

Bewertung: C

Nur im Gräberfeldplan und im anthropologischen Gutachten enthalten.

\section{Grab 54}

Mann? (23 Jahre).

Bewertung: C

Nur im Gräberfeldplan und im anthropologischen Gutachten enthalten.

\section{Grab 55 (Abb. 10)}

Nur Schädel und Teile des Brustkorbes vorhanden; deutliche, tiefschwarze Baumsargreste.

Beigaben:

Eisenmesser zwischen dem linken Oberarm und dem Brustkorb (nicht vorhanden).

Bewertung: A2 


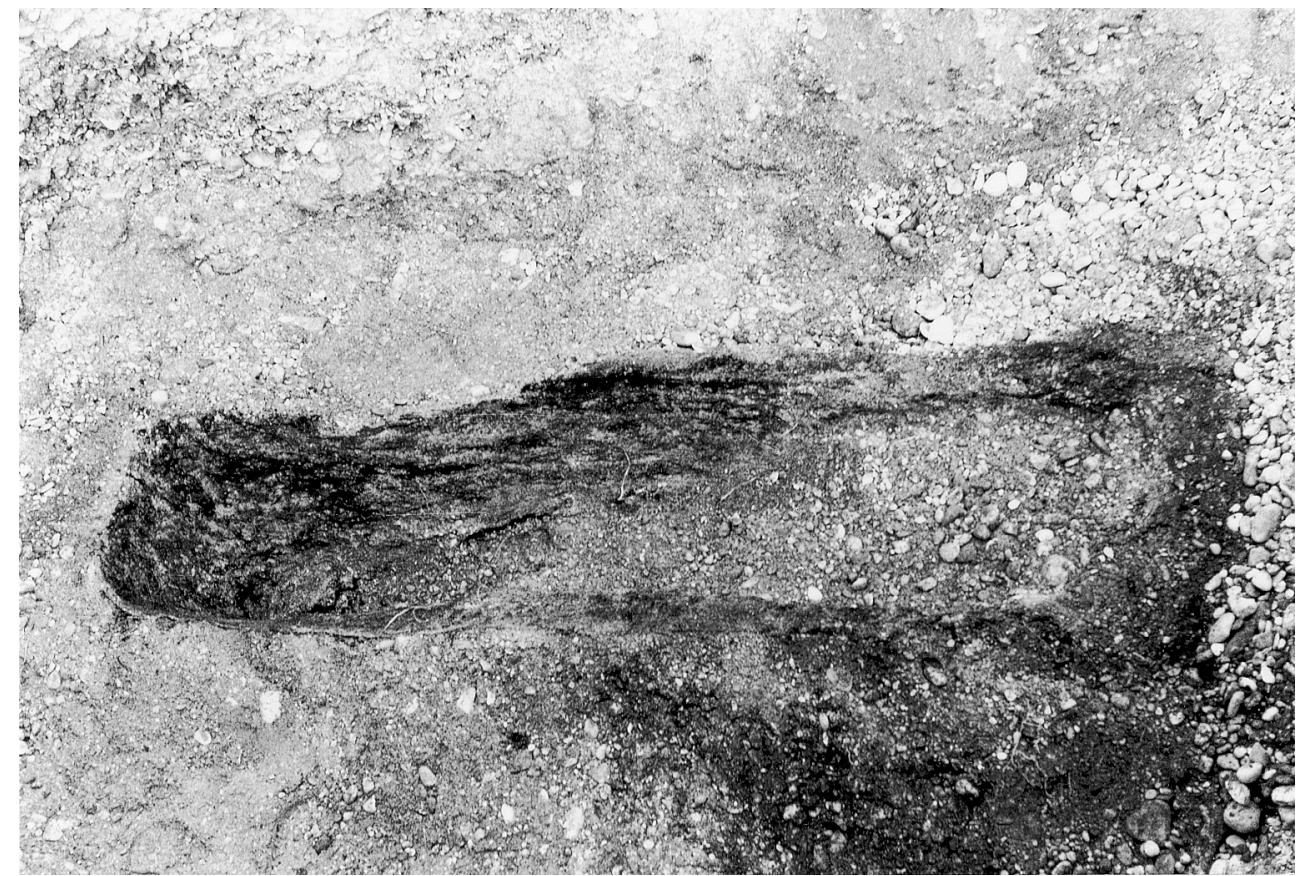

Abb. 10. Rudelsdorf. Grab 55, Baumsarg.

\section{Grab 56}

Keine Angaben.

Bewertung: C

\section{Grab 57}

Frau (33 Jahre); linker Unterarm rechtwinkelig, rechter fast gestreckt, rechte Hand auf dem Kreuzbein, Oberarme nur $12 \mathrm{~cm}$ auseinander, Füße überkreuz; Skelettlänge $148 \mathrm{~cm}$; Grabtiefe 165 cm; Sargverfärbungen; keine Beigaben.

Bewertung: A1

\section{Grab 58A}

Frau? (40 Jahre)

Bewertung: C

Im Plan als Doppelgrab eingezeichnet.

\section{Grab 58B}

Frau (33 Jahre)

Bewertung: C

Siehe Grab 58A

\section{Grab 59}

Jugendliche(r) (15-21 Jahre); W-O-Orientierung; Rückenstrecklage; linker Unterarm fast rechtwinkelig, linke Hand auf dem rechten Ellbogen, rechte Hand unter dem Kreuzbein; Skelettlänge $157 \mathrm{~cm}$; Grabtiefe $200 \mathrm{~cm}$; auf der linken Seite Sargverfärbungen.

Beigaben:

a) Griffangelmesserfragment am unteren linken Oberarm, Spitze zum linken Schultergelenk, Rücken gerade; erh. L 17,5 cm (A, Taf. 12/2, Inv. Nr. A-10727).

b) Beinkammfragment, unverziert (B, Taf. 12/3, Inv. Nr. A10728). c) Rechteckschnalle auf dem Becken, Eisen; nicht vorhanden.

d) Kammstrichscherbe (Bodenstück), graphitiert, latènezeitlich (nicht vorhanden).

Bewertung: B1

Der Beinkamm ist nur in der Fundkartei erwähnt.

\section{Grab 60}

Kind (4 Jahre); W-O-Orientierung; Rückenstrecklage; offene Stirnfontanelle; Skelettlänge $78 \mathrm{~cm}$; Grabtiefe $110 \mathrm{~cm}$; Sargreste.

Beigaben:

Eisenring mit aufgesetztem Ringlein zwischen linken Schulter und Hals; Dm $5 \mathrm{~cm}$ (nicht vorhanden).

Bewertung: A2

Der im Originalprotokoll genannte Eisenring ist nicht vorhanden.

\section{Grab 61}

Keine Angaben.

Bewertung: C

Im anthropologischen Gutachten nicht erwähnt, im Plan als Doppelgrab mit Nr. 62 dokumentiert.

\section{Grab 62}

Keine Angaben über das Individuum.

Beigaben:

a) Eisennagel, vierkantig mit flachem Kopf; L 2,8 cm (B, Taf. 12/4, Inv. Nr. A-10729).

b) Tüllenfragment einer Pfeilspitze, tordiert; erh. L 3,2 cm (B, Taf. 12/5, Inv. Nr. A-10730). 
c) Schnallenbügelfragment und Blechbeschlag aus Eisen (B, Taf. 12/6,7, Inv. Nr. A-10731).

Bewertung: C

Siehe Grab 61. Beigaben nur in der Fundkartei erwähnt.

\section{Grab 63}

W-O-Orientierung; Rückenstrecklage; Skelett stark zerstört, nur beide Unterschenkel samt Füßen geborgen; Sargverfärbung (L $212 \mathrm{~cm}$, max. B $60 \mathrm{~cm}$ ); unterhalb des linken Knies ein Tierzahn, nicht vorhanden.

Bewertung: A2

Im anthropologischen Gutachten nicht erwähnt.

\section{Grab 64}

Unterhalb von Grab 63; wahrscheinlich überlagerte Doppelbestattung.

Frau (17-25 Jahre); W-O-Orientierung; Rückenstrecklage; Skelettlänge $166 \mathrm{~cm}$; deutliche Sargverfärbung (L $184 \mathrm{~cm}$, $\max . \mathrm{B} 62 \mathrm{~cm})$.

Beigaben:

a) Beinkammfragmente beim rechten Scheitelbein, dreilagig und zweireihig, unverziert, 4 Eisennieten; erh. L ca. 9,2 cm (A, Taf. 12/8, Inv. Nr. A-10732).

b) Pfeilspitze neben dem rechten Bein, lanzettförmiges Blatt mit 4 Bohrungen; L 6,8 cm (B, Taf. 12/9, Inv. Nr. A10733).

c) Pfeilspitze neben A-10733 (nicht vorhanden).

d) Gürtelschnalle aus Eisen; bei der rechten Hüfte (nicht vorhanden).

e) Sporn am rechten Fuß (nicht vorhanden).

Bewertung: B1

Beinkamm in Originalprotokoll und Fundkartei genannt, alle übrigen Beigaben nur in der Fundkartei; drei davon nicht vorhanden

\section{Grab 65}

Kleinstkind (0,5 Jahre); W-O-Orientierung; Rückenstrecklage, Skelett schlecht erhalten, Schädel etwas nach links verschoben; Grabtiefe $50 \mathrm{~cm}$; spärliche Sargverfärbung; keine Beigaben.

Bewertung: A1

\section{Grab 66}

Kind (3 Jahre);W-O-Orientierung; Rückenstrecklage; Schädel etwas nach links gekippt, Hände an den Hüften; Skelettlänge $88 \mathrm{~cm}$; Grabtiefe $45 \mathrm{~cm}$; spärliche Sargverfärbung; keine Beigaben.

Bewertung: A1

\section{Grab 67}

Keine Angaben.

Bewertung: C

\section{Grab 68}

Kind (4 Jahre); W-O-Orientierung; leichte Hockerstellung nach links; Schädel zerdrückt; rechte Hand auf rechter Hüfte, linker Arm stark nach links gewinkelt; Skelettlänge ca. $105 \mathrm{~cm}$; Grabtiefe $40 \mathrm{~cm}$; deutliche Sargverfärbung; keine Beigaben.

Bewertung: A1

\section{Gräber 69-74}

Leernummern.

Grab 75 (Abb. 11)

Kind im Zahnwechsel; WNW-OSO-Orientierung; Rückenstrecklage; Skelettlänge $105 \mathrm{~cm}$; Grabtiefe $90 \mathrm{~cm}$.

Beigaben:

Bronzenadel mit polyedrischem Kopf, Schaft leicht geschwungen, Spitze in der Mundhöhle; L 7,1 cm (A, Taf. 12/10, Inv. Nr. A-10734).

Bewertung: A1

Siehe Grab 33. Im anthropologischen Gutachten nicht erwähnt.

\section{Grab 76 (Abb. 12)}

Mann? (23 Jahre); gut erhalten; W-O-Orientierung; Rückenstrecklage; Skelettlänge $178 \mathrm{~cm}$; Grabtiefe $72 \mathrm{~cm}$; Sargverfärbung; keine Beigaben.

Bewertung: A1

Siehe Grab 34
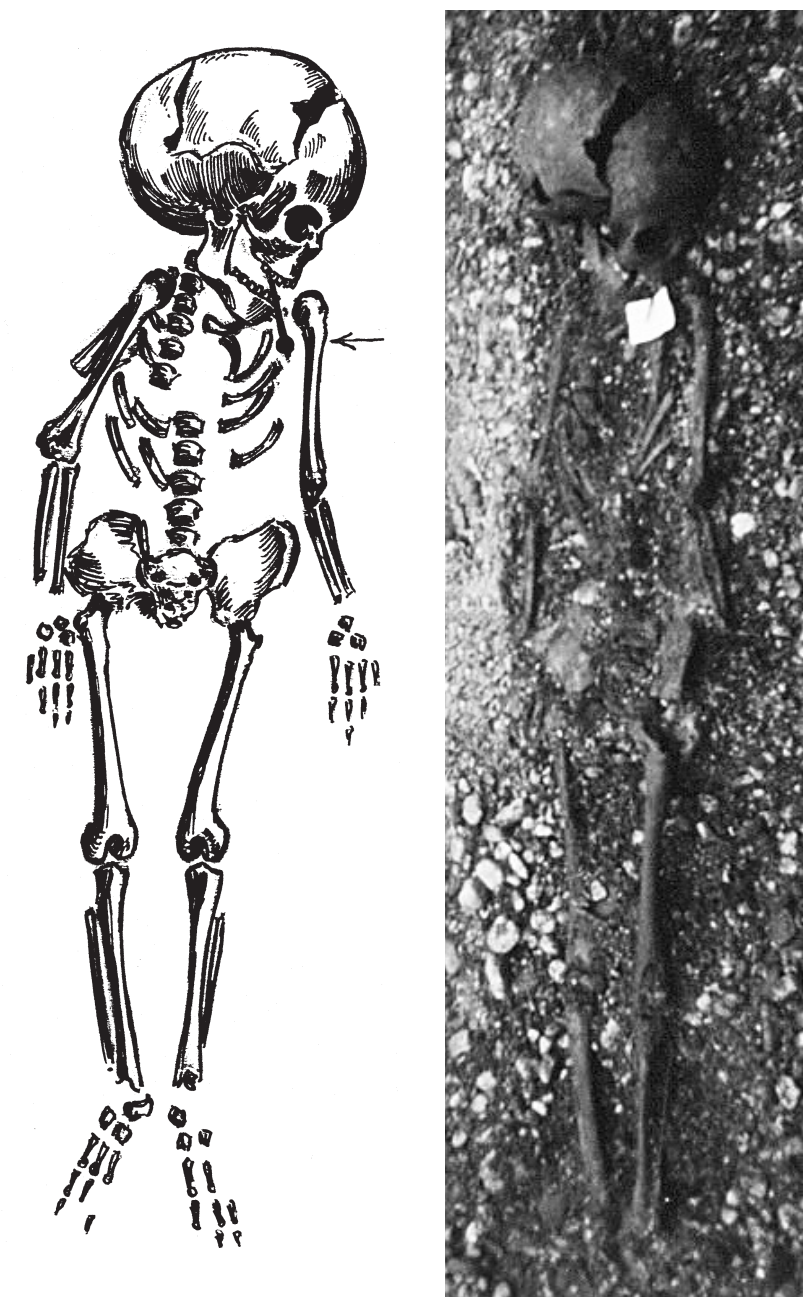

Abb. 11. Rudelsdorf. Grab 75. $\leftarrow$ Bronzenadel. Zeichnung M. Pertlwieser. 

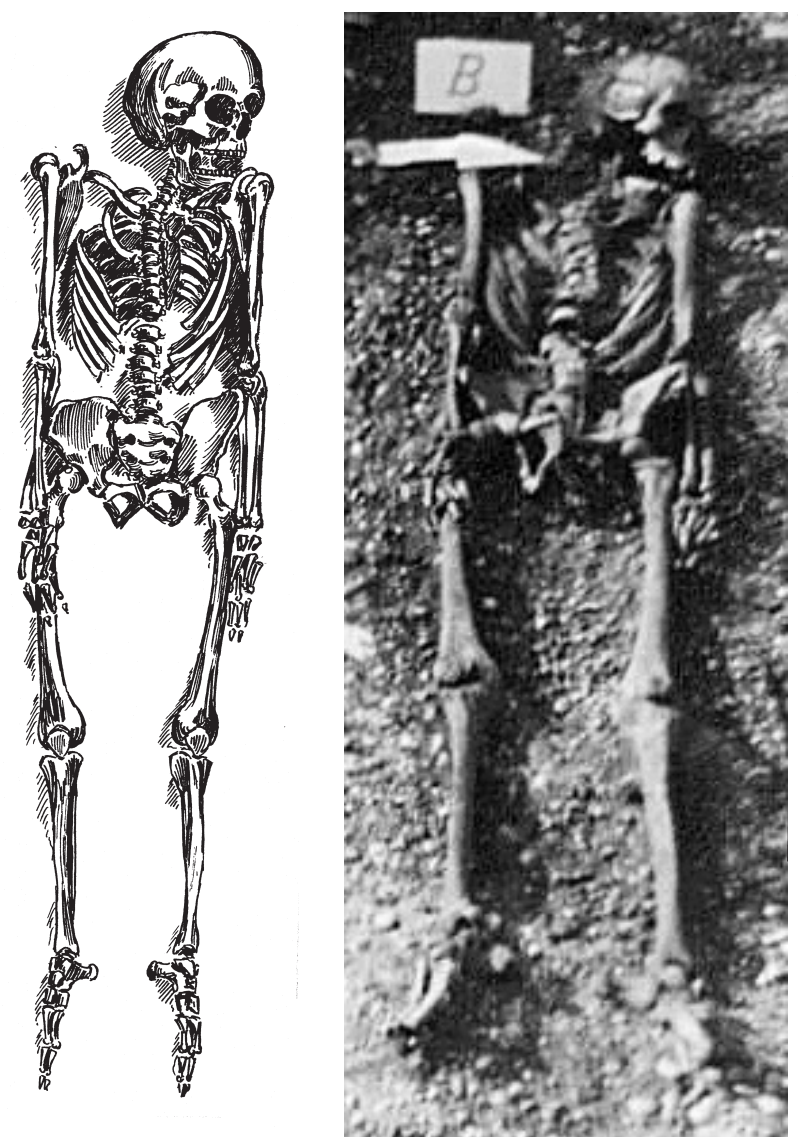

Abb. 12. Rudelsdorf. Grab 76. Zeichnung M. Pertlwieser.

Grab 77 (Abb. 13)

Mann; WSW-ONO-Orientierung; Rückenstrecklage; Skelettlänge $168 \mathrm{~cm}$; Grabtiefe $60 \mathrm{~cm}$.

Beigaben:

Eisenschnalle auf dem linken Darmbein, Bronzedorn, Gewebereste (A, Taf. 13/1, Inv. Nr. A-10735)

Bewertung: A1

Siehe Grab 35.

\section{Grab 78A}

Erwachsener; W-O-Orientierung; Skelett schlecht erhalten; Grabtiefe 50 cm; Sargverfärbung (L 105 cm, B 50 cm); keine Beigaben.

Bewertung: A1

Möglicherweise Doppelnummerierung mit 30iger-Grab.

\section{Grab 78B}

Mann; Grab gestört; Grabtiefe 100 cm; Holzsargverfärbung (B $45 \mathrm{~cm}$ ); keine Beigaben.

Bewertung: A1

Siehe Grab 78A.

Grab 79 (Abb. 14)

Frau (32 Jahre); W-O-Orientierung; Rückenstrecklage; Skelett schlecht erhalten; rechter Unterarm abgewinkelt; Skelettlänge $156 \mathrm{~cm}$; Grabtiefe $120 \mathrm{~cm}$; deutliche Reste eines

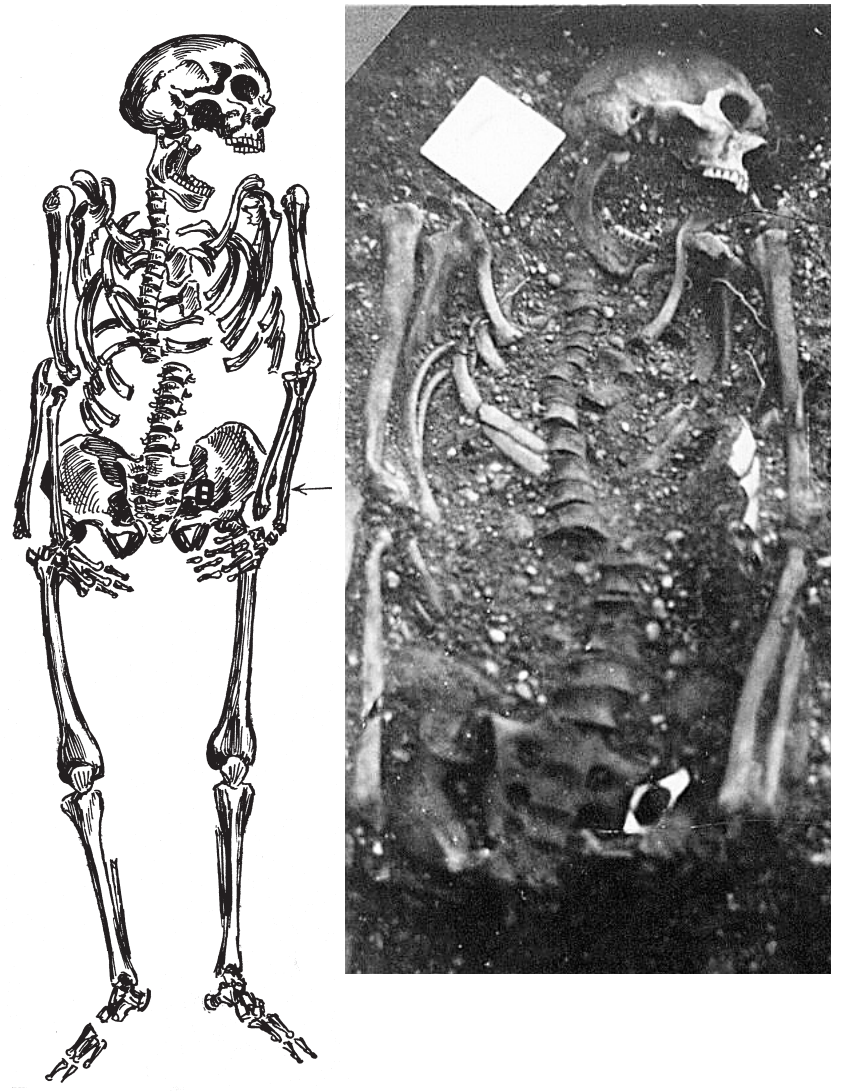

Abb. 13. Rudelsdorf. Grab 77. $\leftarrow$ Eisenschnalle. Zeichnung M. Pertlwieser.

Baumsarges (196x52x44 cm), Deckel teilweise eingedrückt; keine Beigaben.

Bewertung: A1

Siehe Grab 37.

Grab 80 (Abb. 15)

Mann (32 Jahre); W-O-Orientierung; Rückenstrecklage; Skelett gut erhalten; kräftiger Knochenbau; Skelettlänge 173 cm; Grabtiefe 130 cm; spärliche Sargverfärbungen entlang der Schienbeine.

Beigaben:

a) Eisenschnallenfragment mit Dorn beim rechten Schambein (B, Taf. 13/2, Inv. Nr. A-10736).

b) Eisenschnallenfragment mit Dorn auf dem ersten Kreuzbeinwirbel; möglicherweise zu A-10736 gehörig (B, Taf. 13/3, Inv. Nr. A-10737)

c) Riemenzwinge aus Eisen mit 2 Bronzenieten, zu A10737 gehörig; $2,8 \times 2,2 \mathrm{~cm}(\mathbf{B}$, Taf. 13/4, Inv. Nr. A10738)

d) Flügelpfeilspitze beim linken Oberschenkel, Holzreste in der Tülle; L 7 cm (B, Taf. 13/5, Inv. Nr. A-10739).

e) Stachelsporn aus Eisen beim linken Fuß, Lederreste; erh. L $9 \mathrm{~cm}$ (B, Taf. 13/6, Inv. Nr. A-10740).

f) Dicker Eisenring bei der rechten Handwurzel; Dm $4 \mathrm{~cm}$ (B, Taf. 13/7, Inv. Nr. A-10741). 

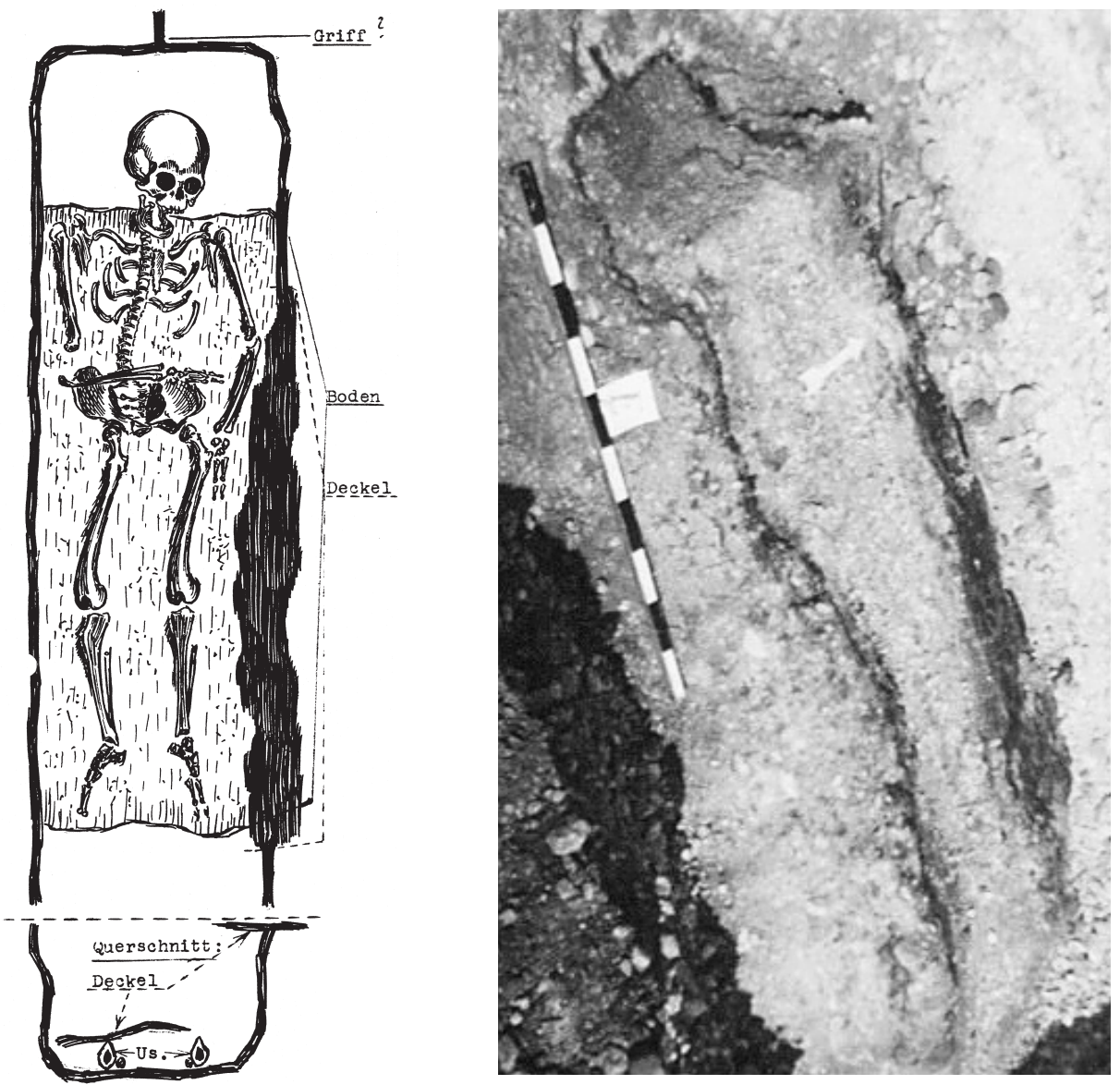

Abb. 14. Rudelsdorf. Grab 79. Bestattung in Baumsarg. Zeichnung M. Pertlwieser.

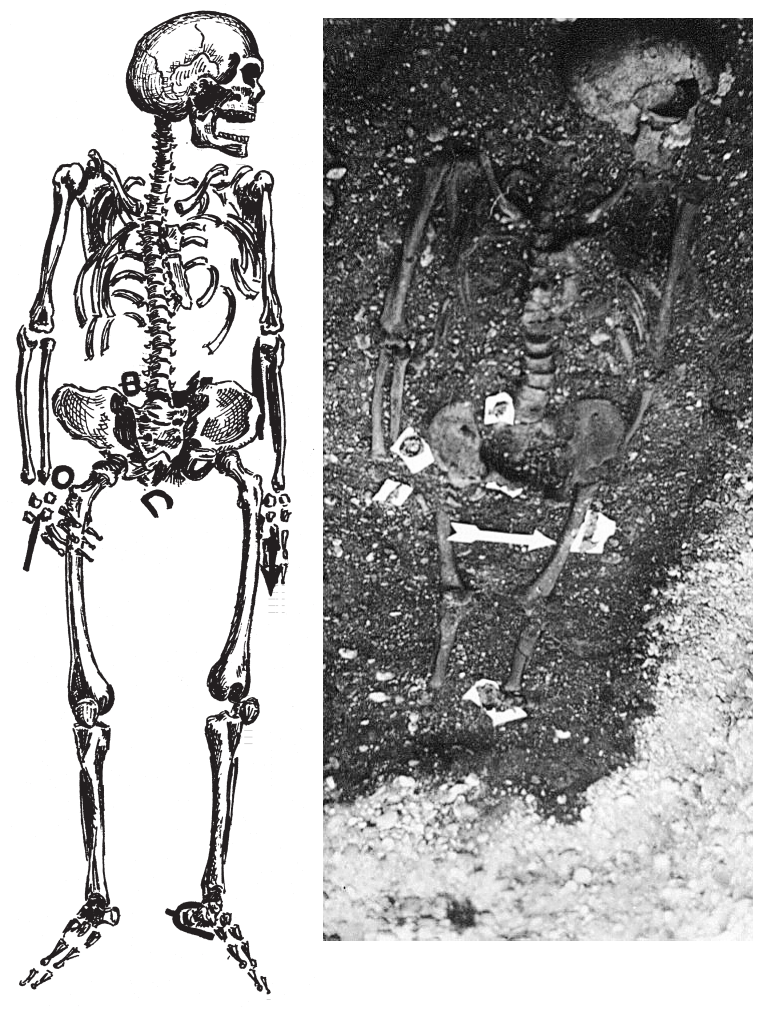

Abb. 15. Rudelsdorf. Grab 80. Zahlreiche Beigaben. Zeichnung M. Pertlwieser. g) Eisenschaft, rundstabig, Holzreste; erh. L 6,5 cm (B, Taf. 13/8, Inv. Nr. A-10742).

Bewertung: B1

Siehe Grab 38. Die Existenz des Grabes scheint aber durch alle zur Verfügung stehenden Quellen gesichert.

\section{Grab 81 (Abb. 16)}

Kind (1,5 Jahre); W-O-Orientierung; Rückenstrecklage; Skelett schlecht erhalten; rechter Arm fast gestreckt, linker Arm auf der linken Hüfte; Skelettlänge $80 \mathrm{~cm}$; Grabtiefe 110 cm; deutliche Sargverfärbung an der linken Seite vom Schädel bis zum Becken.

Beigaben:

Griffangelmesser in Fortsetzung des linken Unterarmes mit der Spitze fußwärts; L 10,5 cm (A, Taf. 13/9, Inv. Nr. A10743).

Bewertung: A1

\section{Grab 82A}

W-O-Orientierung; Rückenstrecklage; Skelett stark beschädigt; Unterschenkel und Füße zerstört; Skelettlänge ca. 155 $\mathrm{cm}$; Grabtiefe $35 \mathrm{~cm}$; keine Beigaben.

Bewertung: A1

Grab 82B (Abb. 17)

Kind; W-O-Orientierung; Rückenstrecklage; Skelettlänge $124 \mathrm{~cm}$; Grabtiefe $50 \mathrm{~cm}$; deutliche Holzsargreste, rechte Seitenwand und Bodenteile erhalten. 


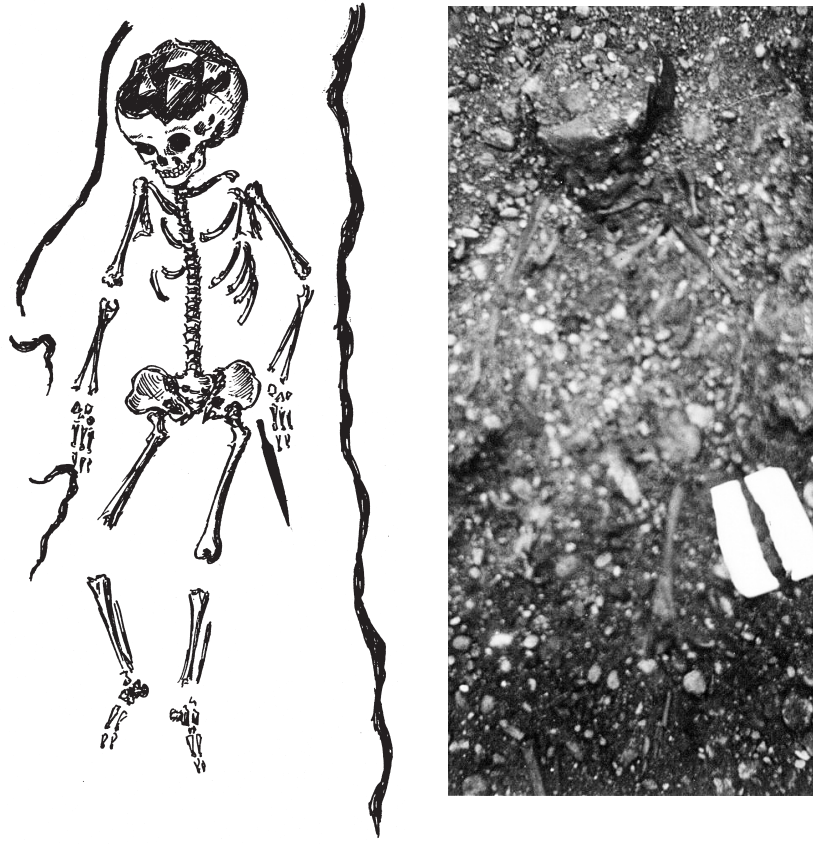

Abb. 16. Rudelsdorf. Grab 81. Sargverfärbung. Zeichnung M. Pertlwieser.

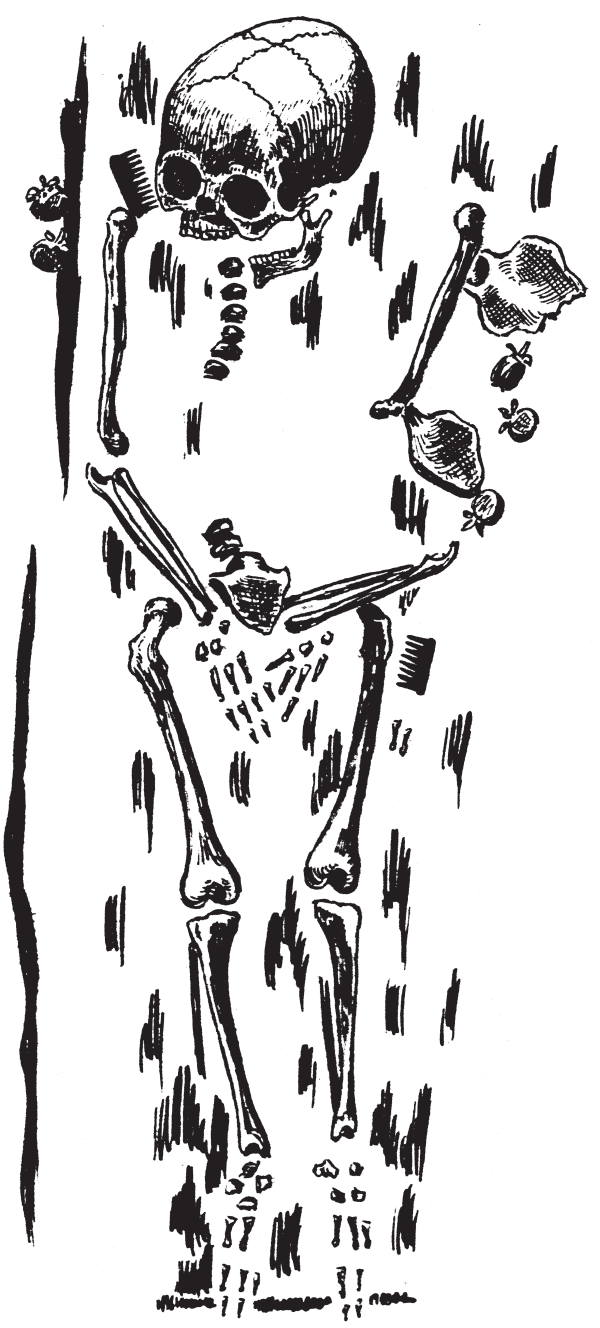

Beigaben:

a) Beinkammfragment neben dem rechten Oberarm, dreilagig und zweireihig, feine und grobe Zähnung, senkrechte Linienverzierung, 4 Eisennieten; erh. L $5,5 \mathrm{~cm}$ (A, Taf. 13/10, Inv. Nr. A-10744).

b) Beinkammfragment außen neben dem linken Oberschenkel (nicht vorhanden; möglicherweise Kamm mit Inv. Nr. A-10704, siehe Grab 39).

Bewertung: A1

\section{Grab 83 (Abb. 18)}

Mann (33 Jahre); W-O-Orientierung; Rückenstrecklage; Schädel nach links gerutscht; Skelettlänge $173 \mathrm{~cm}$; Grabtiefe $125 \mathrm{~cm}$; deutlicher Sargboden (schwarze Verfärbung L 235 $\mathrm{cm}, \mathrm{B} 70 \mathrm{~cm})$.

Beigaben:

a) Spatha schräg über dem Oberkörper, wellenförmige Damastverzierung im Klingenmittelteil, Holzreste von der Scheide; GesamtL 83 cm, KlingenB 4 cm, GriffL 11 $\mathrm{cm}$, Parierplatte $7,6 \times 2,2 \mathrm{~cm}$, Knaufplatte $7 \times 2 \mathrm{~cm}$ (A, Taf. 14/1, Inv. Nr. A-10745).

b) Riemenzwinge aus Eisen zwischen den Oberschenkelschäften, Lederreste; $3 \times 2 \mathrm{~cm}$ (A, Taf. 14/2, Inv. Nr. A-10746).

Bewertung: A1

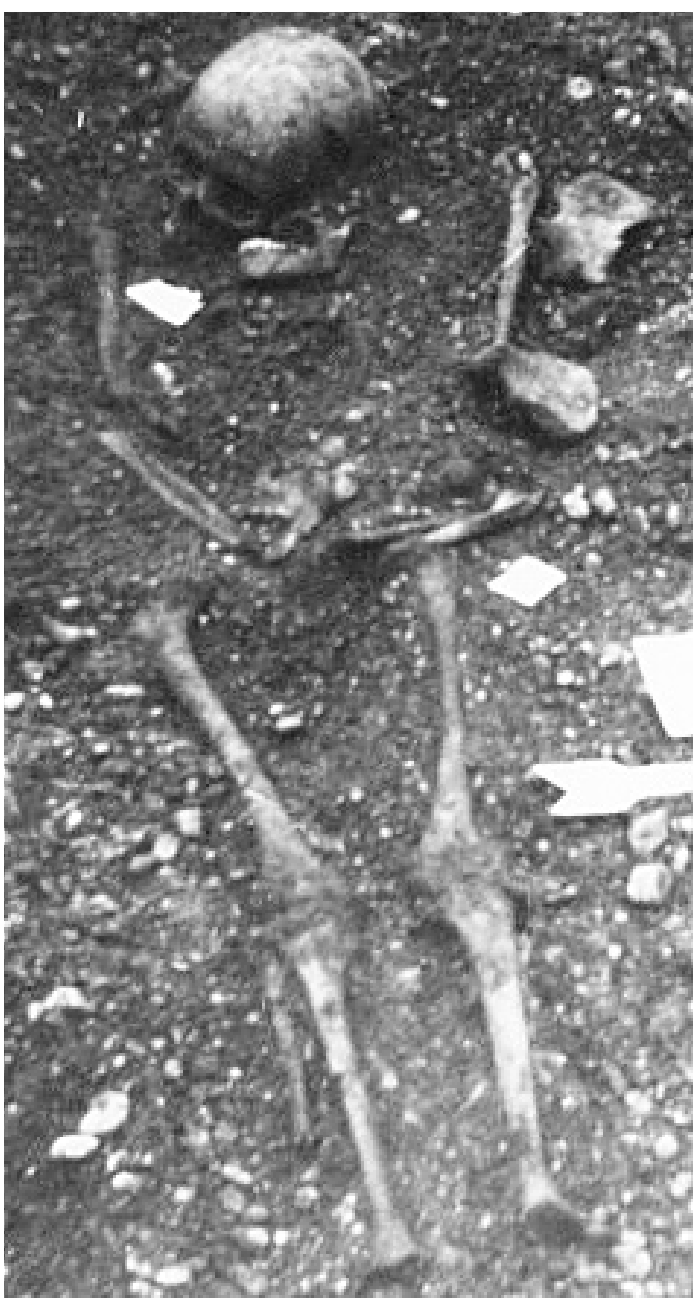

Abb. 17. Rudelsdorf. Grab 82B. Sargreste. Zeichung M. Pertlwieser. 


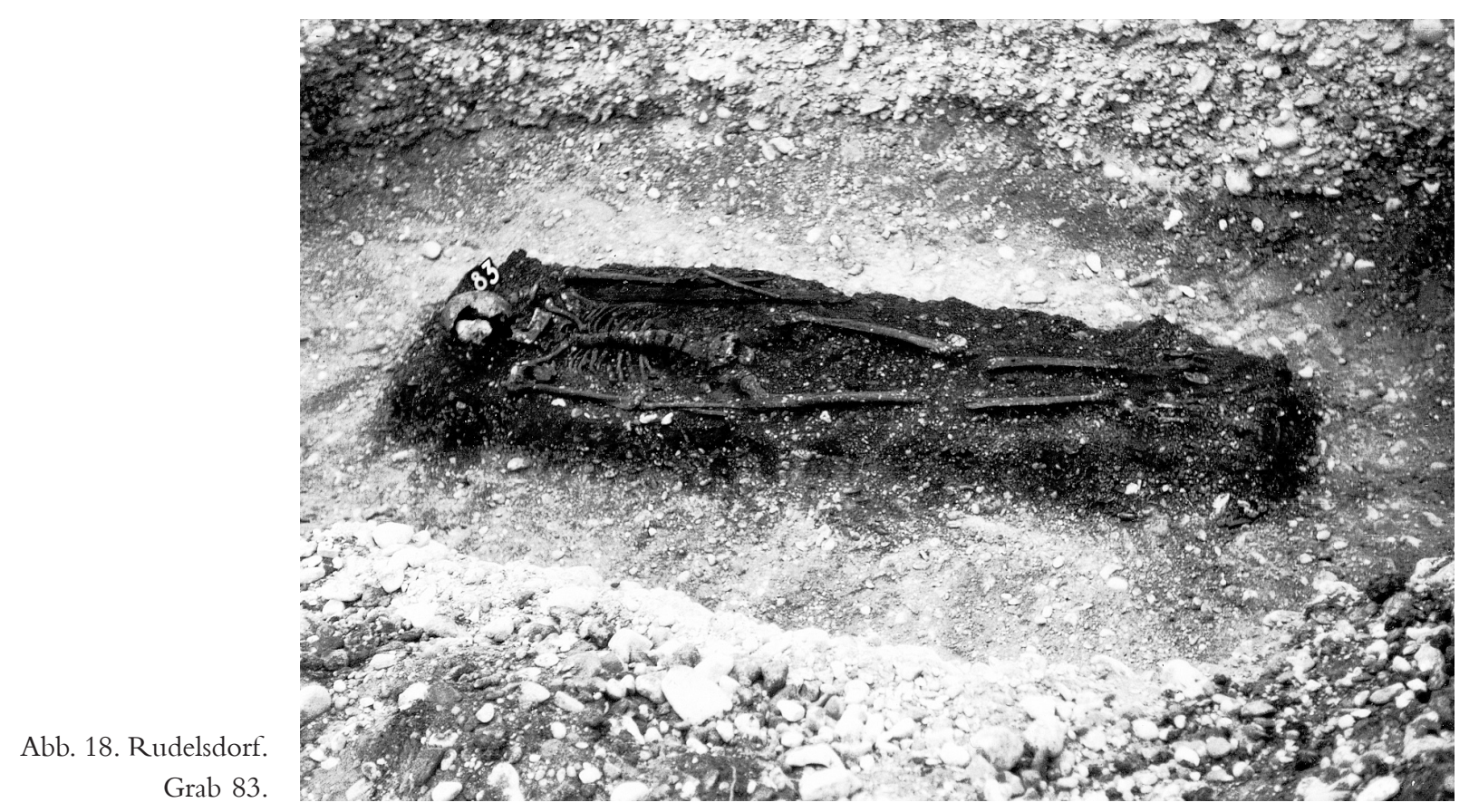

\section{Grab 84}

Mann (23 Jahre);W-O-Orientierung; Rückenstrecklage; alte Störung des Skeletts; isolierter Schädel, Unterkiefer ca. 40 cm entfernt, Oberkörper ca. 60 cm tiefer; Grabtiefe ca. 120 $\mathrm{cm}$; Sargverfärbungen.

Beigaben:

a) Flügelpfeilspitzenfragment; erh. L 6,5 cm (A, Taf. 14/3, Inv. Nr. A-10747a).

b) Flügelpfeilspitzenfragment; erh. L 3,2 cm (A, Taf. 14/4, Inv. Nr. A-10747b).

c) Beschlagfragment aus Eisenblech (B, Taf. 14/5, Inv. Nr. A-10748).

d) Eisenschnalle in der Beckengegend, oval, Dornrest; 2,5 $\times$ $1,7 \mathrm{~cm}$ (B, Taf. 14/6, Inv. Nr. A-10749).

Bewertung: B1

Sowohl Originalprotokoll als auch Fundkartei nennen zwei Pfeilspitzen. Beschlag und Schnalle nur in der Fundkartei, „,messerartiger Gegenstand“ nur im Originalprotokoll enthalten.

\section{Grab 85}

Kind (7 Jahre); Rückenstrecklage; Schädel nach links gerutscht und völlig eingedrückt, Beine nach außen gekippt; Skelettlänge $120 \mathrm{~cm}$; rötlich-braungraue Sargverfärbung. Beigaben:

a) Beinkammfragment rechts oberhalb des Kopfes, dreilagig und zweireihig, Zickzackmuster; erh. L 10,2 cm (A, Taf. 14/7, Inv. Nr. A-10750).

b) Bronzeringfragment am linken Hüftbein, Gewebereste (A, Taf. 14/8, Inv. Nr. A-10751).

Bewertung: A2

\section{Grab 86}

Mann (23 Jahre); W-O-Orientierung; Rückenstrecklage; Skelettlänge 166 cm; Grabtiefe 100 cm; Sargreste.

Beigaben:

a) Rechteckschnallenfragment zwischen Kreuzbein und rechtem Hüftbein, Eisen (A, Taf. 14/9, Inv. Nr. A10752).

b) Rechteckschnallenfragment; möglicherweise zu A-10752 gehörig (A, Taf. 14/10, Inv. Nr. A-10753).

c) 2 Blechbeschlagfragmente aus Eisen mit Niete, zu A10752 gehörig (A, Taf. 14/11,12, Inv. Nr. A-10754).

Bewertung: A1

\section{Grab 87}

Kind (4 Jahre); W-O-Orientierung; Grab gestört.

Beigaben:

a) Beinkammfragment neben dem Schädel, dreilagig und zweireihig, Dreiecke und senkrechte Linienverzierung; erh. L 6 cm (A, Taf. 15/1, Inv. Nr. A-10755).

b) Kleiner Blechbeschlag aus Eisen, 4 Eisenniete; 1,5 × 1,3 cm (B, Taf. 15/2, Inv. Nr. A-10756).

c) Hakenöse aus Eisen, Holzreste (B, Taf. 15/3, Inv. Nr. A10757).

Bewertung: B1

Sowohl Originalprotokoll als auch Fundkartei bestätigen den Beinkamm. Den kleinen Blechbeschlag und die eiserne Hakenöse kennt nur die Fundkartei.

Grab 88 (Abb. 19)

Mann (45 Jahre); W-O-Orientierung; Rückenstrecklage; linkes Bein verdreht, linker Fuß nach rechts außen gekippt; Skelettlänge $177 \mathrm{~cm}$; Grabtiefe $125 \mathrm{~cm}$; deutliche, verschiedenfarbige Sargverfärbungen $(215 \times 48 \mathrm{~cm})$. 


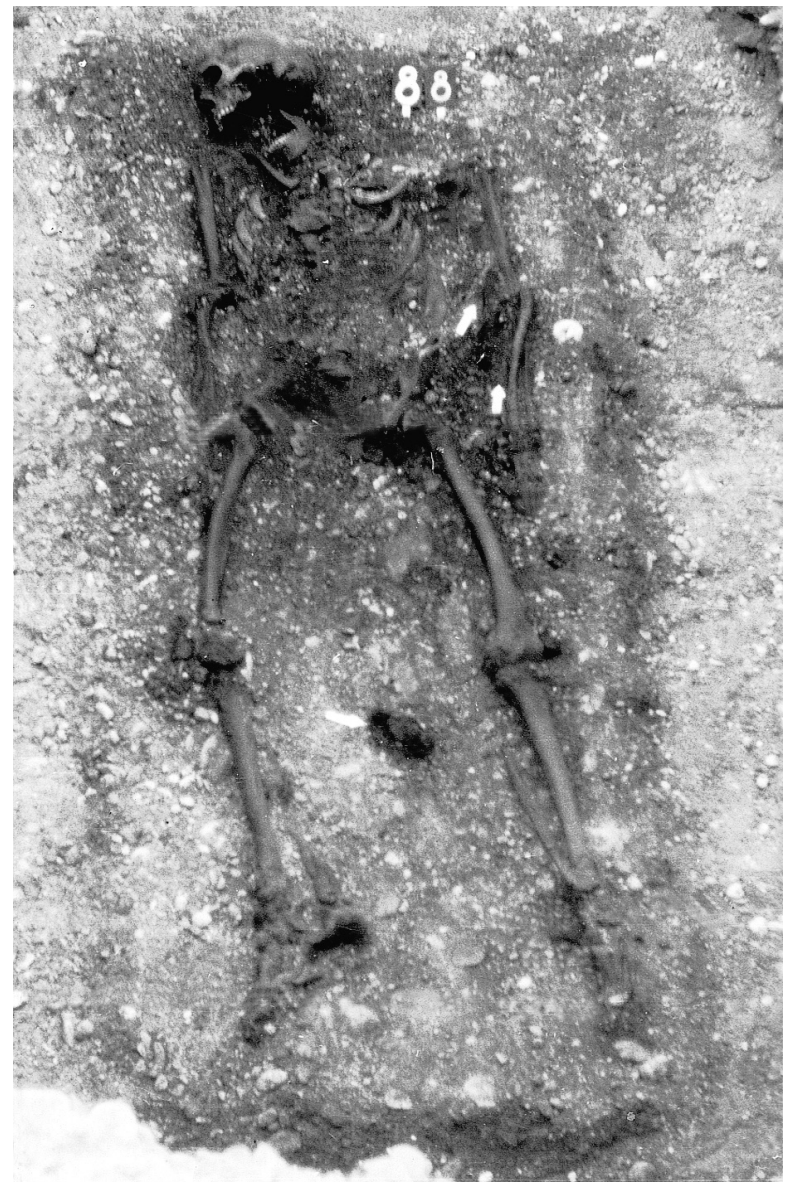

Abb. 19. Rudelsdorf. Grab 88.
Beigaben:

a) Griffangelmesser beim linken Ellbogen, lange Klinge, Rücken gerade; L 17,5 cm, KlingenB $2 \mathrm{~cm}$ (A, Taf. 15/4, Inv. Nr. A-10758).

b) Rasiermesser mit Rollöse zwischen den Knien; L $12 \mathrm{~cm}$, B 2,4 cm (A, Taf. 15/5, Inv. Nr. A-10759).

c) Rasiermesserfragment; erh. L 8,5 cm (B, Taf. 15/6, Inv. Nr. A-10760).

d) Beinkammfragment, dreilagig und zweireihig, waag- und senkrechte Linienverzierung; erh. L $8 \mathrm{~cm}$ (A, Taf. 15/7, Inv. Nr. A-10761).

Bewertung: B1

Sowohl das Originalprotokoll als auch die Fundkartei kennen das Messer, den Beinkamm und das Rasiermesser. Das Rasiermesserfragment ist nur in der Fundkartei genannt.

Grab 89

Kleinstkind; W-O-Orientierung; geringe Skelettreste; Grabtiefe $55 \mathrm{~cm}$; deutliche Sargverfärbungen; keine Beigaben.

Bewertung: A1

\section{Grab 90}

Frau (17-25 Jahre); W-O-Orientierung; Rückenstrecklage; Skelettlänge $168 \mathrm{~cm}$; Grabtiefe $120 \mathrm{~cm}$; deutliche Sargverfärbungen.

Beigaben:

a) Topf neben dem rechten Fuß mit der Öffnung kopfwärts, handgeformt, grobe Glimmermagerung, leicht ausladender Rand, im Schulterbereich Wellenlinienverzierung; Höhe $13 \mathrm{~cm}$, RandDm 8,5 cm, SchulterDm 9,5 cm, BodenDm $7 \mathrm{~cm}$ (A, Taf. 16/1, Inv. Nr. A-10762).

b) Eisenschnalle unter dem linken Sitzbein, D-förmig, Dorn fragmentiert $(3 \times 2,5 \mathrm{~cm})$; ein kleiner, zerbrochener Blechbeschlag (A, Taf. 16/2, Inv. Nr. A-10763).

Bewertung: A1

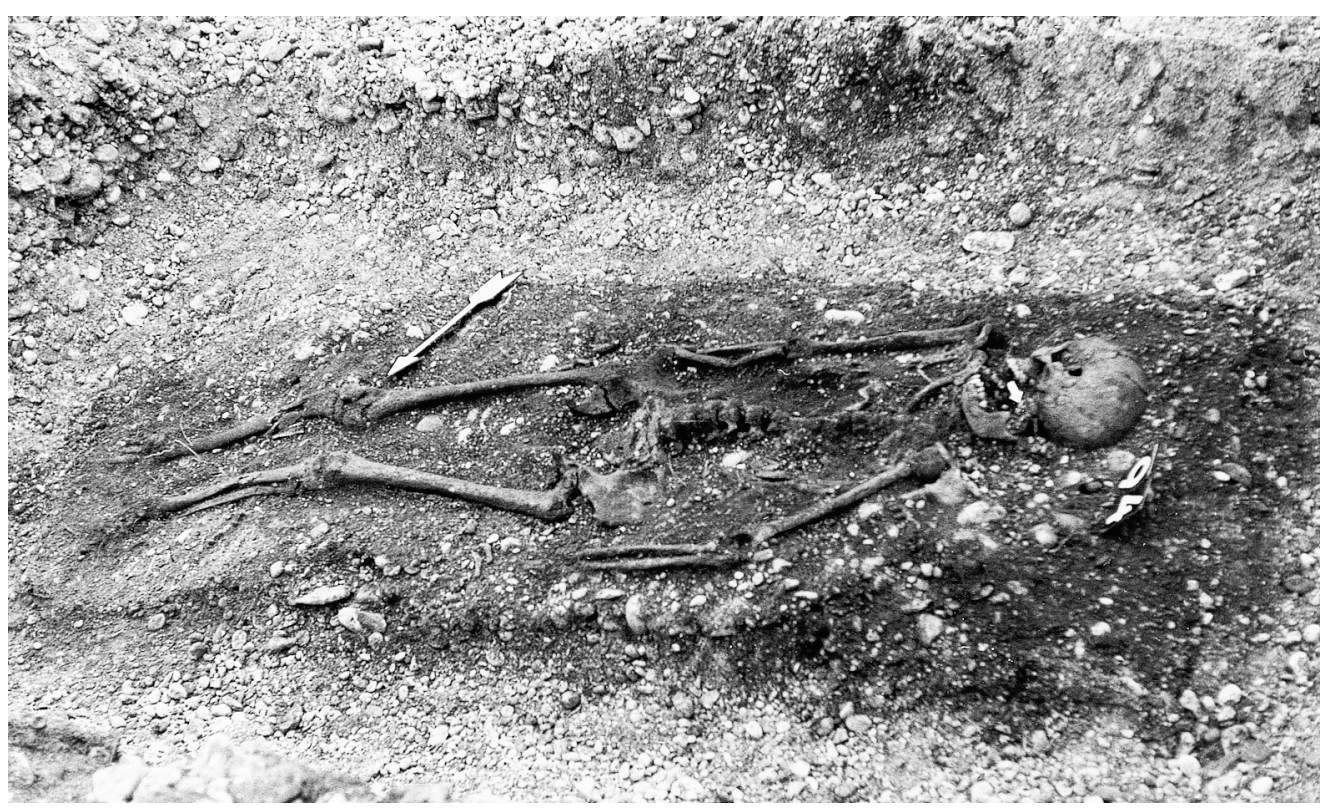

Abb. 20. Rudelsdorf. Grab 94 
Grab 91

Kleinstkind; Skelettlänge $65 \mathrm{~cm}$; Grabtiefe $20 \mathrm{~cm}$; keine Beigaben.

Bewertung: A1

\section{Grab 92}

Mann (56 Jahre); W-O-Orientierung; Rückenstrecklage; Schädel nach links gekippt; Skelettlänge $162 \mathrm{~cm}$; Grabtiefe $105 \mathrm{~cm}$; deutliche Sargverfärbung (L $198 \mathrm{~cm}$ ).

Beigaben:

a) Griffangelmesser parallel zum rechten Oberarm, Spitze kopfwärts; erh. L $10 \mathrm{~cm}$ (A, Taf. 16/3, Inv. Nr. A10764).

b) Eisenring, rundstabig; Dm $4 \mathrm{~cm}$ (A, Taf. 16/4, Inv. Nr. A-10765).

c) Eisenzwinge mit Schnallenrest, 2 Eisennieten; zwischen den Oberschenkeln; L 3 cm (A, Taf. 16/5, Inv. Nr. A10766).

Bewertung: A1

\section{Grab 93}

Mann? (52-61 Jahre); W-O-Orientierung; leichte Hockerstellung nach links; Skelettlänge $150 \mathrm{~cm}$; Grabtiefe $60 \mathrm{~cm}$; keine Beigaben.

Bewertung: A1

\section{Grab 94 (Abb. 20)}

Frau (17-25 Jahre); W-O-Orieniterung; Rückenstrecklage; Skelettlänge $155 \mathrm{~cm}$; Grabtiefe $60 \mathrm{~cm}$.

Beigaben:

a) 2 Knötchenohrringe aus Silber, je 2 dünne Drahtringe auf den Ohrringen, ein Ohrring offen, Anhänger zylindrisch und geriffelt (B, Taf. 16/6,7, Inv. Nr. A-10767).

b) Halskette aus 7 Glaspasteperlen; 1 gedrückt kugelig, schwefelgelb, opak; 1 doppelkonisch, schmutzigweiß, opak; 1 doppelkonisch, ockerbraun, opak; 1 doppelkonisch, karminbraun, opak; 1 zylindrisch, orange, opak; 1 oval, grünblau, transluzid; 1 Drehperle, blauschwarz, mit türkisblauer Spiralfadenauflage, opak (A, Taf. 16/8, Inv. Nr. A-10768).

Bewertung: B1

Die Ohrringe existieren nur in der Fundkartei.

\section{Grab 95 (Abb. 21)}

Frau (33 Jahre);W-O-Orientierung; Rückenstrecklage; Skelettlänge $155 \mathrm{~cm}$; Grabtiefe $65 \mathrm{~cm}$; vor allem auf der rechten Längsseite deutliche Sargverfärbungen.

Beigaben:

a) Halskette aus 53 Glas- und Silberblechperlen; 1 kugelig, schwefelgelb, opak; 13 kugelig, orange, opak; 9 kugelig, braunocker, opak; 1 gedrückt kugelig, weiß, opak; 5 gedrückt kugelig, orange, opak; 5 gedrückt kugelig, braunocker, opak; 1 gestreckt doppelkonisch, braunschwarz, opak; 1 zylindrisch, schwarzblau, opak; 1 quaderförmig, braunschwarz, opak; 1 walzenförmig, hellgrünlichblau, opak; 1 gedrückt kugelig, kobalt, transluzid; 1 gedrückt kugelig, dunkelviolettblau, transluzid; 1 ringförmig, dunkelviolettblau, transluzid; 1 doppelkonisch, hellkobalt,

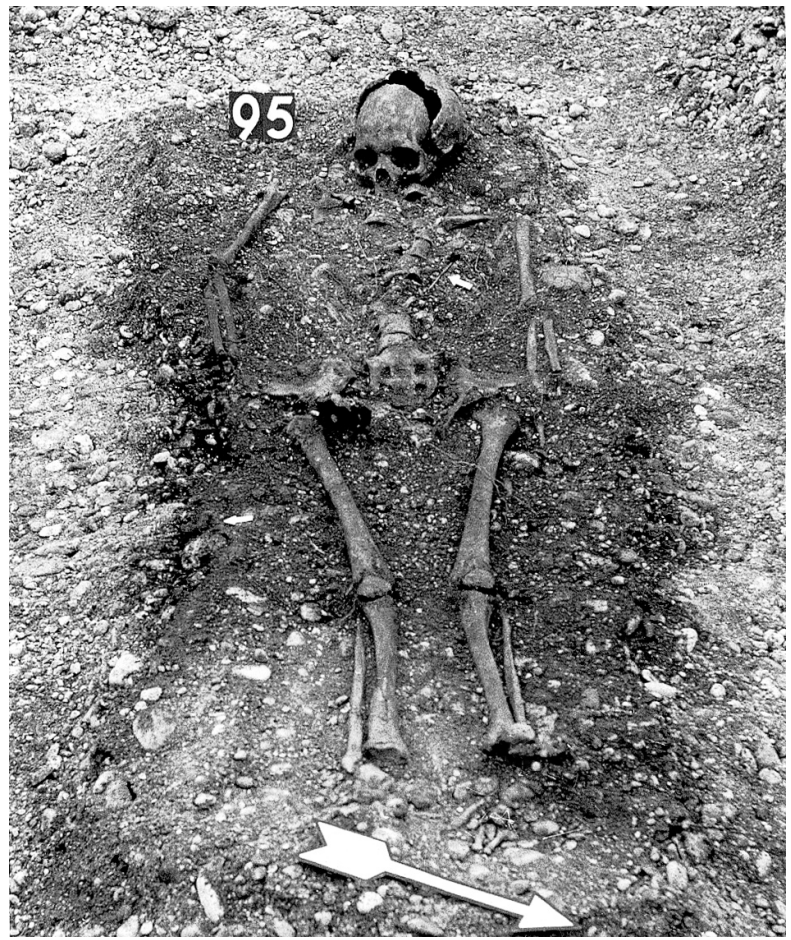

Abb. 21. Rudelsdorf. Grab 95.

transluzid; 1 zylindrisch, dunkelviolettblau, transluzid; 2 quaderförmig. dunkelviolettblau, transluzid; 1 quaderförmig, wasserblau, transluzid; 1 tropfenförmig, violettblau, transluzid; 1 sechsflächig prismenförmig, smaragdgrün, transluzid; 1 Bronzeperle, doppelkonisch; 4 Silberblechperlen (A, Taf. 16/9, Inv. Nr. A-10769).

b) Beinkammfragment neben dem rechten Oberschenkel, dreilagig und einreihig, feine und gröbere Zähnung, schraffierte Dreiecke und waag- und senkrechte Linienverzierung; erh. L $11 \mathrm{~cm}$ (A, Taf. 17/1, Inv. Nr. A10770).

c) Flügelpfeilspitzenfragment an der linken Brustseite, Gewebe- und Schnurreste; erh. L 3,7 cm (A, Taf. 17/2, Inv. Nr. A-10771).

d) Ösennadel aus Bronze auf der linken Brustseite, Schaft gebogen, am Schaftansatz umlaufende Rillenverzierung, Schaftspitze abgebrochen; erh. L 7,5 cm (A, Taf. 17/3, Inv. Nr. A-10772).

Bewertung: A1

\section{Grab 96}

Mann (52 Jahre); W-O-Orientierung; Rückenstrecklage; Skelettlänge $170 \mathrm{~cm}$; Grabtiefe $70 \mathrm{~cm}$; deutliche Sargverfärbung (L $200 \mathrm{~cm}, \mathrm{~B} 50 \mathrm{~cm}$ ).

Beigaben:

Eisenschnalle mit Dorn und Lasche am Oberrand des Kreuzbeines, Gewebereste; $2 \times 2 \mathrm{~cm}$ (A, Taf. 17/4, Inv. Nr. A-10773).

Bewertung: A1 


\section{Grab 97}

Kind (1 Jahr); W-O-Orienitierung; nur geringe Skelettreste erhalten; Grabtiefe $30 \mathrm{~cm}$; keine Beigaben.

Bewertung: A1

\section{Grab 98}

Kind, weiblich (6 Jahre); W-O-Orientierung; Schädel zerdrückt; Skelettlänge $90 \mathrm{~cm}$; Grabtiefe $60 \mathrm{~cm}$; Sargverfärbung.

Beigaben:

Ohrring aus dünnem Silberdraht mit Öse und Haken links neben dem Schädel (A, Taf. 17/5, Inv. Nr. A-10774).

Bewertung: A1

\section{Grab 99}

Kind, weiblich (12 Jahre); W-O-Orientierung; Rückenstrecklage; enge Schulter- und Beinlage (ähnlich Grab 50 und 80); Skelettlänge $135 \mathrm{~cm}$; Grabtiefe 120 cm; Sargverfärbung.

Beigaben:

a) Halskette aus 43 Glasperlen; 8 kugelig, orange, opak; 5 kugelig, braunocker, opak; 3 gedrückt kugelig, braunocker, opak; 2 gedrückt kugelig, orange, opak; 2 zylindrisch, schmutzigweiß, opak; 2 doppelkonisch, dunkelgraublau, opak; 2 quaderförmig, krapprot, opak; 1 gedrückt kugelig, dunkelbraun, opak; 1 gedrückt kugelig, ockerbraun, opak; 1 doppelkonisch, braunocker, opak; 1 kugelig, braunocker, opak; 1 kugelig, schwefelgelb, opak; 1 kugelig, ockerbraun, opak; 1 gedrückt kugelig, blauschwarz, opak; 1 oval, hellbläulichgrün, transluzid; 1 walzenförmig, dunkelviolettblau, transluzid; 1 doppelkonisch, karminbraun, opak; 1 oval, grünblau, transluzid; 1 ringförmig, bläulichgrün, transluzid; 1 würfelförmig krapprot, opak; 1 mandelförmig, hellbläulichgrün, transluzid, mit Bronzeröllchen; 1 Drehperle, grünlichblau, mit mattgrauer Spiralfadenauflage, opak; 1 gedrückt kugelig, blauschwarz, mit horizontal umlaufender Rippung; 1 polyedrische, violettultramarin, opak (A, Taf. 17/6. Inv. Nr. A-10775).

b) 2 Bronzeringe, offen und geriffelt, einer zerbrochen; Dm $2 \mathrm{~cm}$ (B, Taf. 17/7,8, Inv. Nr. A-10776).

c) Beinkammfragment, dreilagig und zweireihig, unverziert, 3 Eisennieten; erh. L $11 \mathrm{~cm}$ (B, Taf. 18/1, Inv. Nr. A10777).

d) Wadenbindengarnitur in Trachtlage (A, Inv. Nr. A10778): 2 Riemenzungen mit kugeligem Abschlussknopf und 2 Nieten, Bronze, L je 6 cm (Taf. 17/11,12); dazu 2 ovale Eisenschnallen, $2,2 \times 1,5 \mathrm{~cm}$, eine davon fragmentiert (Taf. 17/9,10).

Bewertung: B1

Nur die Fundkartei kennt den Beinkamm und die beiden Bronzeringe.

\section{Grab 100}

Mann (23 Jahre); W-O-Orientierung; Rückenstrecklage; Skelettlänge $162 \mathrm{~cm}$; Grabtiefe $80 \mathrm{~cm}$; Sargverfärbung (L $194 \mathrm{~cm}, \mathrm{~B} 70 \mathrm{~cm})$.
Beigaben:

a) Langsax schräg über dem Rumpf, Spitze schädelwärts, Griff auf dem linken Oberschenkel; beidseitig Blutrinne; GesamtL $72 \mathrm{~cm}$, KlingenB $4 \mathrm{~cm}$, GriffL $13 \mathrm{~cm}$ (A, Taf. 18/2, Inv. Nr. A-10779).

b) Schaft einer Bronzenadel am linken Ohr, gebogen, Öse abgebrochen; erh. L $7 \mathrm{~cm}$ (A, Taf. 18/3, Inv. Nr. A10780).

c) Griffangelmesserfragment beim rechten Ellbogen; erh. L $7,5 \mathrm{~cm}$ (A, Taf. 18/4, Inv. Nr. A-10781).

d) 2 Flügelpfeilspitzen neben dem rechten Unterschenkel, Holzschaftreste; erh. L ca. 6,5 cm (A, Taf. 18/5,6, Inv. Nr. A-10782).

e) Bronzeschnalle mit Dorn auf dem Kreuzbein, oval; 1,5 $\times 1 \mathrm{~cm}$ (A, Taf. 18/7, Inv. Nr. A-10783)

Bewertung: A1

\section{Grab 101}

Mann (43 Jahre); WSW-ONO-Orientierung; Skelettlänge $156 \mathrm{~cm}$; Grabtiefe $80 \mathrm{~cm}$; schwarze Sargverfärbungen.

Beigaben:

a) Bronzebeschlag, U-förmig, facettierte Kanten, auf der Rückseite 2 Nietdornen, Tremolier- und Kerbschnittverzierung; 2,5 × 1,5 cm (B, Taf. 19/3, Inv. Nr. A-10784).

b) Griffangelmesser neben dem rechten Oberschenkel, Rücken stark gekrümmt, Holzgriffreste; L 16 cm, KlingenB 2,5 cm (A, Taf. 19/1, Inv. Nr. A-10785a).

c) Griffangelmesserfragment, ähnlich A-10785a (B, Taf. 19/2, Inv. Nr. A-10785b).

\section{Bewertung: B1}

Nur die Fundkartei kennt das zweite Messer und den Bronzebeschlag .

\section{Grab 102}

Skelettreste; WSW-ONO-Orientierung; Rückenstrecklage; Grabtiefe $45 \mathrm{~cm}$; deutliche Sargreste.

Beigaben:

a) Griffangelmesser beim linken Knie, Rücken zur Spitze kantig abfallend; erh. L 13,5 cm (A, Taf. 19/4, Inv. Nr. A-10786).

b) 2 verzierte, kleine Silberbleche (nicht vorhanden).

Bewertung: A2

\section{Grab 103}

WSW-ONO-Orientierung; Rückenstrecklage; nur Skelettreste erhalten; Skelettlänge ca. $155 \mathrm{~cm}$; Grabtiefe $15 \mathrm{~cm}$; deutliche Sargspuren.

Beigaben:

a) Rechteckschnallenfragment mit Dorn am linken Ellbogen, Eisen (A, Taf. 19/5, Inv. Nr. A-10787).

b) Griffangelmesser neben der rechten Hand, Rücken zur Spitze kantig abfallend; L $10 \mathrm{~cm}$ (A, Taf. 19/6, Inv. Nr. A-10788).

c) Tüllenrest einer Pfeilspitze; erh. L $3 \mathrm{~cm}$ (B, Taf. 19/7, Inv. Nr. A-10789).

Bewertung: B1

Nur die Fundkartei kennt den Tüllenrest der Pfeilspitze. Das Grab ist im anthropologischen Gutachten nicht erwähnt. 


\section{Grab 104}

Kind (4 Jahre); WSW-ONO-Orientierung; Rückenstrecklage; Skelettlänge $93 \mathrm{~cm}$; Grabtiefe $50 \mathrm{~cm}$; deutliche Sargverfärbungen.

Beigaben:

Griffangelmesserfragment parallel zum rechten Oberschenkel; erh. L 10 cm (A, Taf. 19/8, Inv. Nr. A-10790).

Bewertung: A1

\section{Grab 105}

Frau (17-25 Jahre); WSW-ONO-Orientierung; Rückenstrecklage; Schädel und Oberkörper zum Teil zerstört; Skelettlänge ca. $155 \mathrm{~cm}$; Grabtiefe $60 \mathrm{~cm}$; schwarze Sargverfärbung (L $210 \mathrm{~cm}$, B $48 \mathrm{~cm}$ ).

Beigaben:

28 Perlen aus Silberblech, halbschalig, die meisten fragmentiert (A, Taf. 20/1, Inv. Nr. A-10791).

Bewertung: A1

\section{Grab 106}

WSW-ONO-Orientierung; Skelett weitgehend zerstört; Grabtiefe $40 \mathrm{~cm}$.

Beigaben:

a) Griffangelfragment eines Messers; erh. L $3 \mathrm{~cm}$ (A, Taf. 20/2, Inv. Nr. A-10792).

b) Tüllenfragment einer Pfeilspitze; erh. L 2,5 cm (A, Taf. 20/3, Inv. Nr. A-10793).

c) Eisenschaftfragment; erh. L 4,8 cm (A, Taf. 20/4, Inv. Nr. A-10794).

d) Gürtelschnallenfragmente aus Eisen (A, Taf. 20/5, Inv. Nr. A-10795).

Bewertung: A1

\section{Grab 107}

Keine Angaben.

Bewertung: C

Im anthropologischen Gutachten nicht erwähnt, im Plan als Erwachsenengrab eingezeichnet.

\section{Grab 108}

Frau (37 Jahre); WSW-ONO-Orientierung; Rückenstrecklage; rechter Ellbogen leicht nach außen gewinkelt, Hände auf den Oberschenkeln; Skelettlänge $162 \mathrm{~cm}$; Grabtiefe 45 cm; deutliche, schwarze Sargverfärbung (L $200 \mathrm{~cm}$, B 70 $\mathrm{cm})$.

Beigaben:

Feuerstahl, nierenförmig, in der rechten Darmbeinschaufel; L 7,6 cm, B $3 \mathrm{~cm}$ (A, Taf. 20/6, Inv. Nr. A-10796).

Bewertung: A1

Grab 109

Kind (2,5 Jahre); WSW-ONO-Orientierung; Skelett schlecht erhalten; Grabtiefe $60 \mathrm{~cm}$; keine Beigaben.

Bewertung: A2

\section{Grab 110}

Kind (5 Jahre); WSW-ONO-Orientierung; Rückenstrecklage; Skelettlänge $94 \mathrm{~cm}$; Grabtiefe $60 \mathrm{~cm}$; deutliche Sargverfärbung (L $130 \mathrm{~cm}, \mathrm{~B} 48 \mathrm{~cm}$ ); keine Beigaben.

Bewertung: A1
Grab 111

Frau (53-62 Jahre); WSW-ONO-Orientierung; Rückenstrecklage; Skelettlänge $165 \mathrm{~cm}$; Grabtiefe $50 \mathrm{~cm}$; deutliche, schwarze Sargverfärbung (L 190 cm, B 50 cm); keine Beigaben.

Bewertung: A1

\section{Grab 112}

Keine Angaben.

Bewertung: C

\section{Grab 113}

Frau (23 Jahre); SW-NO-Orientierung; Rückenstrecklage; Schädel etwas nach rechts gekippt, Finger auf den Oberschenkeln; Skelettlänge $153 \mathrm{~cm}$; Grabtiefe $105 \mathrm{~cm}$; deutliche Sargverfärbung (L $190 \mathrm{~cm}$, B $60 \mathrm{~cm}$ ); keine Beigaben. Bewertung: A1

Grab 114

Frau (35 Jahre); SW-NO-Orientierung; enge Rückenstrecklage; Skelettlänge $152 \mathrm{~cm}$; Sargverfärbungen.

Beigaben:

Rechteckschnalle mit Riemenzwinge in der Taillengegend, Eisen, 3 Rosettennieten, Gewebe- und Lederreste (A, Taf. 20/7, Inv. Nr. A-10797).

Bewertung: A1

\section{Grab 115 (Abb. 22)}

Kind, männlich (4 Jahre); Rückenstrecklage; Skelett gut erhalten; Skelettlänge $95 \mathrm{~cm}$; Grabtiefe $140 \mathrm{~cm}$; schwarze Sargverfärbung.

Beigaben:

a) Griffangelmesser in der linken Hüftgelenksgegend, Rücken gerade; L 15 cm (A, Taf. 20/8, Inv. Nr. A-10798).

b) Flügelpfeilspitze neben dem rechten Oberschenkel, Gewebe- und Schnurreste an der Tülle; erh. L 6,5 cm (A, Taf. 20/9, Inv. Nr. A-10799).

c) Klingenfragment eines weiteren Messers unter dem Schädel; erh. L 9,4 cm (A, Taf. 20/10, Inv. Nr. A10800).

d) Beinkamm unter dem Schädel, dreilagig und zweireihig, feine und grobe Zähnung, Kreis- und senkrechte Linienverzierung, umgeben von Zickzackmuster, 2 Eisennieten; erh. L 5 cm (A, Taf. 20/11, Inv. Nr. A-10801).

e) Bronzenadel, geschweift, verziert und gelocht (nicht vorhanden).

Bewertung: A2

\section{Grab 116}

Kleinstkind (0,5 Jahre); SW-NO-Orientierung; nur Zähne erhalten; Grabtiefe 120 cm; Sargverfärbung (L ca. 50 cm).

Beigaben:

Drehperle mit weißer Fadenauflage (B, Taf. 21/1, Inv. Nr. A-10802).

\section{Bewertung: B1}

Photo eines Griffangelmessers mit der Aufschrift „Rudo 116". Messer weder im Originalprotokoll noch in der Fundkartei erwähnt. Die Drehperle kennt nur die Fundkartei. 


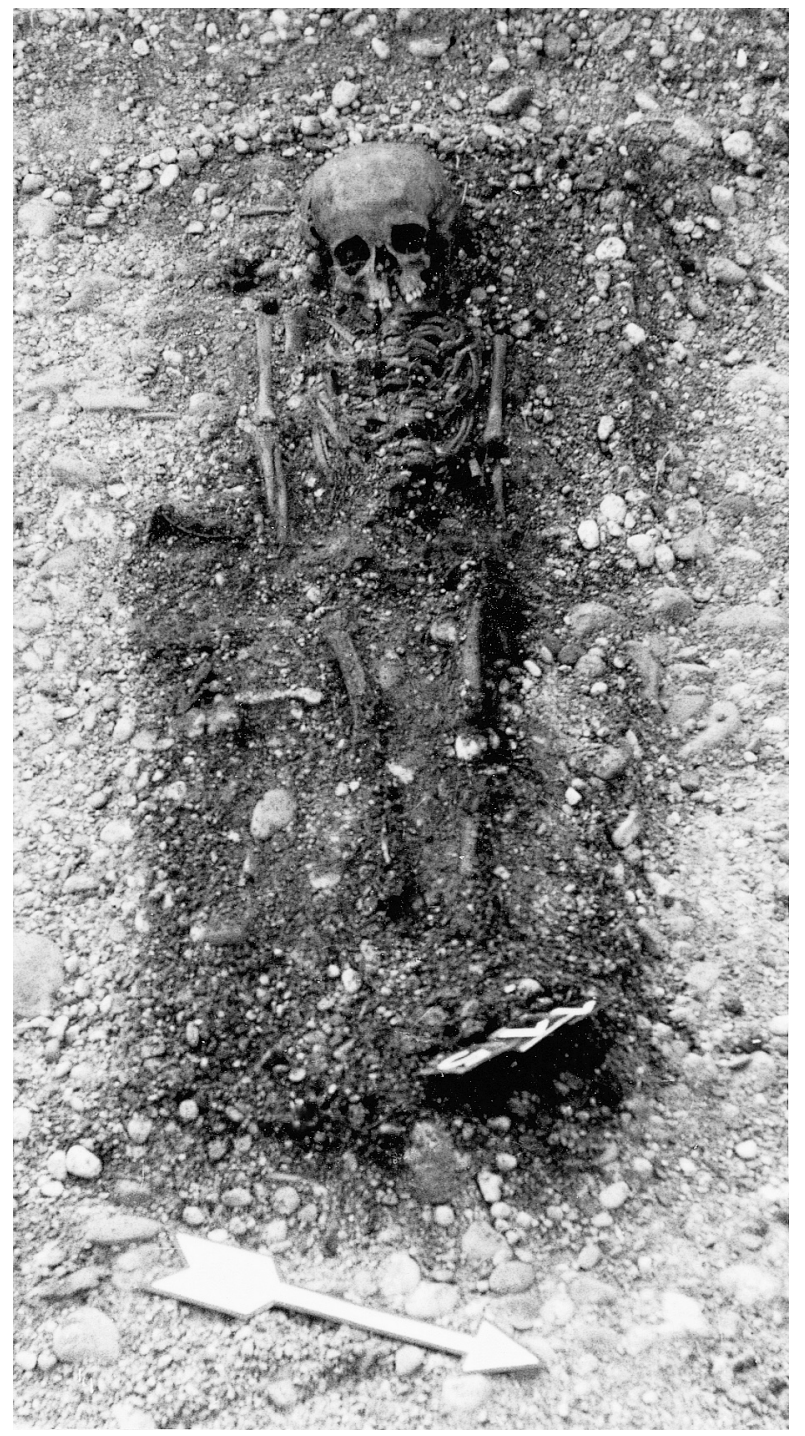

Abb. 22. Rudelsdorf. Grab 115.

\section{Grab 117}

Kind (1,5 Jahre); SW-NO-Orientierung; nur Schädelbruchstücke erhalten; Skelettlänge ca. $75 \mathrm{~cm}$; Sargverfärbung. Beigaben:

a) Griffangelmesser quer auf dem linken Unterarm, gerader Rücken; L 14,5 cm (A, Taf. 21/2, Inv. Nr. A-10803).

b) Flügelpfeilspitze am unteren rechten Schienbein; L 6,6 cm (A, Taf. 21/3, Inv. Nr. A-10804).

\section{Bewertung: A1}

Grab 118

Kind, weiblich (8 Jahre); Rückenstrecklage; Skelett gut erhalten; Skelettlänge $109 \mathrm{~cm}$; Grabtiefe $190 \mathrm{~cm}$; deutliche Sargverfärbung (L $135 \mathrm{~cm}$, B $45 \mathrm{~cm}$ ).

Beigaben:

a) Beinkamm neben dem linken Knie, dreilagig und zweireihig, grobe und feine Zähnung, schraffierte Dreiecke und waag- und senkrechte Linienverzierung, 7 Eisennieten; erh. L ca. 12,5 cm (A, Taf. 21/4, Inv. Nr. A10805).

b) 3 kugelige, opake Glasperlen; 1 orange, 2 braunocker (A, Taf. 21/5, Inv. Nr. A-10806).

c) Bronzenadelfragment in der linken Achselgegend; erh. L 3,8 cm (A, Taf. 21/6, Inv. Nr. A-10807).

Bewertung: A2

Grab 119 (Abb. 23)

Frau (19-28 Jahre); Rückenstrecklage; Skelettlänge $158 \mathrm{~cm}$; Grabtiefe ca. 160 cm; Sargverfärbung (L 190 cm, B 60cm). Beigaben:

a) Halskette aus Glas- und Silberperlen sowie 1 großen Amethystperle, zum Teil am Originalfaden; 1 kugelig, braunocker, opak; 1 doppelkonisch, krapprot, opak; 1 zylindrisch, indigo, opak; 1 doppelkonisch, blau, opak; 2 blauschwarz, opak, davon 1walzenförmig und eine oval; 6 gedrückt kugelig, dunkelviolettblau, transluzid; 1 dop-

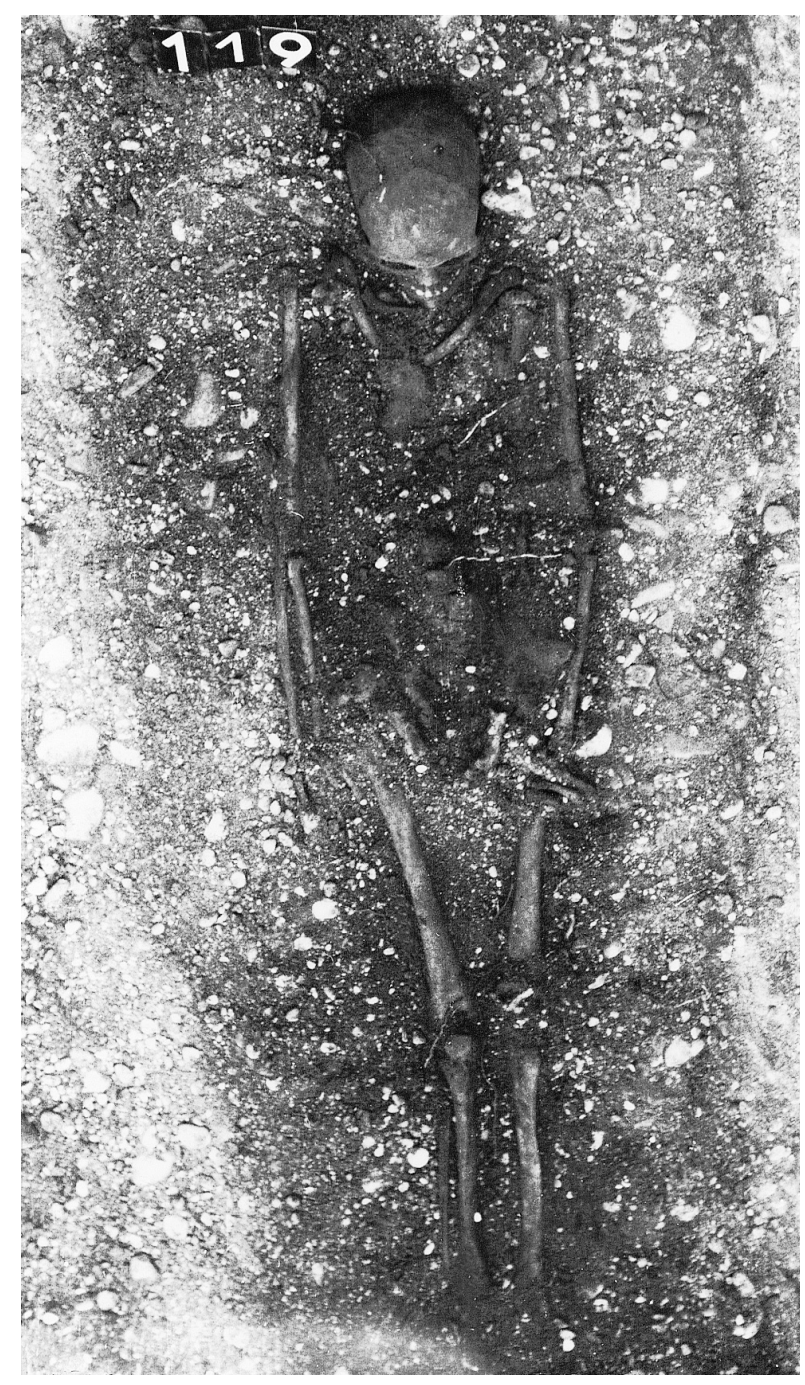

Abb. 23. Rudelsdorf. Grab 119. 
pelkonisch, violettblau, transluzid; 1 zylindrisch, grünblau, transluzid; 1 mandelförmig hellbläulichgrün, transluzid; 1 blassvioletter Amethyst; 5 zweischalige Silberblechperlen (A, Taf. 21/7. Inv. Nr. A-10808).

b) Gürtelgehänge aus Eisen, Befestigung durch 2 Kettchen, daran Perlen, Klingelstäbchen und ein Klappmesser; L ca. $100 \mathrm{~cm}$ (A, Taf. 22/1, Inv. Nr. A-10809).

c) Bommelohrgehänge (Paar) aus dünnem Goldblech in Trachtlage, offener Tragring mit dreiteiligem Bommelgehänge, Bommeln mit Zierbuckeln und Filigranverzierung (A, Taf. 22(2,3, Inv. Nr. A-10810).

d) Wadenbindenzunge mit spitzem Ende, Bronze, zu A10809 gehörig (A, Taf. 22/4).

e) Rasiermesser aus Eisen; L 15 cm (mit Rollöse); zu A10809 gehörig (A, Taf. 22/5).

Bewertung: A1

Grab 120

Frau; W-O-Orientierung; Grabtiefe ca. 80 cm; Sargreste. Beigaben:

a) Beinkamm, dreilagig und einreihig, dreieckige Griffplatte, grobe Zähnung, Winkel-, Kreis- und Linienmuster, 5 Eisennieten; L 15 cm, B 3,5 cm (B, Taf. 23/1, Inv. Nr. A-10811).

b) Halskette aus 39 Glasperlen; 26 kugelig bis gedrückt kugelig, orange bis braunocker, opak; 1 doppelkonisch, weiß, opak; 1 kugelig, hellgrünlichblau, transluzid; 1 konisch, hellgrünlichblau, transluzid; 2 doppelkonisch, grünlichblau, transluzid; 4 dreiflächig längliche, grünlichblau, transluzid; 1 kugelig, lilaschwarz mit dunkellilagrauer Spiralfadenauflage, opak; 1 dreiflächig längliche, braunschwarz mit schwefelgelber Spiralfadenauflage, opak (B, Taf. 23/2, Inv. Nr. A-10812).

c) Griffangelmesser; L 12,5 cm (B, Taf. 23/3, Inv. Nr. A10813).

d) Eisenschnalle, länglich oval, Dorn fehlt; 3,5 × 2,8 cm $(\mathbf{B}$, Taf. 23/4, Inv. Nr. A-10814).

\section{Bewertung: B1}

Laut Originalprotokoll „keine Beigaben“. Die oben erwähnten Gegenstände kennt nur die Fundkartei.

\section{Grabung 1959}

\section{Grab 121}

Frau (?); SW-NO-Orientierung; Grab durch Bagger zerstört; Grabtiefe ca. 105 cm; tiefschwarze Verfärbungen eines Holzsarges.

Beigaben:

a) Griffangelmesser (nicht vorhanden)

b) Eisenschnalle (nicht vorhanden)

c) einreihiger, verzierter Dreilagenkamm aus Bein (nicht vorhanden).

Bewertung: B1
Grab 122

Frau (14-20 Jahre); SW-NO-Orientierung; Grab durch Bagger zerstört; Grabtiefe $105 \mathrm{~cm}$.

Beigaben:

a) Bronzenadel, rundstabig, 5 umlaufende Rillen am abgerundeten Kopfende; L 12,3 cm (A, Taf. 24/1, Inv. Nr. A-10815).

b) Ösennadel aus Eisen, rundstabig, Schaft gebogen; erh. L $8 \mathrm{~cm}$ (B, Taf. 24/2, Inv. Nr. A-10816)

c) Halskette aus 14 durchlochten, römischen Bronzemünzen; 3 Gallienus (253-268), 1 Claudius II (268-270), 1 Probus (276-282), 1 Constantin der Große (306-337), 1 Constans (333-350), 4 Constantin II (337-361), 1 Constantinus Gallus (351-354), 1 Valens (364-378), 1 Follis aus Constantinopel (A, Taf. 24/3, Inv. Nr. A-10817).

d) Griffangelmesser; erh. L $12 \mathrm{~cm}$ (A, Taf. 24/4, Inv. Nr. A10818).

e) Beinkamm, dreilagig und einreihig, grobe Zähnung, unverziert, 3 Eisennieten; erh. L 8 cm (A, Taf. 24/5, Inv. Nr. A-10819).

f) Griffangelmesser (nicht vorhanden).

Bewertung: B1

Nur das Originalprotokoll kennt das zweite Messer, nur die Fundkartei die eiserne Ösennadel.

\section{Grab 123}

Mann (37 Jahre); Grab durch Bagger zerstört; Grabtiefe ca. $125 \mathrm{~cm}$.

Beigaben:

a) Breitsax, Griffangel kaum abgesetzt, beidseitig 2 Blutrinnen; Spitze abgebrochen; erh. L $58 \mathrm{~cm}$, Klingen B 5,5 cm (A, Taf. 24/6, Inv. Nr. A-10820).

b) Griffangelmesser (nicht vorhanden).

c) 2 Flügelpfeilspitzen (nicht vorhanden).

d) Eisenschaft, tordiert (nicht vorhanden, Inv. Nr. A10821).

e) Eisenhaken (nicht vorhanden).

Bewertung: B1

Die beiden nicht vorhandenen Pfeilspitzen und den Eisenschaft nennt nur die Fundkartei.

\section{Grab 124}

Mann (27 Jahre); WSW-ONO-Orientierung; Skelett stark beschädigt; deutliche Sargverfärbung (L 226 cm, max. B 85 $\mathrm{cm})$.

Beigaben:

a) 4 Flügelpfeilspitzen mit tordierten Schäften und geschlitzten Tüllen; L 9,5, 9, 8 und $8 \mathrm{~cm}$ (A, Taf. 25/1-4, Inv. Nr. A-10822).

b) Pfeilspitze, dreiflügelig mit Schaftdorn, awarisch; L 8,8 cm (A, Taf. 25/5, Inv. Nr. A-10823).

c) 4 Bronzeziernieten eines Saxscheidenbeschlages, rund und flach mit je 3 Nietlöchern; Dm. 1,3 cm (A, Taf. 25/6-9, Inv. Nr. A-10824).

d) Bronzeschnalle, gegossen mit festem Beschlag, Bügel oval mit Dornaufsatz, Durchbruchornamentik; 4,7 × 3,3 cm (A, Taf. 25/10, Inv. Nr. A-10825).

e) Griffangelmesser, gerader Rücken; L $15,5 \mathrm{~cm}$ (B, Taf. 25/11, Inv. Nr. A-10826). 
f) Beinkammfragment im Hüftbereich, dreilagig und zweireihig; erh. L 4,1 cm (A, Taf. 25/12, Inv. Nr. A10827).

g) S-förmiger Gürtelhaken zwischen rechtem Hüft- und Kreuzbein; L 3,7 cm (A, Taf. 25/13, Inv. Nr. A-10828). Bewertung: B1

Als sicher zu diesem Grab gehörig können nur der Gürtelhaken und der Beinkamm gelten. Die fünf Pfeilspitzen, vier Knopfnieten und die silberne (tatsächlich bronzene) Gürtelschnalle wurden laut Originalprotokoll ,,von Erdarbeitern geborgen“. Nur in der Fundkartei ist das Messer erwähnt.

\section{Grab 125}

Kind (5 Jahre); SW-NO-Orientierung; Grab gestört; Grabtiefe $125 \mathrm{~cm}$; Sargverfärbung (L $110 \mathrm{~cm}, \mathrm{~B} 40 \mathrm{~cm}$ ).

Beigaben:

Eisenschnalle mit Dorn, oval (nicht vorhanden).

Bewertung: A2

\section{Grab 126}

Kind (1 Jahr); SW-NO-Orientierung; Skelett stark zersetzt; Grabtiefe ca. $95 \mathrm{~cm}$.

Beigaben:

Scherenfragment aus Eisen unter dem rechten Schulterbein; L 17 cm (A, Taf. 26/1, Inv. Nr. A-10830).

Bewertung: A1

\section{Grab 127}

Frau (25-35 Jahre); WSW-ONO-Orientierung; Skelett zerstört, nur Beinskelette intakt und in situ; Skelettlänge 156 cm; Grabtiefe 120 cm; Sargverfärbung (L $220 \mathrm{~cm}$, max. B $100 \mathrm{~cm})$.

Beigaben:

Eisenschnalle mit Dorn auf dem rechten Hüftbein, oval; $4 \times 2,5 \mathrm{~cm}$ (A, Taf. 26/2, Inv. Nr. A-10829).

Bewertung: A1

\section{Grab 128}

Mann (23 Jahre); SW-NO-Orientierung; Grab gestört, Beinskelette, linkes Hüftbein und Wirbelsäule in situ; Skelettlänge ca. $155 \mathrm{~cm}$; Grabtiefe $125 \mathrm{~cm}$; deutliche Sargverfärbung.

Beigaben:

a) Griffangelmesser am rechten Oberschenkel, Rücken kantig zur Spitze abfallend; L 15,5 cm, KlingenB 1,9 cm (A, Taf. 26/3, Inv. Nr. A-10831).

b) Beinkammfragment unter dem Schädel, dreilagig und zweireihig, schraffierte Dreiecke und senkrechte Linienund Punktverzierung; erh. L 2,3 cm (A, Taf. 26/4, Inv. Nr. A-10832).

c) Flügelpfeilspitze am linken Oberschenkel, Tülle tordiert und geschlitzt; L 8,2 cm (A, Taf. 26/5, Inv. Nr. A10833).

Bewertung: A1

Grab 129

Frau (?); SW-NO-Orientierung; Skelett beschädigt; Skelettlänge $168 \mathrm{~cm}$; Grabtiefe $105 \mathrm{~cm}$.
Beigaben:

a) Beinkammfragment, dreilagig und zweireihig, senkrechte Linienverzierung, 4 Eisennieten; erh. L 6,7 cm (B, Taf. 26/6, Inv. Nr. A-10834).

b) Glasröhrenperle, gerillt (nicht vorhanden).

Bewertung: B1

Das Beinkammfragment scheint nur in der Fundkartei auf.

\section{Grab 130}

Kind (3,5 Jahre); SW-NO-Orientierung; Skelett gut erhalten; Skelettlänge $95 \mathrm{~cm}$; Grabtiefe $110 \mathrm{~cm}$; Sargverfärbung. Beigaben:

Beinkamm an der rechten Hüfte, dreilagig und zweireihig, waagrechte Linienverzierung; erh. L 6 cm (A, Taf. 26/7, Inv. Nr. A-10835).

Bewertung: A1

\section{Grab 131}

Frau? (35-45 Jahre); SW-NO-Orientierung; Rückenstrecklage; Skelett beschädigt; Skelettlänge $170 \mathrm{~cm}$; Grabtiefe 120 $\mathrm{cm}$.

Beigaben:

a) Eisenschnalle mit Dorn, oval, in Beckenmitte; $4 \times 2,5$ cm (A, Taf. 27/1, Inv. Nr. A-10836).

b) Glasperle unter dem Schädel, kugelig, rotbraun mit 4 weißen Warzen, umrahmt von schwefelgelben Fäden; Dm 1,2 cm (A, Taf. 27/2, Inv. Nr. A-10837).

Bewertung: A1

\section{Grab 132}

Kind, weiblich (?); SW-NO-Orientierung; nur Schädelfragmente und Zähne erhalten; Skelettlänge ca. $95 \mathrm{~cm}$; Grabtiefe $135 \mathrm{~cm}$; Sargverfärbung (L $125 \mathrm{~cm}$ ).

Beigaben:

a) Gürtelschnalle, oval mit dickem Dorn, Eisen, auf der unteren Brust; 4,3 × 3,3 cm (A, Taf. 27/3, Inv. Nr. A10838).

b) Halskette aus 4 römischen Kupfermünzen (Gallienus (253-268), Constantin der Große (306-337) und Valens (364-378) (A, Taf. 27/5) und einem Saxscheidezierknopf (A, Taf. 27/4, Inv. Nr. A-10839).

c) Eisendrahtfragment eines Kettenverschlusses (A, Taf. 27/ 6, Inv. Nr. A-10840).

d) Halskette aus 8 Perlen (nicht vorhanden).

e) Eisenschnalle an der linken Hüfte (nicht vorhanden).

f) Knopf aus Bronzeblech (nicht vorhanden).

Bewertung: A2

\section{Grab 133}

Frau (25-35 Jahre); SW-NO-Orientierung; Skelettlänge 156 cm; Grabtiefe 160 cm; Hinweise auf zeitgenössischen Grabraub wegen Knochenverlagerungen.

Beigaben:

a) Körbchenohrgehänge (Paar) in Trachtlage, rundstabiger, offener Bronzeohrring mit Ringschleife, Körbchenanhänger aus dünnem Silberblech mit Granulation (A, Taf. 27/7,8, Inv. Nr. A-10841).

b) Halskette aus 59 Glas- und Silberhohlperlen; 1 kugelig, dunkelgrünblau, opak; 1 kugelig, braunschwarz, opak; 3 doppelkonisch, weiß, opak; 1 doppelkonisch, schwefel- 
gelb, opak; 1 doppelkonisch, grünlichblau, opak; 4 doppelkonisch, karminbraun, opak; 5 doppelkonisch, braunschwarz, opak; 2 quaderförmig, schwefelgelb, opak; 1 zylindrisch, weiß, opak; 1 zylindrisch, schwefelgelb, opak; 1 zylindrisch, karminbraun, opak; 1 quaderförmig, karminbraun, opak; 1 quaderförmig, lebhaftultramarin, opak; 1 kugelig, dunkelgrünblau, transluzid; 1 gedrückt kugelig, dunkelgrünblau, transluzid; 1 ringförmig, bläulichgrün, transluzid; 1 ringförmig, violettultramarin, transluzid; 1 konisch, dunkelviolettblau, transluzid; 3 doppelkonisch, dunkelgraublau, transluzid; 2 doppelkonisch, blauschwarz, transluzid; 1 zylindrisch, dunkelgraublau, transluzid; 1 kugelig, schwefelgelb mit dünner, dunkelgrüner, nichtumlaufender Fadenauflage, opak; 2 kugelig, braunschwarz mit 3 schwefelgelben Punkten, opak; 2 kugelig, braunschwarz mit schwefelgelber Auflage, opak; 4 doppelkonisch, karminbraun mit mattgrauer Spiralfadenauflage, opak; 2 quaderförmig, schwefelgelb mit dunkelgrüner Spiralfadenauflage, opak; 1 quaderförmig, karminbraun mit mattgrauer Spiralfadenauflage; 2 quaderförmig, braunschwarz mit mattgrauer Spiralfadenauflage, opak; 1 kugelig, karminbraun mit eingeritzter Wellenbandverzierung, opak; 3 kugelig, braunschwarz, vorgeritzte, schwefelgelbe Wellenbandverzierung, opak; 1 kugelig, braunschwarz mit eingeritzter Verzierung, opak; 1 kugelig, krapprot mit 4 weißen Warzen, schwefelgelbe Fäden, eingeritzte Wellenbandverzierung, opak; 1 kugelig, grünlichblau, 2 dunkelviolettblaue Warzen mit weißer Basis, 1 weiße Warze, 1 schwefelgelber Punkt, opak; 1 doppelkonisch, blauschwarz, transluzid mit dünnen, karminbraunen Fäden; 5 Silberblechhohlkugeln (A, Taf. 27/239, Inv. Nr. A-10842).

c) Römische Kupfermünze, fragmentiert (A, Inv. Nr. A10843) (nicht vorhanden).

Bewertung: A1

\section{Grab 134}

Mann (25-34 Jahre); SW-NO-Orientierung; zeitgenössische Beraubung, nur Beinskelette in situ; Grabtiefe $115 \mathrm{~cm}$.

Beigaben:

Mehrteilige Gürtelgarnitur aus Eisen und Bronze (A, Taf. 28/1-9, Inv. Nr. A-10844): Hauptriemenzunge mit 2 Eisennieten; $10 \times 1,8 \mathrm{~cm}$ (A, Taf. 28/1). - U-förmige Gürtelbeschläge, teilweise mit Befestigungsösen auf der Rückseite (A, Taf. 28/2-7). - Gürtelschlaufe aus Eisen, ursprünglich tauschiert; L 3,9 cm (Taf. 28/8, nicht vorhanden). - S-förmiger Gürtelhaken; L 6,2 cm (A, Taf. 28/9).

Bewertung: A1

\section{Grab 135}

Kind, weiblich (?); SW-NO-Orientierung; Knochenverlagerungen; Skelettlänge $110 \mathrm{~cm}$; Grabtiefe $130 \mathrm{~cm}$; deutliche Sargverfärbung.

Beigaben:

a) Spinnwirtel aus feingeschlämmtem Ton, doppelkonisch, an der rechten Hüfte; Höhe $2 \mathrm{~cm}$, Dm 3,5 cm (A, Taf. 28/10, Inv. Nr. A-10845). b) Halskette aus 7 Glasperlen; 1 kugelig, weiß, opak; 2 kugelig, braunschwarz, opak; 2 gedrückt kugelig, dunkelgraublau, opak; 1 doppelkonisch, schwefelgelb, opak; 1 zylindrisch, dunkelbraun mit 4 schwefelgelben Warzen, opak (A, Taf. 28/11, Inv. Nr. A-10846).

c) Beinkammfragment links neben dem Schädel, dreilagig und zweireihig, grobe und feine Zähnung; erh. L $7 \mathrm{~cm}$ (A, Taf. 28/12, Inv. Nr. A-10847).

Bewertung: A1

Grab 136

Mann (19-28 Jahre); SW-NO-Orientierung; durch zeitgenössische Eingriffe verlagertes Skelett; Skelettlänge $160 \mathrm{~cm}$; Grabtiefe $100 \mathrm{~cm}$.

Beigaben:

a) Mehrteilige Gürtelgarnitur aus Eisen und Bronze in Trachtlage (A, Taf. 29/1-12, Inv. Nr. A-10848):

Schnalle mit festem, rechteckigem Beschlag, flachoval; Reste zweier Schlaufenösen, 3 Bronzenieten; L 5 cm (Taf. 29/1). - Eisenschnalle mit Dorn, ovaler Bügel; 3,4 × 2,5 cm (Taf. 29/2).- Bronzebeschlag; 2,6 × 2 cm (Taf. 29/3). - 7 Beschläge: achter- (Taf. 29/4), pilz- (Taf. 29/12) und U-förmig (Taf. 29/5-9). - Schnallenbügelfragmente (Taf. 29/10,11).

b) Pfeilspitze am rechten Hüftbein mit der Spitze fußwärts, rautenförmig, Tülle geschlitzt; L 9,5 cm, BlattB $2 \mathrm{~cm}$ (A, Taf. 30/1, Inv. Nr. A-10849).

\section{Bewertung: A1}

\section{Gräber 137 und 138}

Keine Angaben.

Bewertung: C

Obwohl wahrscheinlich Leernummern, sind sie im Gräberfeldplan eingezeichnet.

\section{Grabung 1960}

\section{Grab 139}

Mann (40-48 Jahre); W-O-Orientierung; Rückenstrecklage; Skelett gestört; nur Bein-Skelette in situ; Skelettlänge 165 cm; Grabtiefe 95 cm; Sargspuren (L 180 cm, B $60 \mathrm{~cm}$ ). Beigaben:

Mehrteilige Gürtelgarnitur aus Eisen, unverziert, in Trachtlage (A, Taf. 30/2-14, Inv. Nr. A-10850): 5 Spaltriemenzungen mit je einem Befestigungsniet, unter dem Niet waagrechte Verzierungsstreifen; L 5-5,6 cm, B ca. 1,5 cm (Taf. 30/2-6). - 5 Beschläge, U-förmig, 2 davon fragmentiert (Taf. 30/7-11). - 3 Blechbeschlagfragmente (Taf. 30/1214).

\section{Bewertung: A1}

\section{Grab 140}

Mann (62-71 Jahre); W-O-Orientierung; Knochenverlagerungen; Skelettlänge $158 \mathrm{~cm}$; Grabtiefe $155 \mathrm{~cm}$; Sargverfärbung (L $170 \mathrm{~cm}$, B $60 \mathrm{~cm}$ ).

Beigaben:

a) 2 Eisenschnallen mit Dorn, oval, eine davon fragmentiert (B, Taf. 31/1,2, Inv. Nr. A-10851a,b) 
b) Gürtelgarnitur aus Eisen (B, Taf. 31/3-7, Inv. Nr. A10851): Beschlag, quadratisch, 4 Buckelnieten; $3,5 \times 3,1$ cm (Taf. 31/3). - 4 Dreieckbeschläge mit je einer rechteckigen Riemenschlaufe und 3 Buckelnieten, einer davon fragmentiert (Taf. 31/4-7).

c) Beinkamm (nicht vorhanden).

Bewertung: B1

Der nicht vorhandene Kamm wird nur im Originalprotokoll, die restlichen Funde nur in der Fundkartei erwähnt.

\section{Grab 141}

Frau (34-43 Jahre); W-O-Orientierung; Schädel sowie beide Arme und Rippen verlagert; Skelettlänge 155 cm; Grabtiefe $80 \mathrm{~cm}$.

Beigaben:

a) Rechteckschnallenfragment mit Dornrest beim rechten Darmbein, Eisen; 2,9 × 2,1 cm (A, Taf. 31/8, Inv. Nr. A-10852).

b) 5 Glasperlen, kugelig bis gedrückt kugelig, 1 olivgelb, 4 schwefelgelb, opak (A, Taf. 31/9, Inv. Nr. A-10853).

Bewertung: A1

\section{Grab 142}

Mann (23 Jahre); W-O-Orientierung; Skelett gestört; Arme, Rippen, Wirbelsäule, rechtes Hüftbein sowie Unterschenkel und Füße in situ; Grabtiefe $110 \mathrm{~cm}$; deutliche Sargverfärbung (L $195 \mathrm{~cm}, \mathrm{~B} 75 \mathrm{~cm}$ ).

Beigaben:

Rest einer Gürtelgarnitur aus Eisen (B, Taf. 31/10-12, Inv. Nr. A-10854): Spaltriemenzunge, 1 Niet, darunter 2 waagrechte Verzierungslinien; L 5,2 cm (Taf. 31/10). - Beschlag, U-förmig, Befestigungsöse auf der Rückseite; $2,5 \times 1,7 \mathrm{~cm}$ (Taf. 31/11). - Riemenschlaufe; L 3,2 cm (Taf. 31/12).

Bewertung: B1

Die Funde scheinen nur in der Fundkartei auf, während das Originalprotokoll von einem Kamm und einer eisernen Schnalle spricht.

\section{Grab 143}

Erwachsener;W-O-Orientierung; nur Beinskelette erhalten; Grabtiefe 160 cm; großflächige Sargverfärbungen.

\section{Beigaben:}

a) Glasbecher, flaschengrün und matt durchsichtig, regelmäBige, eingeschlossene Glasblasen, Rand etwas verdickt und trichterförmig; Höhe 7,5 cm, RandDm 6,5 cm, BauchDm 7,8 cm (B, Taf. 32/1, Inv. Nr. A-10855).

b) Griffangelmesser; L $13 \mathrm{~cm}$ (B, Taf. 31/13, Inv. Nr. A10856).

c) Eisenschnallenfragment mit Dorn, oval; $3 \times 2,5 \mathrm{~cm}(\mathbf{B}$, Taf. 31/14, Inv. Nr. A-10857).

Bewertung: B1

Das Originalprotokoll erwähnt keine Beigaben, da das Glasgefäß, das auch in der Fundkartei aufscheint, erst nach der Grabung dazugeschrieben wurde. Das Messer und das Schnallenfragment existieren nur in der Fundkartei.

Das Grab wird im anthropologischen Gutachten nicht berücksichtigt.

\section{Grab 144}

Leernummer.

\section{Grab 145}

Mann (17-25 Jahre); Grab zerstört.

Beigaben:

a) Breitsax, beidseitige Blutrinne; GesamtL $64 \mathrm{~cm}$, KlingenB 4,5 cm, Griffl $20 \mathrm{~cm}$ (B, Taf. 32/2, Inv. Nr. A10858).

b) Knopfschildbuckel aus Eisen, konisch mit abgesetzter Schulter; Höhe 9,5 cm, InnenDm 11,5 cm (B, Taf. 33/1, Inv. Nr. A-10859).

c) Lanzenspitze mit scharfer Mittelrippe, Tülle geschlitzt, Holzschaftreste; erh. L ca. $38 \mathrm{~cm}$, BlattB 2,6 cm, TüllenB $2,5 \mathrm{~cm}$ (B, Taf. 34/1, Inv. Nr. A-10860).

d) Griffangelmesser; L $15 \mathrm{~cm}$ (B, Taf. 34/2, Inv. Nr. A10861a).

e) Griffangelmesser; L $7 \mathrm{~cm}$ (B, Taf. 34/3, Inv. Nr. A10861b).

f) Flügelpfeilspitze, Tülle geschlitzt; L 7,3 cm (B, Taf. 34/4, Inv. Nr. A-10862).

g) Dreiteilige Gürtelgarnitur (B, Taf. 34/5-7, Inv. Nr. A10863a-c): Riemenzunge aus Eisen, silbertauschiert, Flechtornamentik; L $5 \mathrm{~cm}$, B $2,5 \mathrm{~cm}$ (Taf. 34/5). Schilddornschnalle, Eisen, beweglicher, runder Laschenbeschlag, Bügel oval, 3 Buckelnieten; L 7 cm, BügelB 4,5 $\mathrm{cm}$ (Taf. 34/6). - Gegenbeschlag, quadratisch und profiliert, mit 3 schlecht erhaltenen Buckelnieten; 3,7x3,7 cm (Taf. 34/7).

h) Blechbeschlag mit Fragment des Gegenblechs, verbunden durch 1 Niet; $5 \times 4 \mathrm{~cm}(\mathbf{B}$, Taf. 35/1, Inv. Nr. A10863d).

i) Blechbeschlag, Eisen; $3 \times 2 \mathrm{~cm}(\mathbf{B}$, Taf. 34/8, Inv. Nr. A-10863e).

Bewertung: C

Laut Originalprotokoll gehört es zu „,16 zerstörten Gräbern mit den Nrn. 145-160“. Das Originalprotokoll weist diesen Grabnummern keine bestimmten Beigaben zu, sondern enthält nur eine Aufzählung von geborgenen Funde. Die Zuordnung erfolgte erst in der Fundkartei. Es scheint, als wäre aus mehreren Gräbern ein reiches Kriegergrab konstruiert worden.

\section{Grab 146}

Grab zerstört.

Beigaben:

Breitsax, beidseitig je 2 Blutrinnen; GesamtL $52 \mathrm{~cm}$, KlingenB 3,5 cm (B, Taf. 35/2, Inv. Nr. A-10864).

Bewertung: $\mathbf{C}$

Siehe Grab 145. Der Sax ist nur in der Fundkartei genannt.

\section{Grab 147}

Grab zerstört.

Beigaben:

2 Spaltriemenzungen aus Eisen mit 1 Niet, Geweberesten an der Unterseite; L 9,5 und $9 \mathrm{~cm}$, B beide 1,5 cm (B, Taf. 35/3,4, Inv. Nr. A-10865).

Bewertung: C 
Siehe Grab 145. Die beiden Spaltriemenzungen kennt nur die Fundkartei.

\section{Grab 148}

Grab zerstört.

Beigaben:

a) Eisenschere; L $24 \mathrm{~cm}$ (B, Taf. 35/5, Inv. Nr. A-10866).

b) Griffangelmesser, gerader Rücken; erh. L $11 \mathrm{~cm}(\mathbf{B}$, Taf. 36/1, Inv. Nr. A-10867).

c) Halskette aus 9 Glasperlen; 3 kugelig, orange, opak; 1 kugelig, orangegelb, opak; 1 gedrückt kugelig, orange, opak; 1 doppelkonisch, karminbraun, opak; 2 zylindrisch, orange, opak; 1 zylindrisch, karminbraun, opak (B, Taf. 36/2, Inv. Nr. A-10868).

Bewertung: C

Siehe Grab 145. Die Funde sind nur in der Fundkartei ausgewiesen.

\section{Grab 149}

Grab zerstört.

Beigaben:

Bronzeblechbeschlag eines Holzeimers, bandförmig, 3 Nieten, innen Daubenreste; Dm 9-10 cm, B 1,5 cm (B, Taf. 36/3, Inv. Nr. A-10869).

Bewertung: C

Siehe Grab 145. Der Holzeimerbeschlag ist nur in der Fundkartei genannt.

\section{Grab 150}

Grab zerstört.

Beigaben:

Miniatursax, beidseitig je 2 Blutrinnen; GesamtL $33 \mathrm{~cm}$, KlingenB $3 \mathrm{~cm}$, Griffl $10 \mathrm{~cm}$ (B, Taf. 36/4, Inv. Nr. A10870).

Bewertung: C

Siehe Grab 145. Den Miniatursax kennt nur die Fundkartei.

\section{Grab 151}

Grab zerstört.

Beigaben:

Flügelpfeilspitze (nicht vorhanden).

Bewertung: C

Siehe Grab 145.

\section{Grab 152}

Grab zerstört.

Beigaben:

Armbrustfibel (nicht vorhanden).

Bewertung: C

Siehe Grab 145.

Gräber 153-160

Leernummern.

Gräber 161 und 162

„Grabreste“ ohne Beigaben.

Bewertung: C

Grab 163

Kind, weiblich (?).
Beigaben:

Halskette aus 103 Glasperlen; 32 kugelig, orange, opak; 15 kugelig, braunocker, opak; 1 kugelig, karminbraun, opak; 1 kugelig grünlichweiß, opak; 1 kugelig, grünlichblau, opak; 1 kugelig, hellbläulichgrün, opak; 1 kugelig, dunkelblau, opak; 1 kugelig, dunkelviolettblau, opak; 4 gedrückt kugelig, orange, opak; 1 gedrückt kugelig, grünlichblau, opak; 1 gedrückt kugelig, braunschwarz, opak; 2 doppelkonisch, weiß, opak; 4 doppelkonisch, karminbraun, opak; 1 doppelkonisch, grünlichweiß, opak; 1 doppelkonisch, grünlichblau, opak; 2 doppelkonisch, dunkelgraublau, opak; 5 doppelkonisch, braunschwarz, opak; 1 zylindrisch, weiß, opak; 1 zylindrisch, orange, opak; 1 Drehperle, grünlichweiß, opak; 2 konisch, dunkelviolettblau, transluzid; 1 doppelkonisch, weiß, transluzid; 2 doppelkonisch, hellbläulichgrün, transluzid; 1 doppelkonisch, grünlichblau, transluzid; 4 doppelkonisch, dunkelviolettblau, transluzid; 1 zylindrisch, indigo, transluzid; 1 zylindrisch, violettultramarin, transluzid; 1 flachoval, indigo, transluzid; 1 kugelig, leicht gerippt, violettultramarin, transluzid; 1 polyedrisch, dunkelviolettblau, transluzid; 1 dreiflächig länglich, dunkelblau, transluzid; 4 kugelig, braunschwarz mit 3 gelborangen Punkten, opak; 1 zylindrisch, karminbraun mit mattgrauer Wellenverzierung und schwefelgelbem Mittelstrich, opak; 3 Drehperlen, braunschwarz mit gelboranger Spiralfadenauflage, opak (A, Taf. 37/1, Inv. Nr. A-10871).

Bewertung: C

Im anthroplogischen Gutachten nicht erwähnt.

\section{Grab 164}

Frau (23 Jahre); Rückenstrecklage; linker Arm gestreckt, rechter Unterarm zum rechten Becken angewinkelt; deutliche Sargverfärbung.

Beigaben:

a) Riemenzunge aus Bronze mit nach außen abgeschrägtem Rand, auf der Rückseite eine eiserne Deckplatte, mit der die Schauseite unsichtbar durch 3 Bronzenieten verbunden ist, 3 rundköpfige Bronzenieten am oberen Ende, zwischen den Oberschenkeln; L 10 cm, B 1,8 cm (A,Taf. 37/2, Inv. Nr. A-10872).

b) U-förmiger Blechbeschlag; zu A-10872 gehörig (A, Taf. 37/3).

c) Griffangelmesser neben dem linken Bein; erh. L 10,5 cm (A, Taf. 37/4, Inv. Nr. A-10873).

d) Armreif aus Bronze beim rechten Unterarm, bandförmig, an den offenen Enden Zickzackmuster, senkrechte Striche und waagrechte Punktlinien; 6,5 × 5,2 cm (A, Taf. 37/5, Inv. Nr. A-10874).

e) Haarpfeil mit Falkendarstellung aus Bronze und gerilltem Schaftansatz bei der rechten Schulter; L 11,8 cm (A, Taf. 37/6, Inv. Nr. A-10875).

f) 2 Schläfenringe aus Bronze mit verdickten, gerillten Enden; Dm 2,6 cm (B, Taf. 38/1,2, Inv. Nrn. A$10876 \mathrm{a}+\mathrm{b})$.

g) Rechteckschnalle, fragmentiert mit Dorn beim linken Hüftgelenk, Eisen, mehrschichtige Gewebereste (B, Taf. 37/7, Inv. Nr. A-10877). 
h) Bommelohrgehänge, Bronze, offener Ohrring, Bommel aus 2 Halbkugeln waagrecht zusammengefügt; Dm der Bommel 1,3 cm (B, Taf. 37/8, Inv. Nr. A-10878).

i) 3 kleine Bronzedrahtringe; der kleinste $(\operatorname{Dm} 0,7 \mathrm{~cm})$ verbindet die beiden größeren $(\mathrm{Dm} 1 \mathrm{~cm})(\mathbf{B}, \mathrm{Taf} .37 / 9$, Inv. Nr. A-10879).

j) 4 kleine Ringe aus Eisendraht, 2 miteinander verbunden, Gewebereste; Dm 0.8-1 cm (B, Taf. 37/10, Inv. Nr. A10880).

k) 7 Perlen, davon 4 zweischalige aus Silberblech und 3 aus Bronze (B, Taf. 38/3, Inv. Nr. A-10881).

Bewertung: B1

Im Originalprotokoll und in der Fundkartei sind der Armreif, die Riemenzunge, der Haarpfeil und das Messer erwähnt. Die übrigen Funde kennt nur die Fundkartei. Von der laut Originalprotokoll „,vielgliedrigen Perlenkette“ sind in der Fundkartei nur sieben Perlen verblieben.

\section{Grab 165}

Frau (30 Jahre); SW-NO-Orientierung; Rückenstrecklage; Hände am Außenrand des Darmbeins; Sargverfärbung. Beigaben:

a) Halskette aus 39 Glas- und dazwischen Silberblechperlen sowie einem Verschlussring aus Bronze in Trachtlage; 2 kugelig, weiß, opak; 1 kugelig, braunocker, opak; 1 gedrückt kugelig, gelborange, opak; 2 doppelkonisch, weiß, opak; 1 doppelkonisch, schwefelgelb, opak; 2 doppelkonisch, karminbraun, opak; 2 doppelkonisch, dunkelgrünblau, opak; 1 doppelkonisch, graublau, opak; 1 doppelkonisch, dunkelgraublau, opak; 1 doppelkonisch, schwarz, opak; 2 zylindrisch, weiß, opak; 1 zylindrisch, schwefelgelb, opak; 1 zylindrisch, karminbraun, opak; 1 zylindrisch, bräunlichkarmin, opak; 1 gedrückt kugelig, olivbraun, transluzid; 1 gedrückt kugelig, violettultramarin, transluzid; 5 doppelkonisch, hellgrünlich-blau, transluzid; 1 kugelig, karminbraun mit 3 schwefelgelben Punkten, opak; 1 kugelig, braunschwarz mit 3 schwefelgelben Punkten, opak; 1 gedrückt kugelig, karminbraun mit 4 weißen Warzen, umgeben von einer schwefelgelben Auflage, opak; 1 gedrückt kugelig, karminbraun mit 4 weiBen Warzen, umgeben von einer dunkelchromen Auflage, opak; 1 doppelkonisch, karminbraun mit 3 mattgrauen Punkten und mattgrauer Wellenbandverzierung, opak; 1 zylindrisch, dunkelgraublau mit Spuren einer karminbraunen Auflage, opak; 3 Drehperlen, braunschwarz mit schwefelgelber Spiralfadenauflage, opak; 1 Zwillingsperle, lilaschwarz mit 6 bläulichgrünen Warzen auf weißer Basis, opak; 3 Silberblechhohlkugeln (A, Taf. 38/4, Inv. Nr. A-10882).

b) Armreif, Bronze, oval und rundstabig, Enden verdickt und verziert; $7 \times 5,5 \mathrm{~cm}$ (A, Taf. 38/5, Inv. Nr. A10883).

c) Rechteckschnalle mit Dorn am rechten Darmbein, Eisen; 6,5 × 3,5 cm (A, Taf. 38/6, Inv. Nr. A-10884).

d) 2 Ohrringe mit offenen Enden aus dünnem Bronzedraht, in Trachtlage (B, Taf. 38/7,8, Inv. Nr. A-10885).
Bewertung: B1

Die beiden Ohrringe kennt nur die Fundkartei.

Grab 166

Keine Angaben zum Individuum.

Beigaben:

Griffangelmesser; L $15 \mathrm{~cm}$ (B, Taf. 38/9, Inv. Nr. A10886).

Bewertung: C

Weder im anthropologischen Gutachten noch im Gräberfeldplan enthalten. Die Fundkartei aber nennt ein Griffangelmesser.

Gräber 167-180

Leernummern.

\section{Grabung 1963}

\section{Grab 181}

Mann? (35-45 Jahre); SW-NO-Orientierung; Rückenstrecklage; Skelett stark beschädigt; Skelettlänge 168 cm; Grabtiefe $80 \mathrm{~cm}$; schwarzgraue Verfärbung eines Holzsarges.

Beigaben:

a) Gürtelschnalle mit Dorn unter dem rechten Hüftbein, Eisen, D-förmig; L 2,5 cm, B 2 cm (A, Taf. 38/10, Inv. Nr. A-10887).

b) 2 Sargklammern, Eisen, flachgehämmert, Holzreste; L 6,5 cm (A, Taf. 38/11,12, Inv. Nrn. A-10888a+b).

Bewertung: A1

\section{Grab 182}

Kind (8 Jahre); WSW-ONO-Orientierung; Rückenstrecklage; Skelettlänge $116 \mathrm{~cm}$; Grabtiefe $105 \mathrm{~cm}$.

Beigaben:

a) Flügelpfeilspitze am rechten Oberschenkel, Spitze fußwärts; L 6 cm (A, Taf. 40/1, Inv. Nr. A-10889).

b) Beinkammfragment zwischen der Hüfte und dem linken Unterarm, dreilagig und zweireihig, grobe und feine Zähnung, schraffierte Dreiecke, waag- und senkrechte Linienverzierung; erh. L 5,6 cm (A, Taf. 40/2, Inv. Nr. A-10890).

Bewertung: A1

\section{Grab 183 (Abb. 24)}

Mann (25-34 Jahre); SW-NO-Orientierung; Rückenstrecklage; Skelettlänge $170 \mathrm{~cm}$; Grabtiefe $125 \mathrm{~cm}$.

Beigaben:

a) Mehrteilige Gürtelgarnitur in Trachtlage, Eisen, silbermessingtauschiert (A, Taf. 39/1-11, Inv. Nr. A-10891): 2 Scheidenquerbeschläge, wabenplattiert und silber-messingtauschiert, rote und grüne Glaseinlagen, Lederreste; L 12 cm, B 2,5 cm (Taf. 39/1,2). - Hauptriemenzunge; L 10,5 cm, B 2,5 cm (Taf. 39/3), 6 dazu passende Gürtelbeschläge; $4 \times 2,5 \mathrm{~cm}$ (Taf. 39/4-9). - Gürtelschnalle mit ovalem Bügel, Dorn fehlt; $4 \times 6$ cm (Taf. 39/10). Riemenzwinge, quadratisch (A, Taf. 39/11, Inv. Nr. A10894). - Zahlreiche, mehrschichtige Gewebe-, Lederund Schnurreste. 


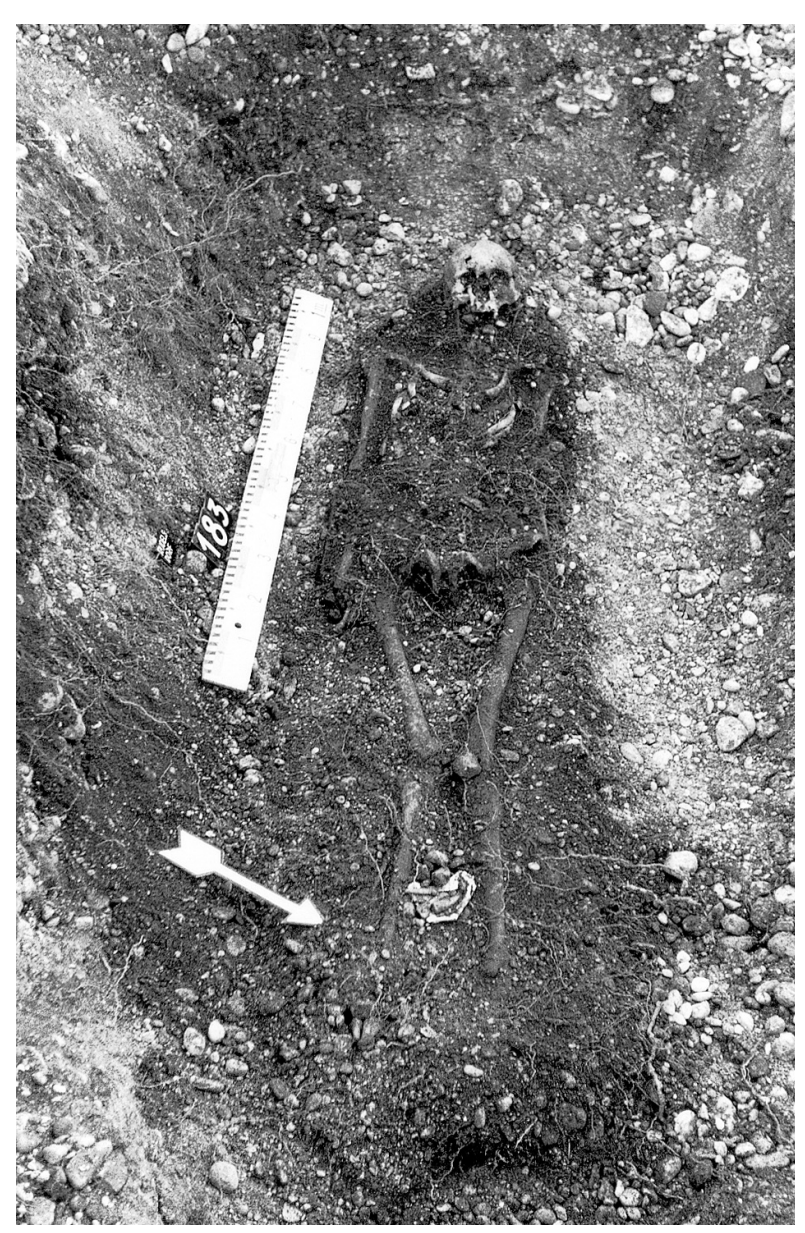

Abb. 24. Rudelsdorf. Grab 183.

b) Griffangelmesser schräg über dem linken Ellbogen; erh. L $8 \mathrm{~cm}$ (A, Taf. 40/4, Inv. Nr. A-10892).

c) Rasiermesser neben dem rechten Hüftbein, stark korrodiert, Holzreste; erh. L $12 \mathrm{~cm}$, B 2,5 cm (A, Taf. 40/3, Inv. Nr. A-10893).

d) Feuerstahl aus einem quadratischen Eisenstab mit winkelig plattgehämmerten Enden, Holzreste; L 5,5 cm (A, Taf. 39/12, ohne Inv. Nr.)

Bewertung: A1

Grab 184

Mann (29 Jahre); SW-NO-Orientierung; Grab zeitgenössisch beraubt; Skelettlänge $160 \mathrm{~cm}$; Grabtiefe $100 \mathrm{~cm}$; keine Beigaben.

Bewertung: A1

\section{Grab 185}

Mann (jugendlich); SW-NO-Orientierung; Rückenstrecklage; Skelettlänge 148 cm; Grabtiefe 105 cm; Sargverfärbung.

Beigaben:

Griffangelmesser bei der linken Elle, Rücken leicht gekrümmt; L 16 cm (A, Taf. 40/5, Inv. Nr. A-10895).

Bewertung: A1
Grab 186

Mann (46 Jahre); WSW-ONO-Orientierung; Rückenstrecklage; Skelett gut erhalten; Schädel etwas erhöht und nach links geneigt; Skelettlänge $172 \mathrm{~cm}$; Grabtiefe $150 \mathrm{~cm}$. Beigaben:

a) Griffangelmesser zwischen dem linken Ellbogen und der Wirbelsäule, Holzgriffreste; L $15 \mathrm{~cm}, \mathrm{~B} 2 \mathrm{~cm}$ (A, Taf. 40/6, Inv. Nr. A-10896).

b) Feuerstahl beim linken Darmbein, nierenförmig mit eingerollten Enden; L 8 cm, B 4 cm (A, Taf. 40/7, Inv. Nr. A-10897).

c) 2 Flügelpfeilspitzenfragmente neben dem rechten Knie; L 5,5 und $3 \mathrm{~cm}$ (A, Taf. 40/8,9, Inv. Nr. A-10898).

d) Riemenschnallenfragment auf dem rechten Oberschenkelhals, Eisen, D-förmig (A, Taf. 40/10, Inv. Nr. A10899).

e) Griffleistenfragment eines beinernen Dreilagenkammes neben dem rechten Knie, unverziert, 3 Eisennieten; erh. L $5 \mathrm{~cm}$ (A, Taf. 40/11, Inv. Nr. A-10900).

Bewertung: A1

\section{Grab 187}

Frau (48-57 Jahre); WSW-ONO-Orientierung; Rückenstrecklage; Grabtiefe 155 cm; Verfärbungen eines Eichenbaumsarges mit schräg eingestürztem Deckel (200x40x49 $\mathrm{cm})$.

Beigaben:

a) Gürtelschnalle mit Dorn, Eisen, oval, auf der Brust; $4 \times$ $3 \mathrm{~cm}$ (A, Taf. 41/1, Inv. Nr. A-10901)

b) Griffangelmesserfragment neben der linken Hand; erh. L $9 \mathrm{~cm}$ (A, Taf. 41/2, Inv. Nr. A-10902)

c) Beinkammfragment bei der linken Schläfe, dreilagig und einreihig, waagrechte Linienverzierung, 4 Eisennieten; erh. L 5,5 cm (A, Taf. 41/3, Inv. Nr. A-10903).

Bewertung: A1

Grab 188

Frau (25-34 Jahre); WSW-ONO-Orientierung; Rückenstrecklage; Skelettlänge 164 cm; Grabtiefe 140 cm; Sargverfärbung.

Beigaben:

a) Bommelohrgehänge (Paar) in Trachtlage, offener Ohrring aus Silberdraht, mit der Bommel über eine Hängeschlaufe und einem horizontalen Band verbunden, Bommeln aus 2 Halbkugeln waagrecht zusammengefügt; Dm 2 cm, Bommel-Dm 1,3 cm (A, Taf. 41/4,5, Inv. Nr. A-10904)

b) Halskette aus 76 Glas- und Silberblechperlen sowie 1 Amethyst; 1 kugelig, weiß, opak; 6 kugelig, orange, opak; 8 kugelig, gelbbraun, opak; 5 kugelig, orangebraun, opak; 28 kugelig, braunocker, opak; 4 gedrückt kugelig, orange, opak; 1 gedrückt kugelig, krapprot, opak; 3 gedrückt kugelig, braunocker, opak; 1 zylindrisch, wasserblau, opak; 2 kugelig, dunkelviolettblau, transluzid; 1 konisch, dunkelviolettblau, transluzid; 1 doppelkonisch, dunkelviolettblau, transluzid; 1 kugelig, braunschwarz mit 3 schwefelgelben Punkten, opak; 2 kugelig, polychrom, opak; 8 Hohlperlen aus Silberblech (A, Taf. 41/6, Inv. Nr. A-10905). 
c) Gürtelschnalle mit Dorn, oval, Eisen, unter dem linken Darmbein; 3,5 × 2,5 cm (A, Taf. 41/7, Inv. Nr. A10906).

d) Nadelschaft beim linken Ellbogen, Eisen; erh. L $6 \mathrm{~cm}$ (A, Taf. 41/8, Inv. Nr. A-10907).

e) „Eiserne Schmucknadel“ auf der Brust (nicht vorhanden).

f) Kette aus kleinen Eisenringen, Gewebereste; zwischen rechtem Unterarm und Darmbein (A, Taf. 41/9, Inv. Nr. A-10908).

g) Hundezahn bei der linken Hüfte (A, Taf. 41/10, ohne Inv. Nr.).

Bewertung: A2

Grab 189

Mann (40-49 Jahre);WSW-ONO-Orientierung; Grab zeitgenössisch beraubt, nur Fußskelette in situ; Grabtiefe 205 cm; tiefschwarze Grubenverfärbung (L $220 \mathrm{~cm}$, B $280 \mathrm{~cm}$ ). Beigaben:

a) Griffangelmesser, Lederscheidenreste; erh. L $10 \mathrm{~cm}(\mathbf{B}$, Taf. 41/11, Inv. Nr. A-10909).

b) Riemenzwinge mit Ring, Bronze, 1 Niet (A, Taf. 41/12, Inv. Nr. A-10910).

Bewertung: B1

Das Griffangelmesser ist laut Originalprotokoll eine „Nachlese".

Grab 190 (Abb. 25)

Mann (37 Jahre); WSW-ONO-Orientierung; Rückenstrecklage; Skelettlänge $168 \mathrm{~cm}$; Grabtiefe $175 \mathrm{~cm}$; keine Beigaben.

Bewertung: A1

Grab 191A (Abb. 26)

Neben Grab 191B.

Frau (23 Jahre); W-O-Orientierung; Skelettlänge $135 \mathrm{~cm}$, Grabtiefe $165 \mathrm{~cm}$.

Beigaben:

a) Bronzeringlein beim rechten $\mathrm{Ohr}$, geriffelt; $\mathrm{Dm} 1,7 \mathrm{~cm}$ (B, Taf. 41/13, Inv. Nr. A-10911). b) Blechbeschlagfragment aus Eisen, 1 Niet; L 2,5 cm (B, Taf. 41/14, Inv. Nr. A-10912).

c) Beinkammfragment, 1 Eisenniet (B, Taf. 41/15, Inv. Nr. A-10913).

Bewertung: B1

Laut Originalprotokoll war das Grab beigabenlos.

Grab 191B (Abb. 26)

Neben Grab 191A.

Frau (40-49 Jahre); Skelettlänge $160 \mathrm{~cm}$.

Beigaben:

a) Ösennadel auf der linken Brust, Bronze; L 8,5 cm (A, Taf. 42/1, Inv. Nr. A-10914).

b) Eisenschnalle an der linken Hüfte, D-förmig; 2,8 $\times 2,2$ cm (A, Taf. 42/2, Inv. Nr. A-10915).

Bewertung: A1

\section{Grab 192}

Frau (19 Jahre); WSW-ONO-Orientierung; Rückenstrecklage; Schädel auf dem rechten Scheitelbein; Skelettlänge 154 cm; Grabtiefe $145 \mathrm{~cm}$; Holzsargreste $(200 \times 44-53 \mathrm{~cm})$; keine Beigaben.

Bewertung: A1

Grab 193

Kind (6,5 Jahre); WSW-ONO-Orientierung; Rückenstrecklage; Grabtiefe $85 \mathrm{~cm}$; Steinsetzung um den Oberkörper, in den unteren Bereichen zerstört, unter Schädel und linker Schulter Holzschatten (L $10 \mathrm{~cm}, \mathrm{~B} 10 \mathrm{~cm}$, D $55 \mathrm{~cm}$ ), darauf 2 Tierzähne (A, Taf. 42/3, ohne Inv. Nr.); keine weiteren Beigaben.

Bewertung: A1

\section{Grab 194A}

Neben Grab 194B.

Kind (1 Jahr); W-O-Orientierung, Grabtiefe $110 \mathrm{~cm}$. Beigaben:

Reste eines Knochenkammes (nicht vorhanden). Bewertung: A2

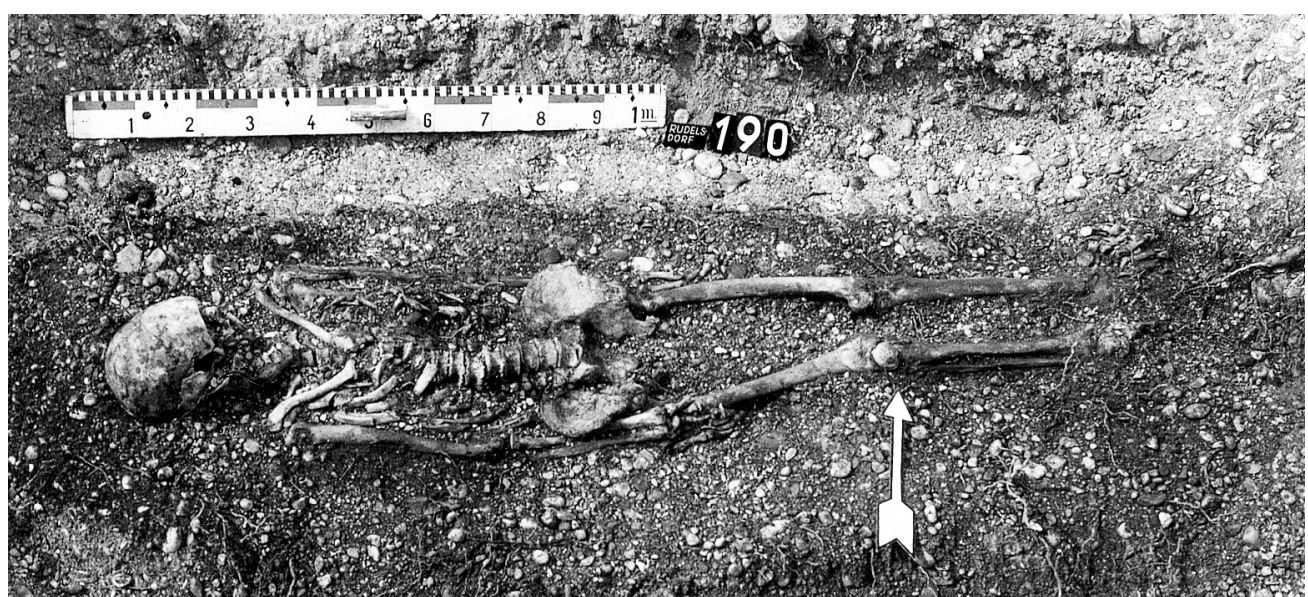

Abb. 25. Rudelsdorf. Grab 190. 


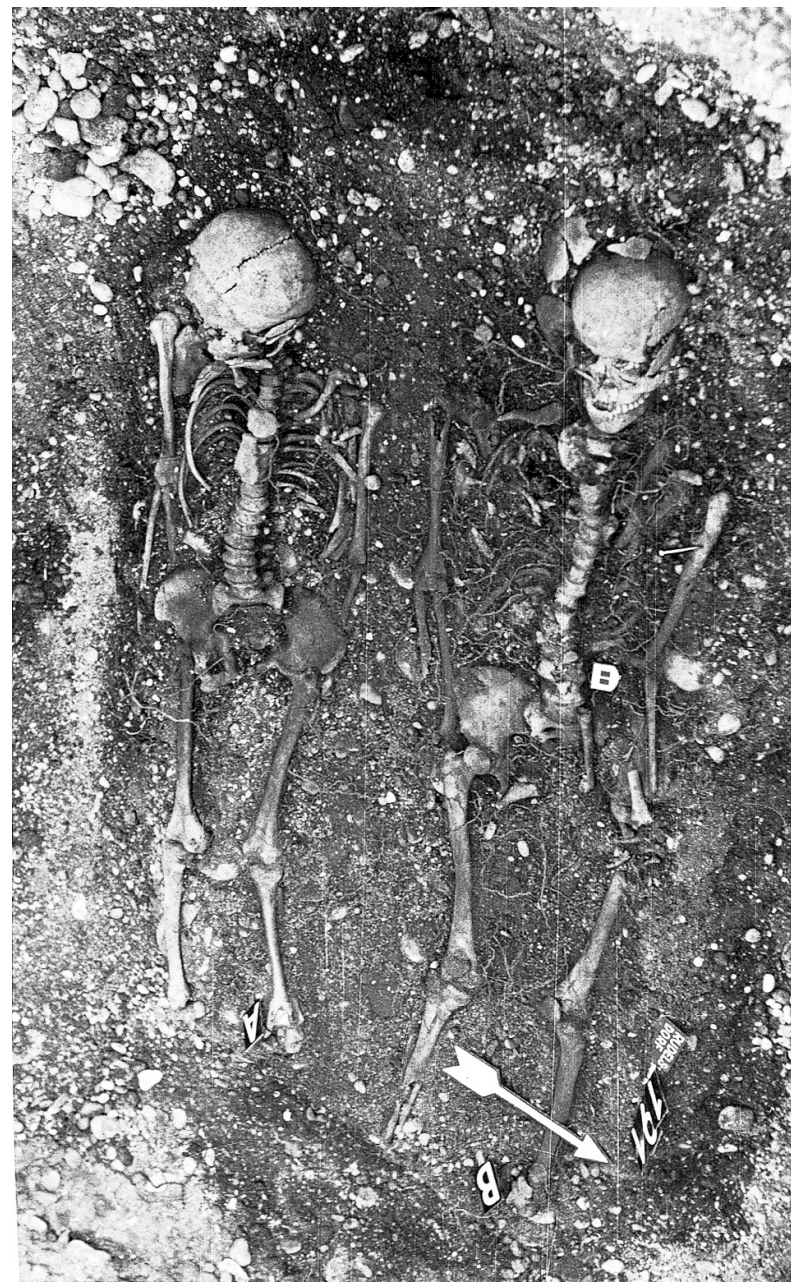

Abb. 26. Rudelsdorf. Gräber 191A und 191B.

\section{Grab 194B}

Neben den Unterschenkeln der Bestattung aus Grab 194A.

Kind (?); W-O-Orientierung; Grabtiefe 110 cm; keine Beigaben.

Bewertung: A2

\section{Grab 195}

Erwachsener (17-25 Jahre); W-O-Orientierung; Rückenstrecklage; Skelett stark beschädigt; Skelett $152 \mathrm{~cm}$; Grabtiefe $150 \mathrm{~cm}$.

Beigaben:

Eisenmesser (nicht vorhanden).

Bewertung: B1

Das im Originalprotokoll als „Nachlese“ bezeichnete Messer ist nicht vorhanden.

\section{Grab 196}

Kind, weiblich (2,5 Jahre); W-O-Orientierung; Rückenstrecklage; Skelettlänge $76 \mathrm{~cm}$; Grabtiefe $110 \mathrm{~cm}$; mäßig deutliche Sargverfärbung $(110 \times 50 \mathrm{~cm})$.
Beigaben:

Halskette aus 11 Glasperlen; 2 kugelig, orange, opak; 3 kugelig, braunocker, opak; 1 gedrückt kugelig, weiß, opak; 1 gedrückt kugelig braunocker, opak; 1 doppelkonisch, weiß, opak; 2 doppelkonisch, dunkelgraublau, transluzid; 1 doppelkonisch, grün mit schwefelgelber Spiralfadenauflage, opak (A, Taf. 42/4, Inv. Nr. A-10916).

Bewertung: A1

\section{Grab 197}

Kind (1,5 Jahre); WSW-ONO-Orientierung; Grab durch Wurzeln zerstört; Grabtiefe $100 \mathrm{~cm}$.

Beigaben:

a) Beinkamm, dreilagig und zweireihig, grobe und feine Zähnung, schraffierte Dreiecke und waag- und senkrechte Linienverzierung, 6 Eisennieten; L 10,2 cm; B $4 \mathrm{~cm}$ (A, Taf. 42/5, Inv. Nr. A-10917).

b) Römische Bronzemünze (Follis von Constantin dem Großen um 330) (Inv. Nr. A-10918, nicht vorhanden).

c) Schnallenfragment (nicht vorhanden).

Bewertung: A2

\section{Gräber 198A, B und C}

Nacheinander erfolgte Bestattungen dreier Kinder in einer gemeinsamen Grabgrube:

\section{Grab 198A}

Kind (2 Jahre); W-O-Orientierung; Skelettlänge 85 cm; Grabtiefe $95 \mathrm{~cm}$; keine Beigaben.

Bewertung: A1

\section{Grab $198 B$}

Kind, weiblich (6 Jahre); WSW-ONO-Orientierung; Skelettlänge 103 cm; Grabtiefe 95 cm; Holzsargreste.

Beigaben:

a) Halskette aus 67 Perlen und 2 römischen Münzen (Centenionales von Valens (364-378) aus Thessalonica), z.T. noch mit Gehängefäden in Trachtlage; 3 kugelig, orange, opak; 1 kugelig, orangebraun, opak; 39 kugelig bis gedrückt kugelig, braunocker, opak; 1 kugelig, braun, opak; 5 gedrückt kugelig, orange, opak; 2 doppelkonisch, karminbraun, opak; 2 doppelkonisch, dunkelgraublau, opak; 5 zylindrisch, weiß, opak; 1 quaderförmig, weiß, opak; 1 rautenförmig, dunkelolivgrün, opak; 4 kugelig, hellgrünlichblau, transluzid; 1 doppelkonisch, preußischblau, transluzid; 1 doppelkonisch, dunkelviolettblau, transluzid (A, Taf. 42/6, Inv. Nr. A-10919).

b) 2 Schlaufenohrringe aus Silberdraht, Schlaufe flachgehämmert, in Trachtlage; Dm ca. 2,5 cm (A, Taf. 42/7,8, Inv. Nr. A-10920).

c) Riemenzunge als Teil einer Wadenbindengarnitur unterhalb des rechten Knies, Bronze, Punzverzierung, 2 Bronzenieten mit unterlegtem Bronzeplättchen; L 6 cm, B 1,8 cm (A, Taf. 42/9, Inv. Nr. A-10921).

d) Bronzering, geschlossen und rundstabig aus dickem Draht; Dm 2 cm (A, Taf. 42/10, Inv. Nr. A-10922).

e) 2 Hohlperlen aus Bronzeblech, Fadenrest; L 1,3 cm (A, Inv. Nr. A-10923; nicht vorhanden).

Bewertung: A1 


\section{Grab $198 C$}

Unterhalb der Gräber 198A und B.

Kind (3 Jahre); SW-NO-Orientierung; Skelettlänge 72 cm; Grabtiefe $125 \mathrm{~cm}$.

Beigaben:

a) Griffangelmesser neben dem rechten Ellbogen, Holzgriffreste; L $16 \mathrm{~cm}$ (A, Taf. 43/1, Inv. Nr. A-10924a).

b) Griffangelmesserfragment bei der rechten. Hand; erh. L $14 \mathrm{~cm}$ (A, Taf. 43/2, Inv. Nr. A-10924b).

c) Flügelpfeilspitze außen neben dem rechten Knie; 7 cm (A, Taf. 43/3, Inv. Nr. A-10925).

d) Beinkammfragment neben dem rechten Kinn, dreilagig und zweireihig, schraffierte Dreiecke; erh. L ca. $11 \mathrm{~cm}$ (A, Taf. 43/4, Inv. Nr. A-10926).

Bewertung: A1

\section{Grab 199}

Frau (19-22 Jahre); SW-NO-Orientierung; zeitgenössische Störung des Schädels; Skelettlänge 164 cm; Grabtiefe 110 $\mathrm{cm}$; keine Beigaben.

Bewertung: A1

Grab 200

Erwachsener (30 Jahre); W-O-Orientierung; Skelettlänge $160 \mathrm{~cm}$; Grabtiefe 140 cm; Hinweis auf Sargverfärbung; keine Beigaben.

Bewertung: A1

Grab 201

Kind, weiblich (1 Jahr); W-O-Orientierung; Rückenstrecklage; Skelettlänge $40 \mathrm{~cm}$; Grabtiefe $95 \mathrm{~cm}$.

Beigaben:

Halskette aus 21 Glasperlen, kugelig bis gedrückt kugelig, opak: 11 schwefelgelb, 4 orange, 1 braunocker und 4 dunkelgraublau, sowie 1 zweischalige Perle aus Silberblech (A, Taf. 43/5, Inv. Nr. A-10927).

Bewertung: A1

\section{Grab 202}

Anthropologisch Frau, archäologisch Mann (16-19 Jahre); ungefähr W-O-orientiert; Rückenstrecklage; aufgrund geborgener Bretterreste Hinweis auf sargartige Grabauskleidung.

Beigaben:

a) Sax mit verziertem Beingriff außen neben dem linken Arm mit dem Griff auf Höhe der Hand und der Spitze bei der Schulter, Griffabschluss abgebrochen; erh. GesamtL $41 \mathrm{~cm}$, GriffL $21 \mathrm{~cm}$ (A, Taf. 44/1, Inv. Nr. A10930a).

b) Saxscheide aus Leder mit 34 Bronzenieten, verziert, auf dem silbernen Scheidemundblech mit eisernem Aufhängebügel 5 Bronzenieten; L $58 \mathrm{~cm}$; ScheidemundB 7,5 cm (A, Taf. 44/2, Inv. Nr. A-10930b).

c) 2 Flügelpfeilspitzen in der rechten Kniegegend, eine mit glattem und eine mit tordiertem Schaft; geschlitzte Tüllen mit Holzresten; L 10 bzw. 7 cm (A, Taf. 44/3,4, Inv. Nr. A-10931a+b)

d) Griffangelmesser neben dem rechten Oberschenkel, ge- rader Rücken; L $12 \mathrm{~cm}$ (A, Taf. 44/5, Inv. Nr. A10933a).

e) Rechteckschnalle mit Dorn in der Darmbeingegend, Eisen; $4 \times 2,5 \mathrm{~cm}$ (A, Taf. 44/6, Inv. Nr. A-10934).

f) Leinenbeutel neben dem rechten Oberschenkel unterhalb der Hüfte, Bronzering, 2 Eisenkettchen zur Befestigung am Gürtel, im Bodenbereich ein Eisensring und Perlenbesatz; L ca. 28 cm (A, Taf. 45/1, Inv. Nr. A10938).

Inhalt: Feuerstahl, nierenförmig mit eingerollten Enden $(9 \times 4 \mathrm{~cm})$ sowie ein Feuerstein aus Hornstein (A, Taf. 44/7,8, Inv. Nr. A-10932a, b), Beinkammfragment, dreilagig und zweireihig (A, Taf.46/1), Griffangelmesserfragment; erh. L 9 cm (A. Taf. 44/9, Inv. Nr. A-10933b), Rasiermesserfragment; erh. L 7,7 cm (A, Taf. 44/11, Inv. Nr. A-10935), Ringfibel, Bronze; Dm außen 5,4 cm, Dm innen 4,5 cm (A, Taf. 46/2,Inv. Nr. A-10936), Armreif mit offenen, verdickten Enden, Bronze (A, Taf. 46/3, Inv. Nr. A-10937), 2 Angelhaken (nicht vorhanden), Eisenband, fragmentiert, Holzreste; BandB 1,3 cm; zu Beutel gehörig (A, Taf. 45/2, Inv. Nr. A-10939).

Bewertung: A2

Widerspruch zwischen Geschlechtsbestimmung im anthropologischen Gutachten und den im Originalprotokoll erwähnten Beigaben.

\section{Grab 203}

Mann (53 Jahre); W-O-Orientierung; Rückenstrecklage; Skelettlänge $170 \mathrm{~cm}$; Grabtiefe $165 \mathrm{~cm}$; Sargverfärbung; keine Beigaben.

Bewertung: A1

\section{Grab 204}

Mann (40-49 Jahre); W-O-Orientierung; Schädel auf der linken Wange; Skelettlänge $184 \mathrm{~cm}$; Grabtiefe $110 \mathrm{~cm}$.

Beigaben:

Eisenschnalle beim linken Darmbein, D-förmig; 2,5 $\times 2 \mathrm{~cm}$ (A, Taf. 46/4, Inv. Nr. A-10928).

Bewertung: A1

\section{Grab 205}

Frau (40-49 Jahre); ungefähr W-O-orientiert; Rückenstrecklage; Schädel nach links geneigt, Unterschenkel- und Fußknochen weitgehend zerstört; Grabtiefe $85 \mathrm{~cm}$; Sargverfärbung (L $190 \mathrm{~cm}$, B $58 \mathrm{~cm}$ ).

Beigaben:

Ösennadel aus Eisen auf der linken Brust; L $5,5 \mathrm{~cm}$ (A, Taf. 46/5, Inv. Nr. A-10929).

Bewertung: A1

\section{Grab 206}

Frau (32 Jahre); SW-NO-Orientierung; Rückenstrecklage; Skelettlänge $152 \mathrm{~cm}$; Grabtiefe 135cm; Holzsargreste (178 $\times 43-50 \mathrm{~cm})$.

Beigaben:

a) Eisenschnalle mit Dorn auf der linken Darmbeinschaufel, oval, Lederreste; $3,5 \times 3,5 \mathrm{~cm}$ (A, Taf. 46/6, Inv. Nr. A-10940). 
b) Halskette aus 75 Glas- und Silberblechperlen; 1 kugelig, weiß, opak; 15 kugelig, orange, opak; 12 kugelig, braunocker, opak; 1 kugelig, grünlichblau, opak; 1 kugelig, braunschwarz, opak; 2 gedrückt kugelig, weiß, opak; 1 gedrückt kugelig, schwefelgelb, opak; 6 gedrückt kugelig, orange, opak; 4 gedrückt kugelig, braunrot, opak; 3 gedrückt kugelig, braunocker, opak; 1 gedrückt kugelig, schwarzblau, opak; 4 zylindrisch, weiß, opak; 1 zylindrisch, grün, transluzid; 2 zylindrisch, karminbraun, opak; 1 würfelförmig, dunkelblau, opak; 1 würfelförmig, schwarzblau, opak; 3 kugelig dunkelviolettblau, transluzid; 1 quaderförmig, dunkelviolettblau, transluzid; 1 würfelförmig, dunkelviolettblau, transluzid; 1 langoval, dunkelviolettblau, transluzid; 11 Silberblechperlen (A, Taf. 46/7, Inv. Nr. A-10941).

Bewertung: A1

\section{Grab 207A}

Kleinstkind; nur geringe Schädelreste erhalten; Grabtiefe ca. $10 \mathrm{~cm}$; keine Beigaben.

Bewertung: A1

\section{Grab 207B}

Frau (31 Jahre), W-O-Orientierung; Rückenstrecklage; Schädel nach links. geneigt; hochschwanger; Skelettlänge $150 \mathrm{~cm}$; Grabtiefe $55 \mathrm{~cm}$; deutlicher Brettersarg (L $183 \mathrm{~cm}$, max. B $55 \mathrm{~cm}$ ); keine Beigaben.

Bewertung: A1

\section{Grab 208 (Abb. 27)}

Mann (23 Jahre); W-O-Orientierung; Rückenstrecklage; Skelettlänge $175 \mathrm{~cm}$; Grabtiefe $175 \mathrm{~cm}$; Baumsarg (L 173 $\mathrm{cm}, \mathrm{B} 76 \mathrm{~cm})$.

Beigaben:

a) Beinkamm mit Klapphülse, dreilagig und einreihig, auf der Klapphülse Rauten- und Linienverzierung; L $24 \mathrm{~cm}$ (A, Taf. 47/1, Inv. Nr. A-10942).

b) Rasiermesser neben dem linken Fußknöchel; L $14 \mathrm{~cm}$ (A, Taf. 47/2, Inv. Nr. A-10943). c) Griffangelmesser neben dem rechten. Fuß; L $17 \mathrm{~cm}(\mathbf{A}$, Taf. 47/3, Inv. Nr. A-10944).

Bewertung: A1

\section{Grab 209}

Kind (1,5 Jahre); W-O-Orientierung; Rückenstrecklage; Skelettlänge $68 \mathrm{~cm}$; Grabtiefe $115 \mathrm{~cm}$; keine Beigaben.

Bewertung: A1

\section{Grab 210}

Mann (17-20 Jahre); SW-NO-Orientierung; Rückenstrecklage; Skelettlänge $176 \mathrm{~cm}$; Grabtiefe $170 \mathrm{~cm}$; deutliche Sargverfärbung (L $228 \mathrm{~cm}$, max. B $53 \mathrm{~cm}$ ).

Beigaben:

a) Spatha neben dem rechten Bein mit dem Griff im Beckenbereich und der Spitze fußwärts, Holz- und Lederreste von der Scheide; GesamtL 78 cm (A, Taf. 47/4, Inv. Nr. A-10948).

b) Griffangelmesser unter der Spatha; erh. L $9 \mathrm{~cm}$ (B, Taf. 47/5, Inv. Nr. A-10949).

c) Rasiermesser mit Rollöse auf dem linken Darmbein; erh. L $9 \mathrm{~cm}$ (A, Taf. 47/6, Inv. Nr. A-10950).

d) Bronzepinzette auf dem Kreuzbein, Eisen, breitarmig, auf beiden Seiten punzverziert; L 6 cm (A, Taf. 48/1, Inv. Nr. A-10951).

e) Flügelpfeilspitze innen beim rechten Ellbogen, Schaft tordiert, Tülle geschlitzt; L $8 \mathrm{~cm}$ (A, Taf. 48/2, Inv. Nr. A-10952).

f) Gürtelschnalle mit Dorn auf dem linken Darmbein, Eisen, oval; $3 \times 2 \mathrm{~cm}$ (A, Taf. 47/7, Inv. Nr. A-10953).

\section{Bewertung: B1}

Das Originalprotokoll nennt noch ein nicht vorhandenes Kettchen, nur die Fundkartei das Griffangelmesser .

\section{Grab 211}

Mann (19-28 Jahre);WSW-ONO-Orientierung; Grab zeitgenössisch beraubt; Skelettlänge $175 \mathrm{~cm}$; Grabtiefe $130 \mathrm{~cm}$; Sargverfärbung (L $210 \mathrm{~cm}$, max. B $60 \mathrm{~cm}$ ).

Abb. 27. Rudelsdorf. Grab 208. Baumsarg.

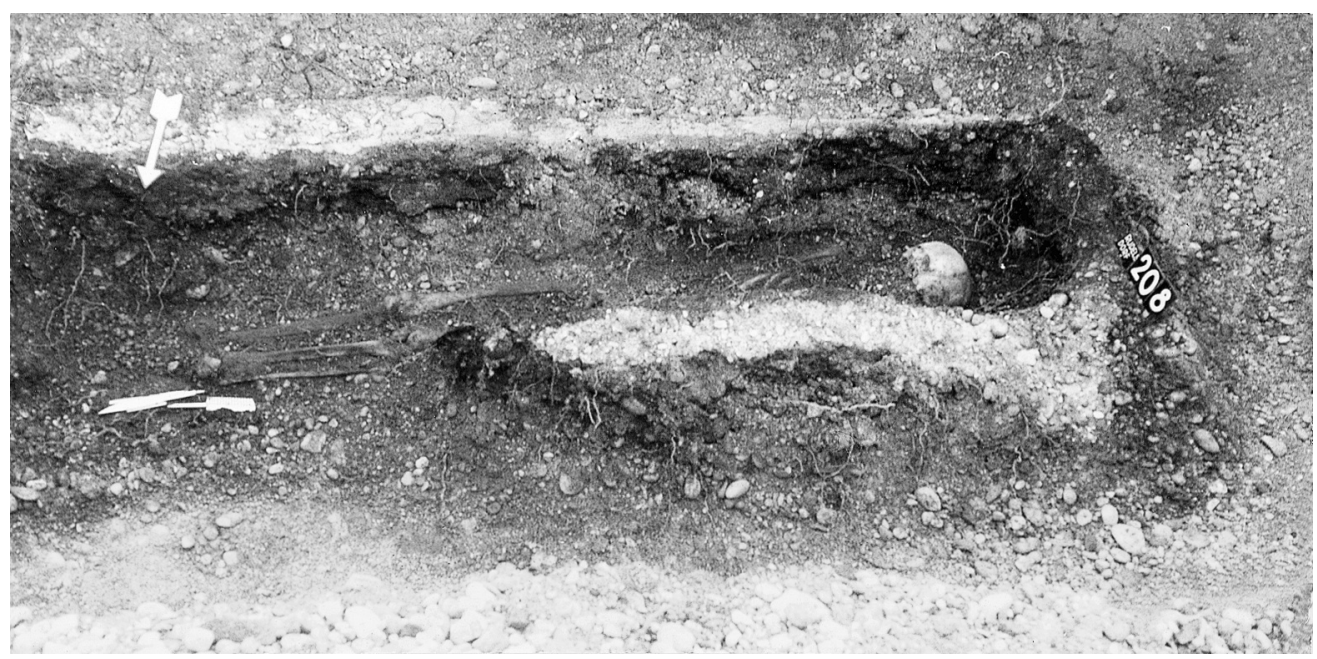




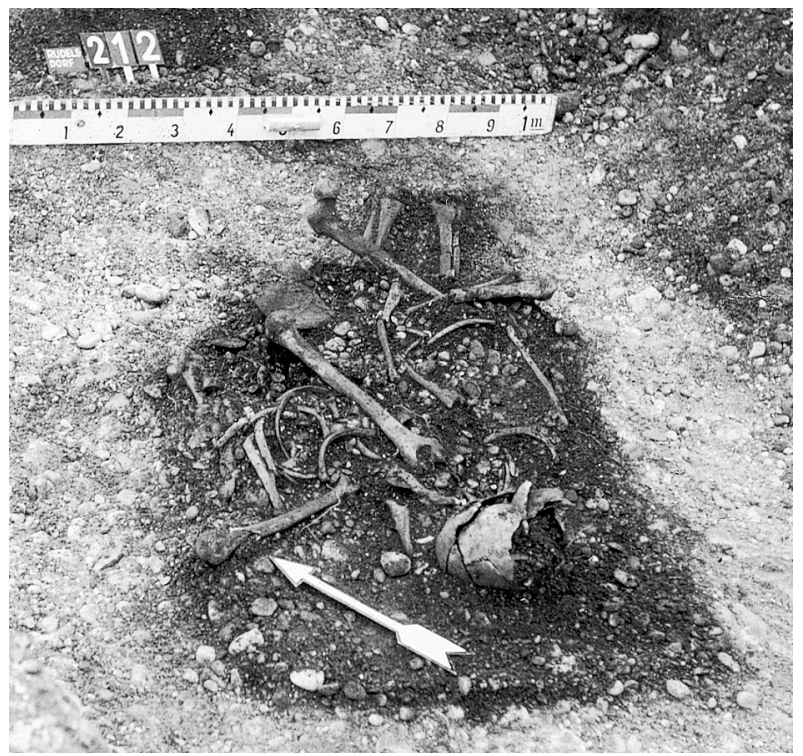

Abb. 28. Rudelsdorf. Grab 212A.

Beigaben:

Rechteckschnalle mit Dorn neben dem linken Knie, Eisen;

$3 \times 2,5 \mathrm{~cm}$ (A, Taf. 47/8, Inv. Nr. A-10945).

Bewertung: A1

Grab 212A (Abb. 28)

Mann (23 Jahre); SW-NO-Orientierung; Grab zeitgenössisch beraubt; Grabtiefe $100 \mathrm{~cm}$; keine Beigaben.

Bewertung: A1

Grab 212B

Knapp unterhalb von Grab 212A

SW-NO-Orientierung; keine Beigaben.

Bewertung: A1

\section{Grab 213}

Erwachsener (40-49 Jahre); SW-NO-Orientierung; Rückenstrecklage; Schädeldach fußwärts verlagert; Skelettlänge $165 \mathrm{~cm}$; Grabtiefe $75 \mathrm{~cm}$.

Beigaben:

a) Beinkamm neben dem rechten Ohr, dreilagig und einreihig, gewölbt, schraffierte Dreiecke und senkrechten Linienverzierung, 10 Eisennieten; L 19,5 cm (A, Taf. 48/3, Inv. Nr. A-10946).

b) Gürtelschnalle auf der rechten Darmbeinkante, Eisen, mit starrem Beschlag; $6 \times 3,5 \mathrm{~cm}$ (A, Taf. 48/4, Inv. Nr. A-10947).

Bewertung: A1

Grab 214

Frau (29 Jahre); SW-NO-Orientierung; Rückenstrecklage; zwergenhafter Wuchs, am Rumpf zahlreiche Missbildungen; Skelettlänge $130 \mathrm{~cm}$; Grabtiefe $180 \mathrm{~cm}$; deutliche Sargverfärbung (L $162 \mathrm{~cm}$, max. B $32 \mathrm{~cm}$ ).

Beigaben:

a) Halskette aus 66 Glas-, Silber- und Bronzeperlen; 1 kugelig, farblos, opak; 7 kugelig, weiß, opak; 3 kugelig, mattgrau, opak; 1 kugelig, gelboliv, opak; 8 kugelig, orange, opak; 7 kugelig, braunocker, opak; 1 kugelig, grauultramarin, opak; 5 kugelig, braunschwarz, opak; 4 gedrückt kugelig, weiß, opak; 1 gedrückt kugelig, grünlichweiß, opak; 1 gedrückt kugelig, chromgelb, opak; 1 gedrückt kugelig, schwefelgelb, opak; 1 gedrückt kugelig, orange, opak; 3 gedrückt kugelig, braunocker, opak; 2 gedrückt kugelig, rotbraun, opak; 1 doppelkonisch, weiß, opak; 4 doppelkonisch braunschwarz, opak; 1 zylindrisch, karminbraun, opak; 1 zylindrisch, schwarzoliv, opak; 2 konische, dunkelviolettblau, transluzid; 3 doppelkonisch, dunkelgraublau, transluzid; 1 zylindrisch, fragmentiert, blau, transluzid; 1 Drehperle, dunkelgraublau, transluzid; 1 kugelig, braunschwarz mit 3 rahmfarbenen Punkten, opak; 1 zylindrisch, türkisblau mit grauweißer Spiralfadenauflage, opak; 1 Drehperle, dunkelgraublau mit mattgrauer Spiralfadenauflage, opak; 1 Drehperle, schwarzbraun mit schwefelgelber Spiralfadenauflage, opak; 1 Bronzeröllchen; 1 Silberblechperle, 1 bajuwarische Goldmünze (1,35 gr) (A, Inv. Nr. A-10954).

b) Beinkamm links neben dem Schädel, dreilagig und zweireihig, grobe und feine Zähnung, waagrechte Linienverzierung; L $10 \mathrm{~cm}$ (A, Taf. 48/6, Inv. Nr. A-10955).

c) Armreif aus dickem Bronzedraht am rechten Handgelenk, Enden verdickt und punziert; Dm 5,5 cm (A, Taf. 48/7, Inv. Nr. A-10956).

d) Bommelohrgehänge aus Silber (Paar) in Trachtlage. Offener Ohrring mit Bommel aus zwei waagrecht zusammengefügten Halbkugeln, mit dem Tragring durch bandförmige Hängeschlaufe verbunden; Bommel-Dm 0,9 cm (A, Taf. 48/8,9, Inv. Nr. A-10957).

e) Glasreiffragmente, latènezeitlich, ultramarin, in der rechten Hüftgegend und ein weiteres, flaschengrünes Glasbruchstück ebendort (A, Taf. 48/10, Inv. Nr. A-10958).

Bewertung: A1

\section{Grab 215}

Mann (27 Jahre); SW-NO-Orientierung; Rückenstrecklage; Skelettlänge $170 \mathrm{~cm}$; Grabtiefe $160 \mathrm{~cm}$; Sargverfärbung. Beigaben:

a) Griffangelmesser an der rechten Schulter, Holzgriffspuren; L $20 \mathrm{~cm}$, B 2,4 cm (A, Taf. 49/1, Inv. Nr. A10959a).

b) Griffangelmesser außen bei der rechten Hand, Rücken gewölbt; erh. L 9 cm (A, Taf. 49/2, Inv. Nr. A-10959b).

c) 2 Flügelpfeilspitzen außen neben dem rechten Knie; erh. L (beide) 7 cm (A, Taf. 49/3,4, Inv. Nr. A-10960).

d) Beinkamm auf der rechten Schädelseite, dreilagig und einreihig, gewölbt, unverziert, 7 Eisennieten; L 16 cm (A, Taf. 49/5, Inv. Nr. A-10961).

Bewertung: A1

\section{Grab 216}

Kind, weiblich (6 Jahre);W-O-Orientierung; Knochen weitgehend aufgelöst; Skelettlänge $70 \mathrm{~cm}$; Grabtiefe $180 \mathrm{~cm}$. Beigaben:

a) Halskette aus 20 Glasperlen mit Verschlussring aus Eisendraht; 2 kugelig, weiß, opak; 1 kugelig, grünlichweiß, 
opak; 3 kugelig, gelboliv, opak; 3 kugelig, orange, opak; 2 kugelig, braunocker, opak; 1 kugelig, dunkelchrom, opak; 2 kugelig, dunkelgraublau, opak; 2 gedrückt kugelig, rotbraun, opak; 1 doppelkonisch, braunschwarz, opak; 1 zylindrisch, dunkelchrom, opak; 1 zylindrisch, schwefelgelb mit dunkelgrüner Spiralfadenauflage, opak; 1 quaderförmig, karminbraun mit mattgrauer Spiralfadenauflage, opak; 1 Saxscheidenzierknopf; 3 gelochte, römische Münzen (Constantin der Große, Valentinian und Valens) (A, Taf. 49/6, Inv. Nr. A-10962).

b) Beinkammfragment, dreilagig und zweireihig, senkrechte Linienverzierung; erh. L 6,8 cm (A, Taf. 49/7, Inv. Nr. A-10963).

c) Griffangelmesser; L $11 \mathrm{~cm}$ (A, Taf. 49/8, Inv. Nr. A10964).

Bewertung: A1

Grab 217 (Abb. 29)

Kind (6 Jahre); SW-NO-Orientierung; Rückenstrecklage; Skelettlänge $109 \mathrm{~cm}$; Grabtiefe $150 \mathrm{~cm}$; deutliche Sargverfärbung (L $165 \mathrm{~cm}$, max. B $38 \mathrm{~cm}$ ), Deckel eingedrückt. Beigaben:

Griffangelmesser am linken Oberarm innen, Spitze abgebrochen; erh. L 14,5 cm (A, Taf. 50/1, Inv. Nr. A-10965). Bewertung: A1

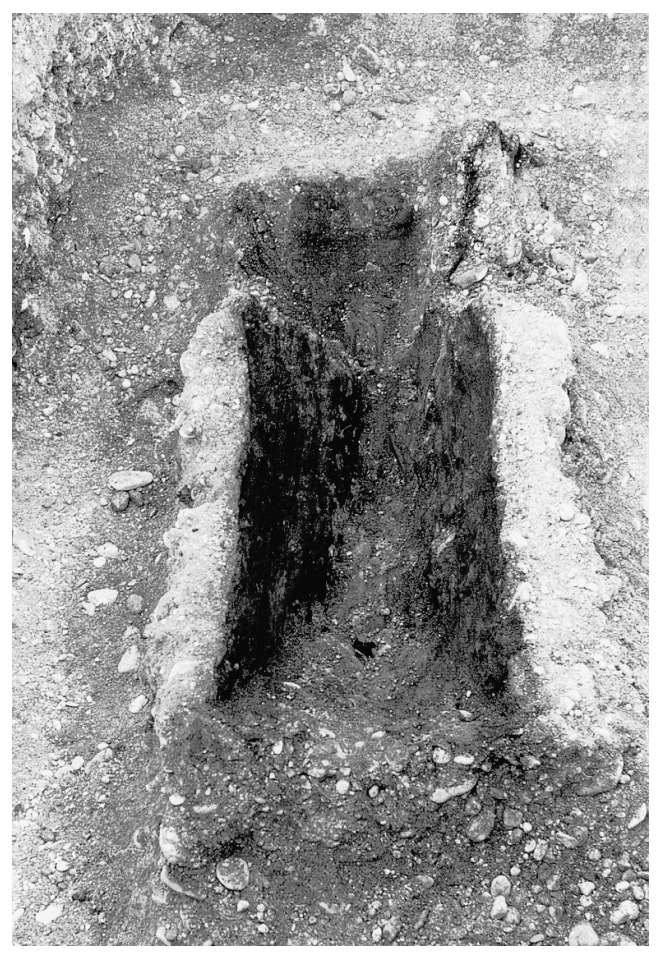

Abb. 29. Rudelsdorf. Grab 217. Sargverfärbung.
Grab 218

Kleinstkind; SW-NO-Orientierung; Grabtiefe $140 \mathrm{~cm}$.

Beigaben:

Nadel (nicht vorhanden).

Bewertung: A2

Grab 219 (Abb. 30)

Frau (35 Jahre); WSW-ONO-Orientierung; Rückenstrecklage; Skelettlänge $154 \mathrm{~cm}$; Grabtiefe $120 \mathrm{~cm}$; deutliche Sargverfärbung (L $205 \mathrm{~cm}, \mathrm{~B} 42 \mathrm{~cm}$ ).

Beigaben:

a) Bommelohrgehänge aus Kupferblech (Paar) in Trachtlage. Dreiteilig, dünner, offener Ohrring mit Hängeschlaufe (verdeckt durch einen waagrechten Blechrand), damit verbunden ein dreikugeliger Mittelteil mit der zweischaligen, waagrecht zusammengefügten Bommel mit 3 Zierbuckeln; GesamtL 4,5 cm, Ring-Dm 1,2 cm, Bommel-Dm 1,4 cm (A, Taf. 50/2,3, Inv. Nr. A-10966).

b) Gürtelschnalle mit Beschlagplatte und ovalem Bügel in der Lendenwirbelgegend, Eisen (A, Taf. 50/4, Inv. Nr. A-10967).

c) Halskette aus 27 Glasperlen; 1 kugelig, weiß, opak; 4 kugelig, orange, opak; 1 kugelig, orangebraun, opak; 1 kugelig, karminbraun, opak; 1 konisch, dunkelgraublau, opak; 1 doppelkonisch, weiß, opak; 1 doppelkonisch,

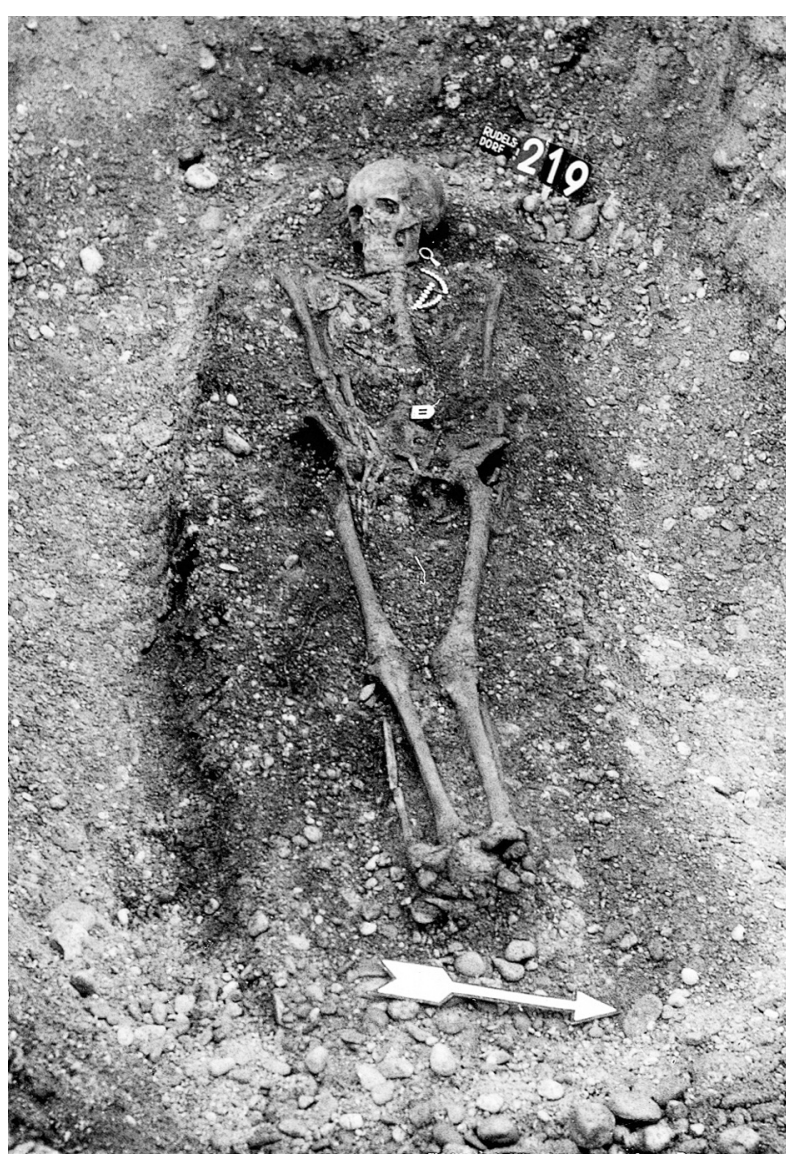

Abb. 30. Rudelsdorf. Grab 219. 
zitronengelb, opak; 2 doppelkonisch, schwefelgelb, opak; 3 doppelkonisch, orange, opak; 2 doppelkonisch, karminbraun, opak; 1 doppelkonisch, wasserblau, opak; 1 zylindrisch, weiß, opak; 1 zylindrisch, orange, opak; 1 quaderförmig, weiß, opak; 1 konisch, fragmentiert, dunkelviolettblau, transluzid; 3 doppelkonisch, dunkelviolettblau, transluzid; 1 zylindrisch, dunkelblau, transluzid (A, Taf. 50/5, Inv. Nr. A-10968).

Bewertung: A1

\section{Grab 220}

Mann (45-55 Jahre); SW-NO-Orientierung; Rückenstrecklage; zeitgenössisch beraubt, Schädel und Rumpf bis zum Darmbein gestört; Skelettlänge $160 \mathrm{~cm}$; Grabtiefe $140 \mathrm{~cm}$. Beigaben:

a) Griffangelmesser beim linken Oberschenkel, Rücken gekrümmt; erh. L 12,5 cm (A, Taf. 50/6, Inv. Nr. A10969).

b) Gürtelschnalle mit Dorn am Kreuzbein, Eisen, oval; $4 \times$ $3 \mathrm{~cm}$ (A, Taf. 50/7, Inv. Nr. A-10970).

c) Feuerstahl, oval, bandförmiges Eisen; L 6,5 cm, B 3,5 cm (A, Taf. 50/8, Inv. Nr. A-10971).

d) Rechteckschnallenfragment, Eisen; $2 \times 2,5 \mathrm{~cm}$ (A, Taf. 50/9, Inv. Nr. A-10972).

Bewertung: A2

Originalprotokoll: „Nachträglich (1969) angefertigte Grabbeschreibung“.

Gräber 221-228

Leernummern.

\section{Die Gräber}

Die Probleme und Unklarheiten in Bezug auf die Gräberfeldpläne wurden bereits im Kapitel „Grabungskritik“ dargestellt. Zur Verfügung standen ein von M. Pertlwieser erstellter Originalplan des Gräberfeldes „Rudelsdorf I“ sowie zwei Handskizzen über die Lage der Gräber 121 bis 144, die „Rudelsdorf II“ zugeordnet werden. Aus diesen Unterlagen wurde schließlich im Auftrag des Autors ein Gesamtplan (Abb. 31) erstellt. Abb. 32 zeigt die Ausdehnung des Gräberfeldes auf Basis des amtlichen Parzellenplans.

Von den nicht eingemessenen Bestattungen 145 bis 162, also jenen „Gräbern“ von „Rudelsdorf II“, die durch den Baggerbetrieb zerstört wurden und deren Beigaben den Erdarbeitern abgekauft werden mussten, existiert kein exakter Plan. Die nicht belegten Grabnummern 167 bis 180 sind im Plan naturgemäß nicht berücksichtigt. Die Gräber 163 bis 165, die sich im Bereich des Gräberfeldes „Rudelsdorf I“ befanden, sind im Plan verzeichnet.

\section{Anlage des Gräberfeldes}

Der Friedhof von Rudelsdorf gehört zu den merowingerzeitlichen Reihengräberfeldern, so genannt wegen der für solche Bestattungsplätze üblichen parallel-reihenartigen Anordnung der Bestattungen in Grabgruppen. Angelegt wurde er als sogenannter Freilandfriedhof, d.h., es gab, soweit festgestellt werden konnte, keine Umzäunung, ${ }^{15}$ was dem üblichen Erscheinungsbild solcher vorchristlichen Gräberfelder durchaus entspricht. Ausnahmen sind jedoch aus Steinhöring ${ }^{16}$ mit exakt nachgewiesenen Pfostenlöchern sowie Straubing ${ }^{17}$ bekannt, wo allerdings nur an Außenrändern bestimmter Areale eine Begrenzung vermutet werden konnte. Überdies kann auch im Gräberfeld von MünchenGiesing $^{18}$ eine Einfriedung angenommen werden.

Der Tradition entsprechend wurden die Toten ausnahmslos unverbrannt in Grabgruben bestattet, die gerade groß genug waren, um den Leichnam bzw. den Sarg, in den er gelegt wurde, aufnehmen zu können.

Aufgrund des Plans lässt sich eine lockere Reihenanordnung der Gräber feststellen, die sich jedoch an den Rändern auflöst, wie z.B. die Gräber 1, 4 und 6 am Westende von „Rudelsdorf I“, die Gräber 59 und 60, nördlich bzw. westlich und die Gräber 204 und 190 im Norden zeigen.

Eine solche recht lockere Reihenanordnung ist allerdings nicht die Ausnahme, sondern die Regel. In anderen Gräberfeldern gibt es noch weitaus größere Abweichungen, weshalb eine Grabreihe nicht unbedingt eine Reihenfolge der Todesfälle widerspiegelt. Vielmehr dürfte sich bei der Anlage des Gräberfeldes jede Familie ein bestimmtes Areal ausgesucht haben, die im Verlauf der Belegung miteinander verschmolzen. ${ }^{19}$

Erwähnenswert ist ferner, dass die ,vornehmeren“ Gräber der bewaffneten Freien an ausgewählten Orten am Terrassenrand, d.h. eher zentral angelegt wurden, und dass sich die zu dieser Zeit üblichen Überschneidungen bzw. Nachbestattungen vor allem im jüngeren Westteil des Gräberfeldes befanden. Möglicherweise handelt es sich im ersteren Fall um eine wiederholte Nutzung bereits heimgefallener Gräber.
15 M. Pertlwieser, Baierngräber an der Traun, Oberösterr. Kulturzeitschr. 27/2, 1977, 22.

16 S. ARNOLD, Das bajuwarische Gräberfeld von Steinhöring, Landkreis Ebersberg, Charybdis-Schr. zur Arch. 5, 1992, 11.

17 H. GeIsLER, Straubing im frühen Mittelalter. Archäologische Bei- träge zur Siedlungstopographie zwischen Römerzeit und Mittelalter, Vortr. d. 5. Niederbayer. Archäologentages, 1987, 608 f.

18 H. Вотт, Der Bajuwarenfriedhof auf dem Riegeranger in München-Giesing, Bayer. Vorgesch.bl. 13, 1936, 43.

19 Reitinger, s. Anm. 2, 54 f. 


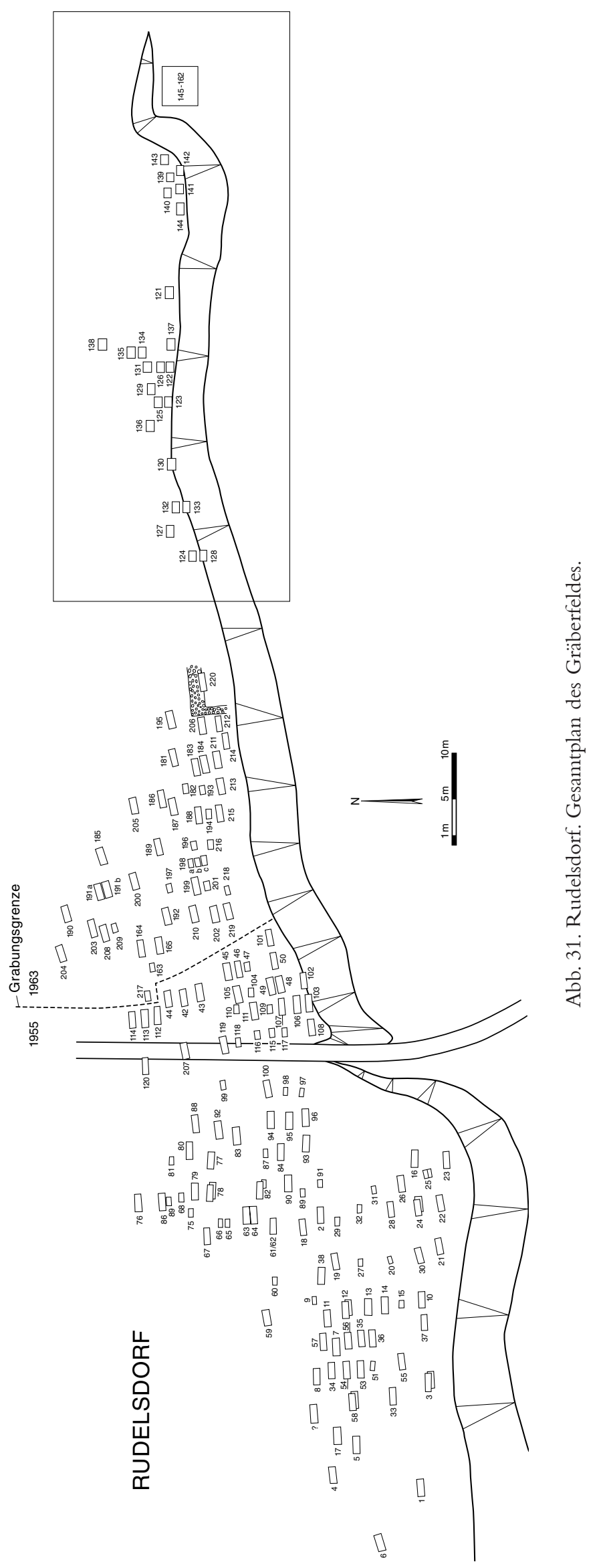




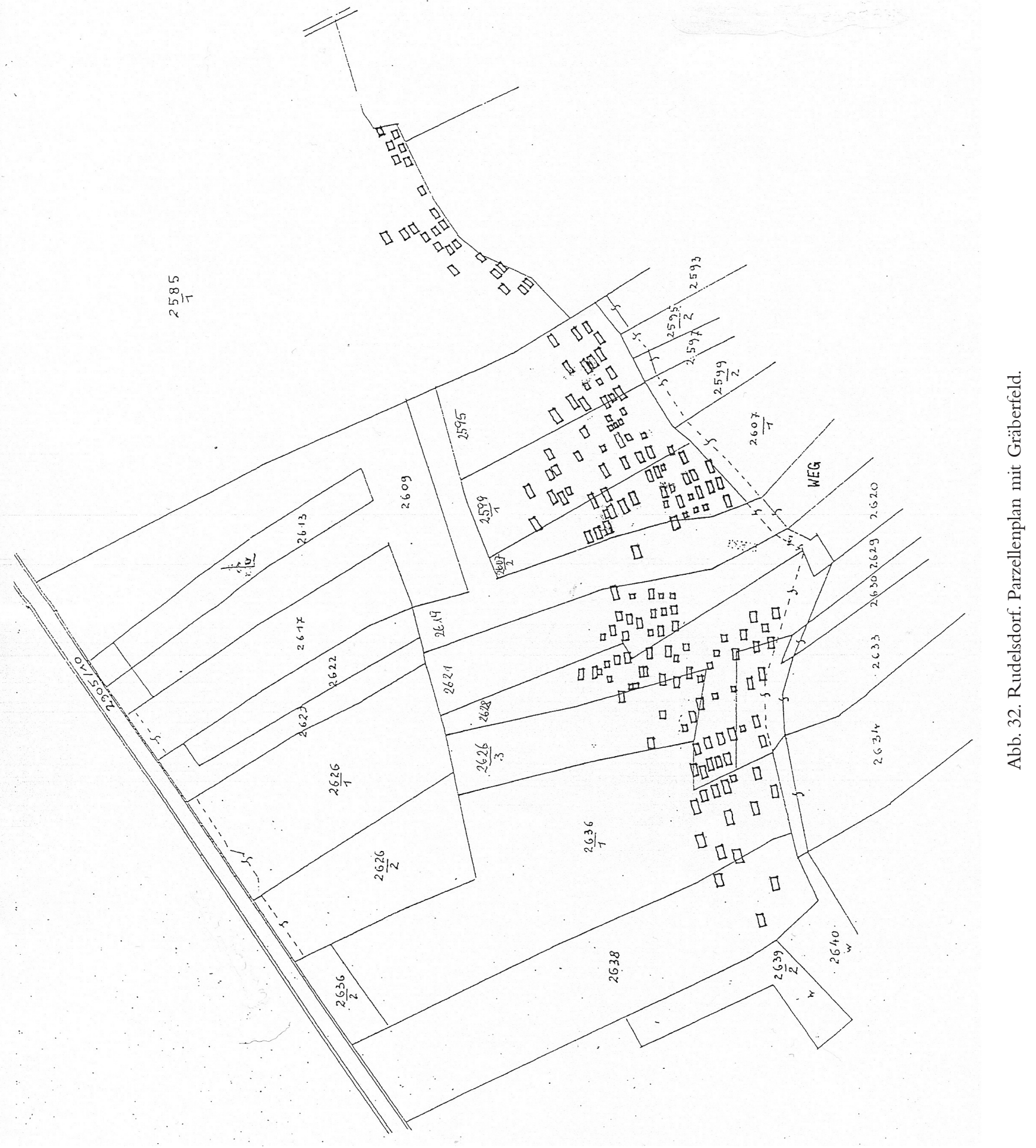

